This item was submitted to Loughborough's Research Repository by the author.

Items in Figshare are protected by copyright, with all rights reserved, unless otherwise indicated.

\title{
Transaction costs, liquidity risk, and the CCAPM
}

\section{PLEASE CITE THE PUBLISHED VERSION}

http://dx.doi.org/10.1016/j.jbankfin.2015.11.011

\section{PUBLISHER}

(C) Elsevier

\section{VERSION}

AM (Accepted Manuscript)

\section{PUBLISHER STATEMENT}

This work is made available according to the conditions of the Creative Commons Attribution-NonCommercialNoDerivatives 4.0 International (CC BY-NC-ND 4.0) licence. Full details of this licence are available at: https://creativecommons.org/licenses/by-nc-nd/4.0/

\section{LICENCE}

CC BY-NC-ND 4.0

\section{REPOSITORY RECORD}

Liu, Weimin, Di Luo, and Huainan Zhao. 2019. "Transaction Costs, Liquidity Risk, and the CCAPM". figshare. https://hdl.handle.net/2134/24076. 


\title{
Transaction Costs, Liquidity Risk, and the CCAPM`
}

\author{
Weimin $\mathrm{Liu}^{a}$, Di Luo ${ }^{b, *}$, and Huainan $\mathrm{Zhao}^{c}$ \\ ${ }^{a}$ Nottingham University Business School UK \& China, and Shanxi University, China \\ ${ }^{b}$ Swansea University, UK \\ ${ }^{c}$ Cranfield University School of Management, UK
}

\begin{abstract}
In this paper, we make a liquidity adjustment to the consumption-based capital asset pricing model $(\mathrm{CCAPM})$ and show that the liquidity-adjusted CCAPM is a generalized model of Acharya and Pedersen (2005). Using different proxies for transaction costs such as the effective trading costs measure of Hasbrouck (2009) and the bid-ask spread estimates of Corwin and Schultz (2012), we find that the liquidity-adjusted CCAPM explains a larger fraction of the cross-sectional return variations.
\end{abstract}

JEL classification: G12; G14

Keywords: Transaction costs; Liquidity risk; Consumption-based asset pricing

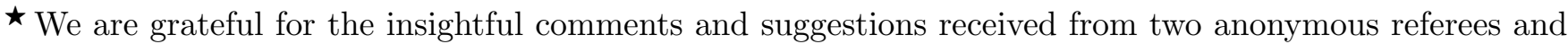
Carol Alexander (the editor). We would also like to thank seminar participants at the University of Nottingham Ningbo China and Shanxi University. Weimin Liu acknowledges financial support from the National Natural Science Foundation of China (No. 71371113).

* Corresponding author.

E-mail address: d.luo@swansea.ac.uk (D. Luo).
} 


\section{Introduction}

Recent studies in asset pricing suggest that liquidity plays an important role in investors' consumption and investment decisions. ${ }^{1}$ Following these leads, we extend the traditional CCAPM (Rubinstein (1976), Lucas (1978), and Breeden (1979)) by incorporating the liquidity effect, in the spirit of Acharya and Pedersen (2005). We show that expected stock return is determined by both consumption risk and liquidity risk with the latter being defined as the covariance between transaction costs and consumption growth. The liquidity-adjusted CCAPM, contingent on the transaction costs proxies and test portfolios, adds up to $79 \%$ additional explanatory power to the cross-sectional variation of expected returns.

Specifically, using different proxies for transaction costs such as the effective trading costs of Hasbrouck (2009) and the high-low-price-based bid-ask spread estimates of Corwin and Schultz (2012), we show that our liquidity-adjusted CCAPM provides a better fit for the cross-sectional expected returns across various liquidity-based portfolios, while the traditional CCAPM fails to capture the liquidity effect. $^{2}$ Our model also accounts for a larger fraction of the variations in expected returns across size and book-to-market portfolios than the CCAPM. Lewellen et al. (2010) demonstrate that it is necessary for asset pricing tests to include other sets of portfolios (e.g.,

\footnotetext{
${ }^{1}$ For instance, Parker and Julliard (2005) suggest that concerns of liquidity are perhaps imperative components neglected by consumption risk alone. Liu (2010) argues that liquidity risk originates from consumption and solvency constraints with latter being also demonstrated by Chien and Lustig (2010) and Pastor and Stambaugh (2003). Næs et al. (2011) find that stock market liquidity can predict consumption growth. Lynch and Tan (2011) show that transaction costs can generate a first-order effect when they add return predictability, wealth shocks, and state-dependent costs to the traditional consuming and investing problems. Further, Lagos (2010) develops a model with search frictions and shows the importance of the liquidity premium in explaining the equity premium puzzle.

${ }^{2}$ Acharya and Pedersen (2005) show that the CAPM (Sharpe (1964) and Lintner (1965)) fails to capture liquidity costs and liquidity risks. Liu (2006) and Liu (2010) find that both the CAPM and the Fama-French (1993) three-factor model have difficulty in capturing the liquidity effect. A few recent studies examine the explanatory power of the traditional CCAPM to the variation of expected return across portfolios sorted by different liquidity proxies. For instance, Kang and Li (2011) use the long-run consumption risk framework of Hansen et al. (2008) to explain liquidity premium.
} 
industry portfolios) to break down the strong factor structure of size and book-to-market portfolios. We show that the liquidity-adjusted CCAPM is robust to the inclusion of industry portfolios.

Recent studies also highlight the importance of the ultimate or long-run consumption risk (Parker and Julliard (2005)), durable consumption (Yogo (2006)), and the fourth-quarter consumption (Jagannathan and Wang (2007)) in explaining the variations of expected returns. We show that applying the long-run, total (durable and nondurable), and fourth-to-fourth quarter consumption growth measures to our liquidity-adjusted model explains a larger fraction of the variation in cross-sectional expected returns than the CCAPM.

Lettau and Ludvigson (2001) and Petkova and Zhang (2005) show that value stocks have higher risk exposure than growth stocks in bad times. We find that the patterns of estimated liquidity betas conditional on the economic states provide a liquidity-risk based explanation for the countercyclical value premium. Specifically, we show that value stocks have higher liquidity risk in bad times than in good times, while growth stocks have lower liquidity risk in good times than in bad times.

Overall, our results suggest that investors do care about the sensitivity of transaction costs to the aggregate consumption growth, and hence demand high return for securities with high exposure to liquidity risk. By tying transaction costs with consumption growth, we provide new evidence to the recent literature that highlights the importance of liquidity risk in asset pricing (e.g., Chordia et al. (2000), Pastor and Stambaugh (2003), Acharya and Pedersen (2005), Liu (2006), Sadka (2006), and Bekaert et al. (2007)). While these studies appear to make liquidity adjustment to the CAPM or the Fama-French three-factor model and show that models with this adjustment improve the models' fit, the focus of our paper is on the liquidity adjustment to the consumption-based pricing models, an area that has attracted little attention in the literature. 
While transaction costs are not taken into account by the traditional CCAPM, they are the subject currently generating much research interests. Amihud and Mendelson (1986) introduce liquidity costs into the present value of stocks and show that liquidity costs are positively related to expected returns. Jacoby et al. (2000) develop a static liquidity-adjusted CAPM using net returns (i.e., returns after bid-ask spread adjustment) and show that market risk and liquidity are related. Lo et al. (2004), using an equilibrium model with heterogeneous agents, show that transaction costs can significantly affect asset prices. Acharya and Pedersen (2005) study how investors maximize expected utility with time-varying liquidity costs and show the evidence that liquidity risk affects stock returns. Recently, studies show that transaction costs can generate liquidity premium that is in the same order as the costs with time-varying investment opportunity sets (Jang et al. (2007)) and with predictable returns, wealth shocks, and state-dependent transaction costs (Lynch and Tan (2011)). ${ }^{3}$ Buss and Dumas (2013) highlight that transaction costs are as important as cash flows. Gârleanu and Pedersen (2013) show the impact of transaction costs on investors' optimal dynamic portfolio policies.

Our model is a generalized version of Acharya and Pedersen (2005) and suggests a novel source of liquidity risk which is the covariance between transaction costs and consumption growth. We show that the three channels of liquidity risk of Acharya and Pedersen (2005) can be captured by the covariance between transaction costs and consumption growth. We extend the literature that highlights the pricing of various systematic risks associated with consumption (e.g., Lettau and Ludvigson (2001), Bansal and Yaron (2004), Parker and Julliard (2005), Yogo (2006), Jagannathan and Wang (2007), Savov (2011), and Boguth and Kuehn (2013)) by showing the positive relation between stock returns and the sensitivity of transaction costs to consumption growth.

\footnotetext{
${ }^{3}$ Early studies such as Constantinides (1986) and Vayanos (1998) show that transaction costs only have a second-order effect in the model with the constant transaction costs.
} 
One study relates to ours is Márquez et al. (2014) where the authors build a liquidity-adjusted stochastic discount factor. The differences between their model and ours are, however, that they assume a market illiquidity shock to consumption while we focus on transaction costs following Acharya and Pedersen (2005). Further, they measure liquidity risk as the covariance between returns and liquidity factor, while we measure liquidity risk as the covariance between transaction costs and aggregate consumption growth.

The economic meaning on incorporating the sensitivity of transaction costs to consumption growth to the CCAPM is straight-forward. When the economy is haunted by uncertainties, impacting consumption and squeezing liquidity, individual investors may unwillingly switch from their securities to cash to smooth out consumption; institutional investors may reluctantly exchange their holdings for cash to fulfill their obligations. Under these circumstances, securities whose transaction costs are less sensitive to consumption fluctuations comfort investors from states of low consumption. On the contrary, securities whose transaction costs are highly sensitive to consumption fluctuations impair investors' abilities to cushion the deterioration in consumption. As a result, investors would be more reluctant to hold high liquidity-risk (the sensitivity of transaction costs to consumption growth) securities unless they offer high expected returns.

The remainder of the paper proceeds as follows. Section 2 derives the liquidity-adjusted CCAPM. Section 3 describes the data. Section 4 presents the cross-sectional regression results. Section 5 carries out the robustness tests. Section 6 concludes the paper.

\section{The model}

In this section, we begin our setting up based on a representative consumer's multiperiod consumption and investment decision model of Samuelson (1969) and Merton (1969). We incorporate 
transaction costs, the key ingredient of this article, into the traditional CCAPM to develop our liquidity-adjusted CCAPM.

\subsection{Transaction costs and budget constraints}

The representative consumer maximizes a serial of expected utility functions with respect to consumption and a terminal bequest function, and chooses to invest in $n$ risky assets and a risk-free asset. The decision interval is a discrete time period and each period is of unit length. In our study, we follow Acharya and Pedersen (2005) by assuming a time-vary transaction cost, which implies that the representative consumer faces uncertainty with the future costs of trading. We later show that shocks of transaction costs are countercyclical, consistent with Acharya and Pedersen (2005) and Lynch and Tan (2011). Specifically, the return of risky asset $i$ after netting out transaction costs is,

$$
\begin{aligned}
R_{i, t+1}^{n} & =\frac{D_{i, t+1}+P_{i, t+1}-T C_{i, t+1}}{P_{i, t}} \\
& =R_{i, t+1}-t c_{i, t+1}
\end{aligned}
$$

where $P_{i, t+1}$ is the ex-dividend stock $i$ 's price, $D_{i, t+1}$ is the dividend, $T C_{i, t+1}$ is the per-share cost of selling stock $i,{ }^{4} R_{i, t+1}$ is the return before transactions costs, $R_{i, t+1}^{n}$ is the net return, and $t c_{i, t+1}$ is the relative time-varying transaction costs. In the spirit of Acharya and Pedersen (2005), investors can buy stock $i$ at $P_{i, t+1}$ but have to sell it at $P_{i, t+1}-T C_{i, t+1}$. This assumption allows us to study the effect of liquidity risk.

Given the above assumption, we incorporate the effect of transaction costs to the budget constraints. Let the representative consumer's time $t$ portfolio weight of the risky asset $i$ be $\omega_{i, t}$ $(i=1,2, \ldots, n)$, the weight of the risk-free asset is then $1-\sum_{i=1}^{n} \omega_{i, t}$. Since the representative

\footnotetext{
${ }^{4}$ Following Acharya and Pedersen (2005), $D_{i, t+1}$ and $T C_{i, t+1}$ are first-order autoregressive processes.
} 
consumer is exposed to the market where she gains the net returns, her wealth at $t+1$ is (assuming trading on the liquid risk-free asset incurs no transaction costs)

$$
W_{t+1}=\left(W_{t}-C_{t}\right)\left[R_{f, t+1}+\sum_{i=1}^{n} \omega_{i, t}\left(R_{i, t+1}-t c_{i, t+1}-R_{f, t+1}\right)\right],
$$

where $C_{t}$ is consumption at $t, W_{t}$ is wealth at $t$, and $R_{f, t+1}$ is the return of the risk-free asset for the period from $t$ to $t+1$.

To illustrate the intuition, let us consider a simple one-period wealth dynamic. Denote $W_{0}$ and $C_{0}$ the representative consumer's wealth and consumption at time 0 (the beginning of the period). She is also assumed to consume all of her wealth $C_{1}$ at time 1 (the end of the period). Then the one-period dynamic wealth has the form:

$$
C_{1}=\left(W_{0}-C_{0}\right)\left[R_{f, 1}+\sum_{i=1}^{n} \omega_{i}\left(R_{i, 1}-t c_{i, 1}-R_{f, 1}\right)\right] .
$$

According to Eq. (3), the consumption at time 1 is more negatively affected when the transaction $\operatorname{costs}\left(t c_{i, 1}\right)$ are higher, consistent with Márquez et al. (2014). That is, the stock payoff at time 1 will have a higher value today in terms of the consumption at time 1 when the liquidity is lower.

\subsection{Liquidity-adjusted CCAPM}

We assume that the representative consumer has a time-additive, monotonically increasing, and strictly concave von Neumann-Morgenstern utility function for lifetime consumption, which is time separable, i.e., utility at time $t$ depends merely on the consuming quantity at $t$ rather than the

consuming quantity before or after $t$. We define $I\left(W_{t}\right)$ as the life-time utility function on wealth, which satisfies the following equation:

$$
I\left(W_{t}\right)=\max _{C_{s}, \omega_{i, s}, \forall s, i} E_{t}\left[\sum_{s=t}^{T-1} \delta^{s} U\left(C_{s}\right)+\delta^{T} B\left(W_{T}\right)\right]
$$


where $\delta$ is the subjective time discount factor, $U\left(C_{s}\right)$ is the utility from consumption at time $s, C_{s}$, $B\left(W_{T}\right)$ is the ending bequest function that is monotonically increasing and strictly concave, and $E_{t}[\cdot]$ is the expectation conditional on information at time $t$.

Eq. (4) indicates that the representative consumer makes decisions with variables $C_{s}$ and $\omega_{i, s}(i=$ $1,2, \ldots, n)$ so as to maximize the expected lifetime utility. Using stochastic dynamic programming, we can write the first-order conditions (FOC) of the optimal choice problem as (see Appendix A for details):

$$
E_{t}\left[\delta \frac{U_{C}\left(C_{t+1}^{*}\right)}{U_{C}\left(C_{t}^{*}\right)} R_{f, t+1}\right]=1
$$

and

$$
E_{t}\left[\delta \frac{U_{C}\left(C_{t+1}^{*}\right)}{U_{C}\left(C_{t}^{*}\right)}\left(R_{i, t+1}-t c_{i, t+1}\right)\right]=1,
$$

where $U_{C}\left(C_{t}^{*}\right)$ is the partial derivative with respect to the representative consumer's optimal consumption. From Eq. (5) and Eq. (6), we have,

$$
E_{t}\left[\delta \frac{U_{C}\left(C_{t+1}^{*}\right)}{U_{C}\left(C_{t}^{*}\right)}\left(R_{i, t+1}-t c_{i, t+1}-R_{f, t+1}\right)\right]=0
$$

Suppose that the representative consumer's consumption utility is a constant relative risk aversion (CRRA) function, i.e., $U(C)=\frac{C^{1-\gamma}}{1-\gamma}$, where $\gamma$ is the coefficient of constant relative risk aversion. Breeden and Litzenberger (1978) show that each individual's consumption at a given date is an increasing function of aggregate consumption in a capital market where an unconstrained Pareto-optimal allocation of consumption is permitted. Suppose that all individuals have the same subjective time discount factor. Each individual's optimal marginal utility of consumption at a given date $t$ is then equal to a scalar, $a$, times a monotonically decreasing function of aggregate 
consumption, $f(C)$. Further, Breeden et al. (1989) show that in a Pareto-efficient capital market, the growth rate in the marginal utility of consumption would be identical for all individuals and equal to the growth rate in the "aggregate marginal utility" of consumption in equilibrium, which can be written as

$$
\frac{U_{C}\left(C_{t+1}^{*}\right)}{U_{C}\left(C_{t}^{*}\right)}=\frac{f\left(C_{t+1}\right)}{f\left(C_{t}\right)}
$$

Take a Taylor series expansion of Eq. (8) at $C_{t}$, we can rewrite Eq. (8) as

$$
\begin{aligned}
\frac{U_{C}\left(C_{t+1}^{*}\right)}{U_{C}\left(C_{t}^{*}\right)} & =\frac{f\left(C_{t+1}\right)}{f\left(C_{t}\right)} \\
& \approx \frac{f\left(C_{t}\right)+f^{\prime}\left(C_{t}\right)\left(C_{t+1}-C_{t}\right)}{f\left(C_{t}\right)} \\
& =1-\left[1-C_{t} f^{\prime}\left(C_{t}\right) / f\left(C_{t}\right)\right] \Delta C_{t+1} \\
& =1-\gamma \Delta C_{t+1},
\end{aligned}
$$

where $\Delta C_{t+1}$ is the aggregate consumption growth from $t$ to $t+1$.

According to Eqs. (7) and (9), the first-order condition yields the following equation:

$$
E_{t}\left[\left(1-\gamma \Delta C_{t+1}\right)\left(R_{i, t+1}-t c_{i, t+1}-R_{f, t+1}\right)\right]=0
$$

According to Cochrane (2005) (see chapter 1 of Cochrane, 2005), the beta representation of Eq. (10) has the form:

$$
\begin{aligned}
E\left(R_{i, t+1}-R_{f, t+1}\right) & =E\left(t c_{i, t+1}\right)+\frac{\gamma}{1-\gamma E\left(\Delta C_{t+1}\right)}\left[\operatorname{Cov}\left(R_{i, t+1}, \Delta C_{t+1}\right)-\operatorname{Cov}\left(t c_{i, t+1}, \Delta C_{t+1}\right)\right] \\
& =E\left(t c_{i, t+1}\right)+\frac{\gamma \operatorname{Var}\left(\Delta C_{t+1}\right)}{1-\gamma E\left(\Delta C_{t+1}\right)}\left(\beta_{R_{i}, c}+\beta_{T C_{i}, c}\right)
\end{aligned}
$$

where $\beta_{R_{i}, c}=\frac{\operatorname{Cov}\left(R_{i, t+1}, \Delta C_{t+1}\right)}{\operatorname{Var}\left(\Delta C_{t+1}\right)}$ and $\beta_{T C_{i}, c}=\frac{-\operatorname{Cov}\left(t c_{i, t+1}, \Delta C_{t+1}\right)}{\operatorname{Var}\left(\Delta C_{t+1}\right)}$. 
Eq. (11) above is our liquidity-adjusted CCAPM. It shows that expected excess return of an asset/portfolio is related to its expected transaction costs $\left(E\left(t c_{i, t+1}\right)\right)$, consumption risk $\left(\beta_{R_{i}, c}\right)$, and liquidity risk $\left(\beta_{T C_{i}, c}\right)$. We elaborate the model below:

(i) Our model (11) shows that the expected return of a stock is positively related to its expected transaction costs, $E\left(t c_{i, t+1}\right)$, which is consistent with prior evidence that transaction costs predict stock returns.

(ii) The sensitivity of stock returns to consumption growth is captured by $\beta_{R_{i}, c}$. It indicates that stocks with higher exposure to consumption risk command higher risk premium.

(iii) The negative covariance between a stock's transaction costs and consumption growth is represented by $\beta_{T C_{i}, c}$, which we define as the liquidity risk in this paper. Namely, if transaction costs increase when consumption growth decreases, the asset is then said to be exposed to high liquidity risk (i.e., large $\beta_{T C_{i}, c}$ ).

Our liquidity-adjusted model shows that high liquidity risk is compensated by high expected return. The basic mechanism is fairly intuitive. During economic contractions, investors may have to give up some of their stocks in exchange of cash either to finance consumption or to honor obligations. Hence, they are more likely to be content with low expected returns on stocks whose transaction costs are impervious to plummeting consumption; while they would require high expected returns on stocks whose transaction costs are highly sensitive to plummeting consumption.

Our model is related to but distinguishable from Acharya and Pedersen's (2005) model. Breeden (1979) shows that the CAPM, as a special case, can be derived from the consumption CAPM. Analogously, we derive the liquidity-adjusted CAPM of Acharya and Pedersen (2005) as a special case of our liquidity-adjusted CCAPM (Appendix B). The liquidity-adjusted CAPM suggests three 
forms of liquidity risk: commonality in liquidity, stock return sensitivity to market liquidity, and stock liquidity sensitivity to market returns. We show that the three channels of liquidity risk can be captured by the covariance between transaction costs and consumption growth, which is new to the literature. Acharya and Pedersen's finding that liquidity risk, measured by the stock liquidity sensitivity to market portfolio returns, has the largest effect on stock returns among all three forms of liquidity risk is consistent with our model's prediction. Moreover, Acharya and Pedersen (2005) use the price impact measure of Amihud (2002) as a proxy for transaction costs, whereas we employ directly the two transaction costs measures recently developed by Hasbrouck (2009) and Corwin and Schultz (2012).

\section{Data}

To empirically test our model, we use two alternative proxies to measure transaction costs. The first is the effective trading costs (cGibbs) of Hasbrouck (2009) and the second is the bidask spread estimates (CSspread) of Corwin and Schultz (2012). ${ }^{5}$ Hasbrouck (2009) develops the effective trading costs measure based on Roll's (1984) model. Roll's measure $\left(\sqrt{-\operatorname{Cov}\left(\Delta p_{t}, \Delta p_{t+1}\right)}\right.$, where $p$ denotes the log trade price) involves the calculation of the negative serial correlation in returns. The measure requires that $\operatorname{Cov}\left(\Delta p_{t}, \Delta p_{t+1}\right)$ is negative. However, Roll finds positive autocovariances in roughly half of the cases. One simple solution is to assign an a priori value of zero. The cGibbs estimate, used in this paper, is based on the Bayesian approach of Hasbrouck

\footnotetext{
${ }^{5}$ We also follow Acharya and Pedersen (2005) to use the adjusted Amihud (2002) measure as a proxy for transaction costs in our robustness tests. We obtain the effective trading costs data from Joel Hasbrouck's website: http://people.stern.nyu.edu/jhasbrou/Research/GibbsCurrent/gibbsCurrentIndex.html. We thank Shane Corwin for sharing with us his high-low-price-based spread estimates.
} 
(2004), which minimizes this problem. Corwin and Schultz (2012) estimate the bid-ask spread in a month with the following equation:

$$
\text { CSspread }=\frac{2\left(e^{\alpha}-1\right)}{1+e^{\alpha}}
$$

where $\alpha=\frac{\sqrt{2 \beta}-\sqrt{\beta}}{3-2 \sqrt{2}}-\sqrt{\frac{\gamma}{3-2 \sqrt{2}}}, \beta=E\left[\sum_{j=0}^{1} \ln \left(\frac{H_{t+j}^{0}}{L_{t+j}^{0}}\right)\right], \gamma=\left[\ln \left(\frac{H_{t . t+1}^{0}}{L_{t . t+1}^{0}}\right)\right]^{2}$, and $H_{t}^{0}\left(L_{t}^{0}\right)$ is the observed high (low) stock price on day $t$. The construction of $c G i b b s$ uses daily closing prices and it relies on daily high and low prices for CSspread. Intuitively, large cGibbs (CSspread) means large negative return serial correlation (high-low price volatility), but it seems unclear that high cGibbs (CSspread) is directly related to a fall in return and vice versa. For the cGibbs measure, for example, both large price increase and decrease can result in large serial correlation. Therefore, endogeneity may not be a serious issue in using returns together with the two costs measures in our tests.

We test our model based on portfolios classified by firm characteristics (e.g., market capitalization, book-to-market ratio, and liquidity) and industries. Liu (2006) highlights four dimensions of liquidity: trading costs, trading quantity, the impact of trading on price, and trading speed. Thus, apart from the two transaction costs measures of cGibbs and CSspread, we also use the following liquidity proxies with each capturing a different dimension:

(i) The negative dollar volume measure of Brennan et al. (1998), $D V$, defined as the negative daily dollar volume averaged over the prior 12 months. To be consistent with other four illiquidity proxies, we use negative dollar volume so that large $D V$ indicates high illiquidity.

(ii) The price impact measure of Amihud (2002), $R V$, defined as the daily absolute-return-todollar-volume ratio averaged over the prior 12 months. 
(iii) The trading discontinuity measure of Liu (2006), $L M$, defined as the standardized turnoveradjusted number of zero daily trading volumes over the prior 12 months. The $L M$ proxy measures the probability of no trading. Large $L M$ (i.e., high infrequent trading) indicates slow trading speed (or low liquidity). ${ }^{6}$

Our sample covers 50-year period from 1950 to 2009, which includes both NYSE and AMEX ordinary common stocks. ${ }^{7}$ Consistent with Brennan et al. (1998), Pastor and Stambaugh (2003), and Acharya and Pedersen (2005), we exclude NASDAQ stocks since its trading volume data only become available from 1983 and are inflated compared with NYSE/AMEX stocks. We collect market capitalization $(M V)$ and monthly stock returns from CRSP. Following Davis, Fama, and French (2000), we calculate the book equity using data from COMPUSTAT. We use the one-month treasury bill rate as the risk-free rate.

Panel A of Table 1 provides descriptive statistics for the main variables. The five illiquidity measures, $D V, R V, L M, c G i b b s$, and CSspread are negatively correlated with $M V$ and positively correlated with book-to-market $(B / M)$. It suggests that small stocks and distress stocks tend to be less liquid: having a large price impact, being less frequently traded, incurring high transaction costs, and having low trading quantities. As expected, the correlations among the five illiquidity proxies are positive ranging from 0.188 to 0.967 . It is not surprising to observe the high correlation of 0.967 between $R V$ and $D V$ since the former is the absolute return deflated by the latter. Because both cGibbs and CSspread measure transaction costs, they are highly correlated at 0.705.

\footnotetext{
${ }^{6}$ Similar to Amihud (2002), the calculation of $R V$ requires that there are at least $80 \%$ non-missing daily trading volumes available in the prior 12 months. In addition, the calculation of $R V$ excludes zero trading volumes over the prior 12 months. Constructions of $D V$ and $L M$ require no missing daily trading volumes in the prior 12 months. Also, $D V$, $R V$, and $L M$ are related to trading quantity, the impact of trading on price, and trading speed.

${ }^{7}$ COMPUSTAT data become available since 1950 . We identify ordinary common stocks as those with CRSP share codes 10 and 11.
} 
We measure the aggregate consumption growth as the percentage change from preceding period (one quarter) of per capita real (chain-weighted) personal consumption expenditures on nondurable goods and services from the National Income and Product Accounts (NIPA Table 7.1). We use the "end of period" timing convention to match the aggregate consumption growth to stock returns and transaction costs. Since consumption data are quarterly, we first compound monthly returns and transaction costs to quarterly values and then employ price deflator series from NIPA to convert quarterly returns and transaction costs to real terms. We also use alternative measures for aggregate consumption growth such as the long-run consumption growth as in Parker and Julliard (2005), ${ }^{8}$ the total consumption growth of Yogo (2006), and the fourth-to-fourth quarter (Q4-Q4) consumption growth of Jagannathan and Wang (2007) to test the robustness of our results.

Our liquidity-adjusted model shows that the expected return of a stock is determined by both consumption risk and liquidity risk. We use the following two regressions to estimate the consumption beta and liquidity beta:

$$
\begin{array}{r}
R_{i, t}-R_{f, t}=\alpha_{i, c}+\beta_{R_{i}, c} \Delta C_{t}+\epsilon_{i, t}, \\
-u_{i, t}=\alpha_{i, t c}+\beta_{T C_{i}, c} \Delta C_{t}+\epsilon_{i, t},
\end{array}
$$

where $R_{i, t}-R_{f, t}$ is the return per quarter of stock $i$ in excess of the risk-free rate, $\Delta C$ is the consumption growth of nondurable goods and services, and $u_{i, t}$ is the residual of the following regression:

$$
t c_{i, t}=\alpha_{i, 0}+\alpha_{i, 1} t c_{i, t-1}+u_{i, t}
$$

where $t c_{i, t}$ is the transaction costs of asset $i$ in quarter $t$. Using innovation in transaction costs, $u_{i, t}$, is due to the persistence of liquidity, e.g., Pastor and Stambaugh (2003). We also estimate

\footnotetext{
${ }^{8}$ The consumption growth over a horizon of $S$ quarters is calculated as $\Delta C_{t}^{S}=\frac{C_{t+S}}{C_{t-1}}-1$.
} 
liquidity betas directly using transaction costs: $-t c_{i, t}=\alpha_{i, t c}+\beta_{T C_{i}, c} \Delta C_{t}+\epsilon_{i, t}$, and find qualitatively similar results (untabulated). In addition, using the innovations of both transaction costs and consumption growth to estimate consumption and liquidity betas, we again find similar empirical evidence corroborating the liquidity-adjusted model in our tests.

Panel B of Table 1 reports the descriptive statistics for various consumption growth measures and the estimated consumption beta and liquidity beta. The average quarterly growth in nondurable goods and services is $0.511 \%$ in real term, which is consistent with Yogo (2006) that reports a growth rate of $0.513 \%$ per quarter over the sample period 1951-2001. On average, the consumption beta is $3.908,{ }^{9}$ and the liquidity beta is 0.107 with $c$ Gibbs proxying for transaction costs and 0.396 with the costs measure of CSspread. The positive liquidity beta and consumption growth indicate positive liquidity risk premium.

In order to provide a visual impression of the time-series property of transaction costs, Figure 1 plots the aggregate innovations of transaction costs. The innovation in market liquidity $\left(u_{m, t}\right)$ is the residual of the following regression:

$$
t c_{m, t}=\alpha_{0}+\alpha_{1} t c_{m, t-1}+u_{m, t}
$$

where $t c_{m, t}$ denotes the average of the transaction costs over the sample stocks in quarter $t$. Figure 1 shows that the aggregate shocks of transaction costs are higher in recessions than in other periods, ${ }^{10}$ consistent with Acharya and Pedersen (2005) and Lynch and Tan (2011). We also plot the liquidity innovations for size-based subsamples. The small-size subsample contains the $1 / 20$ smallest $M V$ stocks and the large-size subsample contains the 1/20 largest $M V$ stocks. In line with the intuition, Figure 1 shows that small stocks experience higher transaction costs shocks during economic crises than large stocks.

\footnotetext{
${ }^{9}$ This result is similar to Yogo (2006) that reports the consumption betas ranging from 1.196 to 6.512 with the 25 FamaFrench (1993) value-weighted portfolios as test assets.

${ }^{10}$ Recession periods are identified based on the NBER data: http://www.nber.org/cycles.html
} 


\section{Regression results}

\subsection{Cross-sectional $R$-squares}

We perform our tests on 20 equally-weighted portfolios sorted by $M V, B / M$, and each of the five liquidity measures. Using NYSE breakpoints, we form portfolios at the end of each (calendar) quarter and hold them for one quarter except the $M V$ portfolios. Fama and French (2008) distinguish microcap stocks in asset pricing tests. Following Fama and French, stocks below the $20^{\text {th }}$ of NYSE market value percentile are defined as microcap stocks. In addition, we also use the $4 \times 5 M V \& B / M$-sorted portfolios formed by independent double sort (4 $M V$ portfolios by $5 B / M$ portfolios). We conduct comparative tests between our model and the CCAPM using the following cross-section regressions:

$$
\begin{aligned}
& R_{p, t}-R_{f, t}=\gamma_{0}+\gamma_{1} \beta_{R_{p}, c}+\epsilon_{p, t}, \\
& R_{p, t}-R_{f, t}=\gamma_{0}+\gamma_{1} t c_{p, t}+\gamma_{2} \beta_{R_{p}, c}+\gamma_{3} \beta_{T C_{p}, c}+\epsilon_{p, t},
\end{aligned}
$$

where $R_{p, t}-R_{f, t}$ is the quarter $t$ return of portfolio $p$ in excess of the risk-free rate, $\beta_{R_{p}, c}$ is the consumption beta, $t c_{p, t}$ is the transaction costs of portfolio $p$, and $\beta_{T C_{p}, c}$ is the liquidity beta. Consumption beta is estimated through a time-series regression of excess return on consumption growth as in Eq. (13). Liquidity beta is estimated through a time-series regression of the liquidity innovation on consumption growth as in Eq. (14). We estimate the consumption beta and liquidity beta over the full sample period, e.g., Lettau and Ludvigson (2001) and Acharya and Pedersen (2005), unless noted otherwise. Kandel and Stambaugh (1995) show that the sample cross-sectional R-square has the following form:

$$
R^{2}=1-\frac{\bar{\epsilon}_{w}^{\prime} W \bar{\epsilon}_{w}}{\bar{\epsilon}_{0}^{\prime} W \bar{\epsilon}_{0}}
$$


where $\bar{\epsilon}_{0}$ is the deviations of mean sample returns from their cross-sectional average, $\bar{\epsilon}_{w}^{\prime} W \bar{\epsilon}_{w}$ is the aggregate pricing-error measure, and $W$ is the $N \times N$ symmetric positive-definite weighting matrix. However, the adjusted R-square may be better for our study as the number of explanatory variables differ between the CCAPM and the liquidity-adjusted model. Thus, we rely on the adjusted Rsquare in our tests. ${ }^{11}$

Figure 2 plots the adjusted R-squares for the CCAPM and our model. ${ }^{12}$ It shows that, across the board, the fraction of cross-sectional return variations explained by the liquidity-adjusted model is larger than that explained by the CCAPM. For instance, for the $20 B / M$-sorted portfolios, $87.79 \%$ (with cGibbs) and $86.46 \%$ (with CSspread) average return variations are explained by our model, while $28.19 \%$ (with cGibbs) and $30.09 \%$ (with CSspread) are explained by the CCAPM. ${ }^{13}$

\subsection{Fitted versus realized returns}

Figure 3 plots the realized average excess returns and the fitted excess returns. The realized average returns are the time-series average returns in excess of the risk-free rate. The fitted excess expected returns for the CCAPM are calculated as the fitted value from Eq. (17). The fitted excess expected returns for our liquidity-adjusted model are calculated as the fitted value from Eq. (18).

The points in Figure 3 represent the $20 M V$-sorted, $B / M$-sorted, $M V \& B / M$-sorted, $D V$-sorted, $R V$-sorted, $L M$-sorted, cGibbs-sorted, and CSspread-sorted portfolios, respectively. The vertical distance of these points to the 45 degree line represents the pricing errors. Figure 3 shows that,

\footnotetext{
${ }^{11}$ Results are similar if using the sample cross-sectional R-square of Kandel and Stambaugh (1995).

${ }^{12}$ We also separately examine the impact of transaction costs and liquidity betas on the improvement of the goodness-offit. Specifically, we estimate the adjusted R-square of our model by excluding transaction costs or liquidity betas from the model. We find that the improvement in the model's fit, relating to transaction costs and liquidity betas, varies between test portfolios and transaction costs measures. For example, liquidity betas contribute more to the fit than transaction costs for the $4 \times 5 M V \& B / M$ test portfolios under the CSspread measure (the CCAPM with liquidity betas has the adjusted R-square of $50.26 \%$, while the R-square with transaction costs is $27.51 \%$ ), while transaction costs contribute more to the fit than liquidity betas for the $20 M V$ test portfolios under the cGibbs measure (the CCAPM with transaction costs has the adjusted R-square of $68.32 \%$, while the R-square with liquidity betas is $48.48 \%$ ).

${ }^{13}$ When using cGibbs (CSspread) as the costs measure, stocks are required to have the cGibbs (CSspread) data available in order to construct the testing portfolios, which leads to slightly different R-squares of the CCAPM.
} 
overall, the pricing errors associated with the liquidity-adjusted model are smaller than those associated with the CCAPM. For each set of test portfolios, Figure 3 shows that the CCAPM mispricing is especially more manifest for the smallest and biggest size portfolios, the highest and lowest book-to-market ratios portfolios, and the most illiquidity and liquidity portfolios. By contrast, the liquidity-adjusted model shortens the vertical distance for above portfolios. To provide numerical descriptions in addition to Figure 3, we also measure the magnitudes of mean squared pricing errors for each set of the test portfolios for the CCAPM and the liquidity-adjusted model, and results are shown in Figure A.1. We find that the liquidity-adjusted model exhibits smaller pricing errors than the traditional CCAPM. For example, the mean squared pricing errors of the $M V$-sorted portfolios are $0.109 \%$ using the cGibbs measure and $0.114 \%$ using the CSspread measure for the CCAMP, while they are $0.044 \%$ under the cGibbs measure and $0.061 \%$ under the CSspread measure for the liquidity-adjusted model. That is, the CCAPM pricing errors tend to be larger than the ones associated with our liquidity-adjusted model, especially for the polar portfolios.

We also use the quoted bid-ask spread $(B A)$ of Amihud and Mendelson (1986), the dollar volume measure $(D V)$ of Brennan et al. (1998), the price impact measure $(R V)$ of Amihud (2002), and the trading discontinuity measure $(L M)$ of Liu (2006) as alternative measures for testing the R-squares and mean squared pricing errors. Because these alternatives do not measure transaction costs directly, we adjust these proxies in our tests following Acharya and Pedersen's (2005) adjustment to $R V$. Overall, we find that the results based on these alternative measures are consistent with those using the cGibbs and CSspread measures. In the robustness check section, we report the results based on the adjusted Amihud (2002) measure to proxy for transaction costs. 


\subsection{Consumption beta and liquidity beta}

Central to our model is the component of liquidity risk in addition to consumption risk. Thus, we estimate the liquidity beta together with the consumption beta, using cGibbs and CSspread as transaction costs measures, for the $20 M V$-sorted, $B / M$-sorted, $M V \& B / M$-sorted, $D V$-sorted, $R V$-sorted, $L M$-sorted, $c G i b b s$-sorted, and CSspread-sorted portfolios, respectively. We report the results in Table 2.

We find that consumption betas are related to firm size, where small (large) stocks have high (low) consumption betas. However, consumption betas for the $20 \mathrm{~B} / \mathrm{M}$ portfolios exhibit a counter intuitive pattern, where low (high) $B / M$ stocks have high (low) consumption betas. Similarly, we also observe that the consumption beta for the lowest $L M$ portfolio is larger than the highest $L M$ portfolio. These paradoxical patterns of consumption betas across $B / M$-sorted and $L M$-sorted portfolios suggest that the CCAPM has difficulties in explaining the value and liquidity premiums. In contrast, the liquidity beta exhibits a consistent tendency: high- $B / M$ and high- $L M$ stocks appear to have large and significant liquidity betas, whereas low- $B / M$ and low- $L M$ stocks tend to have small and insignificant liquidity betas. ${ }^{14}$

\subsection{Liquidity risk and expected returns}

In this sub-section we examine whether stocks with high liquidity betas are related to high expected returns, as indicated by our liquidity-adjusted CCAPM. To test this, we run the following cross-section regression:

$$
R_{p, t}-R_{f, t}=\gamma_{0}+\gamma_{1} t c_{p, t}^{\star}+\gamma_{2} \beta_{R_{p}, c}+\gamma_{3} \beta_{T C_{p}, c}+\epsilon_{p, t}
$$

\footnotetext{
${ }^{14}$ The effect of illiquidity is, however, non-linear. For example, Table 2 shows that the smallest $M V$ and the largest $B / M$ portfolios have higher liquidity betas, while the loadings are flat across the middle. In unreported results, we find that the patterns of liquidity betas are related to the patterns of transaction costs, which show the small variations across these portfolios.
} 
where $R_{p, t}-R_{f, t}$ is the quarterly return of portfolio $p$ in excess of the risk-free rate, $t c_{p, t}^{\star}$ is the transaction costs of portfolio $p$ orthogonalized to liquidity beta (i.e., $t c_{p, t}^{\star}$ is the residual from regressing transaction costs against liquidity betas), $\beta_{R_{p}, c}$ is the consumption beta, and $\beta_{T C_{p}, c}$ is the liquidity beta. Acharya and Pedersen (2005) argue that liquidity level can be correlated with liquidity risk. Thus, the orthogonalization of transaction costs to liquidity beta is to mitigate the potential multicollinearity issue. ${ }^{15}$ Table 3 shows that the coefficients for the liquidity beta are significantly positive after controlling for transaction costs for all the test portfolios, except for the CSspread-sorted portfolios; while none of the coefficients for the consumption beta are positively significant, which is consistent with early studies that the CCAPM does a poor job in explaining cross-sectional stock returns. In addition, transaction costs appear to be insignificantly related to returns, consistent with Liu (2010) that transaction costs lack significant power to predict returns beyond liquidity risk.

As an alternative, we also run the following cross-section regression:

$$
R_{p, t}-R_{f, t}=\gamma_{0}+\gamma_{1} \beta_{R_{p}, c}+\gamma_{2} \beta_{T C_{p}, c}+\epsilon_{p, t}
$$

where the notations are the same as the ones in Eq. (20). We find consistent results (untabulated) that the coefficients of the liquidity beta are significantly positive, indicating that high liquidity risk generally commands high expected returns, but consumption beta again shows no or even negative return predictability.

\footnotetext{
${ }^{15}$ We find that the spearman rank correlation between transaction costs and liquidity betas is 0.263 and 0.358 using the effective trading costs estimate (cGibbs) of Hasbrouck (2009) and the bid-ask spread estimate (CSspread) of Corwin and Schultz (2012).
} 


\subsection{Time-varying risk and risk premium}

Watanabe and Watanabe (2008) and Akbas et al. (2010) highlight the importance of timevarying liquidity risk in asset pricing. Lettau and Ludvigson (2001) and Akbas et al. (2010) argue that the returns of value and growth stocks are related to time-varying risks. Following these studies, we examine the time-varying liquidity betas for value and growth stocks in this sub-section.

Figure 4 plots the average rolling liquidity betas for growth and value stocks in bad and good states. The rolling liquidity betas for each stock are estimated from the 10-year rolling regressions based on Eq. (14). The plotted rolling liquidity betas are the cross-sectional time-series averages for the lowest (growth) and highest (value) $B / M$ portfolios. We use NBER recession periods to identify bad states and other periods as good states. Figure 4 shows that liquidity betas of value stocks are higher than growth stocks, especially in bad times. The low liquidity betas of growth stocks suggest that investors price growth stocks relatively high in economic downturns, in line with the notation of flight to liquidity.

However, this may vary among value stocks. Consider two types of value firms: troubled firms with high $B / M$ ratio who are especially bad during bad times; boring firms with few growth opportunities. Boring stocks are not necessarily costly to trade, even comparing to growth stocks. To test this, we use the payout ratio $(P R)$ to sort value stocks into troubled and boring ones. Payout ratio is measured as the total distributions including dividends paid to preferred stocks, common stocks, and share repurchases divided by the operating income before depreciation. Specifically, value stocks with a high $P R$ ratio (top $1 / 3$ ) are identified as boring firms, which are firms that, despite of having low growth opportunities, generate a stable income and maintain a high payout. Value stocks with a low $P R$ ratio (bottom 1/3) are classified as troubled firms. 
We find that troubled firms have significantly higher liquidity betas than boring firms. For example, using the effective trading costs estimate (cGibbs) of Hasbrouck (2009), the liquidity beta difference between troubled and boring value firms is $0.089(t=9.57)$, implying that troubled firms are exposed to higher liquidity risk than boring ones. We also find that troubled firms have significantly higher liquidity betas than growth firms. Comparing liquidity betas between boring firms and growth firms, we find somewhat mixed evidence. Boring firms have higher liquidity betas than growth firms under the cGibbs measure but lower liquidity betas under the CSspread measure. Overall, trading costs of value stocks are, in general, more sensitive to consumption variations than growth stocks, but the higher liquidity risk exposure is mainly applied to the troubled value stocks, and boring value stocks are not necessarily riskier. Troubled firms also earn higher returns than boring firms, though the difference is statistically insignificant.

In Figure 5, we plot the rolling estimates of liquidity betas over time for the lowest and the highest $B / M$ portfolios. The time-varying feature of liquidity risk is apparent. Value stocks, for example, exhibit high exposure to liquidity risk following the 1973 oil crisis, the 1990 Gulf war, and the 2007 financial crisis. We also study the paths of time-varying risk premium, following Ferson and Harvey (1991, 1999), Lewellen and Nagel (2006), and Gagliardini et al. (2012). Specifically, we estimate the risk premium based on the following two equations:

$$
\begin{aligned}
& R_{i, t}-R_{f, t}=\gamma_{0}+\gamma_{1, t} \beta_{R_{i}, c, t}+\epsilon_{i, t}, \\
& R_{i, t}-R_{f, t}=\gamma_{0}+\gamma_{1, t} \beta_{T C_{i}, c, t}+\epsilon_{i, t},
\end{aligned}
$$

where $R_{i, t}-R_{f, t}$ is the return of portfolio $i$ in excess of the risk-free rate, $\beta_{R_{i}, c, t}$ is the rolling consumption beta, and $\beta_{T C_{i}, c, t}$ is the rolling liquidity beta. We estimate the rolling consumption beta and liquidity beta for each stock using prior 10-year observations. 
Figure 6 shows that the consumption risk premium is small (average 0.07\% per quarter) and does not vary much over time, indicating that the traditional CCAPM has limited power in describing the time variation in expected stock returns. In contrast, the liquidity risk premium exhibits a countercyclical pattern, i.e., high in economic recessions, which is consistent with the path of time-varying equity premium documented by Kandel and Stambaugh (1990) and Harvey (1989). Overall, empirical results in this section support our model that sensitivity of transaction costs to consumption fluctuations commands a significant premium, and the liquidity adjustment improves the power of the CCAPM to explain cross-section stock returns.

\section{Robustness tests}

In this section we test the robustness of our results by examining the R-squares of cross-sectional regressions relying on the industry-extended test portfolios together with different ways of measuring consumption growth.

First, Lewellen et al. (2010) argue that the tight factor structure of size and book-to-market portfolios tends to be less powerful in rejecting misspecified asset pricing models and results in high R-squares in cross-sectional tests. They advocate that asset pricing tests should incorporate other set of portfolios to disintegrate the structure of size and book-to-market portfolios. Following their study, we expand each set of the 20 test portfolios examined earlier with 10 industry portfolios and report the results in Panel A of Table 4. It shows that a greater proportion of cross-sectional variation in expected returns can be explained by the liquidity-adjusted CCAPM than the CCAPM. For example, for the set of the $20 M V$-sorted portfolios plus the 10 industry portfolios, the liquidityadjusted model explains $55.69 \%$ (with cGibbs) and $61.73 \%$ (with CSspread) cross-sectional return 
variations, while the CCAPM explains 30.19\% (with cGibbs) and 25.89\% (with CSspread) variations. $^{16}$

Second, Parker and Julliard (2005) measure the systematic risk as the sensitivity of returns to future and contemporaneous consumption. Following Parker and Julliard, we measure consumption risk by using the consumption growth of nondurable goods over 11 quarters $(S=11)$ to test the CCAPM and the liquidity-adjusted model. Table 4 Panel B shows that the liquidity-adjusted model does a better job than the CCAPM in explaining the cross-sectional return variations. For instance, for the $20 \mathrm{~B} / \mathrm{M}$-sorted portfolios the CCAPM explains $46.88 \%$ (with $c$ Gibbs) and $54.43 \%$ (with CSspread) cross-sectional return variations, whereas the liquidity-adjusted model explains larger proportions of the return variations (71.89\% with cGibbs and $66.49 \%$ with CSspread).

Third, Yogo (2006) highlights the role of durable consumption in explaining the cross-sectional and time-varying expected returns. Following his method, we substitute the total consumption growth (durable and nondurable) for the consumption growth of nondurable goods and services (similarly, Parker and Julliard (2005) also apply this alternative). Table 4, Panel C reports the results and shows that the liquidity-adjusted model performs better than the CCAPM. Take the $20 R V$-sorted portfolios for example, with cGibbs as the transaction costs measure, the liquidityadjusted model adds $15 \%$ additional explanatory power to the return variations, compared to the CCAPM.

Fourth, Jagannathan and Wang (2007) show that the fourth-to-fourth quarter consumption growth has high explanatory power to cross-sectional return variations, since investors are more

\footnotetext{
${ }^{16}$ A number of studies such as Lettau and Ludvigson (2001), Parker and Julliard (2005), Jagannathan and Wang (2007), Acharya and Pedersen (2005), and Sadka (2006) compare R-squares without testing the significance of their differences. Kan, Robotti, and Shanken (2013) argue that it is important to test whether the seemingly better performance of one model over another is statistically significant. Their tests are, however, based on nested or non-nested factor models, while our model makes a transaction costs adjustment to the CCAPM and does not have an aggregate liquidity risk factor. Hence, consumption betas and liquidity betas in our study are estimated based on the same factor, i.e., consumption growth. As a result, the difference test of R-squares proposed in Kan, Robotti, and Shanken (2013) is not directly applicable to our study.
} 
prone to reappraise consumption and investment decisions during the fourth quarter. Following Breeden et al. (1989) and Jagannathan and Wang (2007), we construct a mimicking fourth-to-fourth quarter consumption growth factor using the maximum-correlation portfolio (MCP) approach. We run regression of the demeaned fourth-to-fourth quarter consumption growth on annual excess returns of the $2 \times 3$ equally-weighted $M V \& B / M$-sorted portfolios to obtain the MCP weights. $^{17}$ We then replace the consumption growth of nondurable goods and services with the MCP. Results in Table 4, Panel D show that the liquidity-adjusted model explains a larger fraction of return variations than the CCAPM. For instance, for the $20 M V$-sorted portfolios, the explanatory power increases to $86.24 \%$ (with cGibbs) and $90.17 \%$ (with CSspread) for the liquidity-adjusted model, while they are $68.29 \%$ (with cGibbs) and $66.38 \%$ (with CSspread) for the CCAPM.

Fifth, similar to Acharya and Pedersen (2005), we calculate the net beta (the sum of consumption and liquidity betas) and then regress returns on the net beta. We further cap the transaction costs (cGibbs and CSspread) at a maximum value of $30 \%$ to ensure that our results are not driven by the extreme observations of transaction costs. Table 4, Panels E and F show that the liquidity-adjusted model generally exhibits better fits than the CCAPM.

Finally, following Acharya and Pedersen (2005) we adjust the price impact measure $(R V)$ of Amihud (2002) based on the following equation:

$$
c R V_{i, t}=\min \left(0.25+0.30 R V_{i, t} P_{t-1}, 30.00\right)
$$

where $P_{t-1}$ denotes the ratio of the market cap of the market portfolio at the end of month $t-1$ to the market cap of the market portfolio at the end of January 1950. We use the adjusted $R V$, $c R V$, to proxy for transaction costs. The last two columns of Table 4 report the results of various

\footnotetext{
${ }^{17}$ Returns of the $2 \times 3$ equally-weighted $M V \& B / M$-sorted portfolios are from Kenneth French's website: http://mba.tuck.dartmouth.edu/pages/faculty/ken.french/.
} 
robustness tests using the $c R V$ measure and provide further evidence corroborating the liquidityadjusted model, which has higher $R^{2}$ 's than the CCAPM except for two of the 24 cases considered. $^{18}$

\section{Conclusion}

Motivated by recent studies showing the importance of liquidity in asset pricing, we propose a liquidity adjustment to the consumption-based capital asset pricing model (CCAPM). In addition to the traditional CCAPM risk (i.e., the covariance between asset return and consumption growth), the liquidity-adjusted model suggests that expected return is also associated with transaction costs and liquidity risk (the covariance between transaction costs and consumption growth). This is because high sensitivity of transaction costs to fluctuations in consumption implies the difficulty to convert investment into cash for consumption or honoring obligations. Investors, therefore, demand high expected return to compensate for high liquidity risk. Our model suggests that neglecting transaction costs and liquidity risk would lead to inaccurate estimate of expected return.

Empirically, we find that the average stock is positively exposed to liquidity risk, and the sensitivity of trading costs to consumption variations is significantly related to returns. The evidence indicates that the traditional CCAPM underestimates risk and expected return on average. This also potentially explains why the performance of the CCAPM is empirically poor. In fact, we find consistent results with previous studies that consumption risk shows limited power to describe cross-sectional returns. Supportively, we show that the liquidity-adjusted CCAPM explains a larger fraction of the cross-sectional return variations. Our study extends the existing theoretical and empirical support of liquidity in asset pricing.

\footnotetext{
${ }^{18}$ Since $c R V$ is capped at $30 \%$ according to Eq. (24), the results of the $c R V$ measure in Panels $\mathrm{E}$ and $\mathrm{F}$ are identical.
} 


\section{References}

Acharya, V. V., Pedersen, L. H., 2005. Asset pricing with liquidity risk. Journal of Financial Economics $77,375-410$.

Akbas, F., Boehmer, E., Genc, E., Petkova, R., 2010. The time-varying liquidity risk of value and growth stocks. Working Paper.

Amihud, Y., 2002. Illiquidity and stock returns: cross-section and time-series effects. Journal of Financial Markets 5, 31-56.

Amihud, Y., Mendelson, H., 1986. Asset pricing and the bid-ask spread. Journal of Financial Economics $17,223-249$.

Bansal, R., Yaron, A., 2004. Risks for the long run: A potential resolution of asset pricing puzzles. Journal of Finance 59, 1481-1509.

Bekaert, G., Harvey, C. R., Lundblad, C., 2007. Liquidity and expected returns: Lessons from emerging markets. Review of Financial Studies 20, 1783-1831.

Bellman, R., 1957. Dynamic programming. Princeton, NJ: Princeton University Press.

Boguth, O., Kuehn, L. A., 2013. Consumption volatility risk. Journal of Finance 68, 2589-2615.

Breeden, D. T., 1979. An intertemporal asset pricing model with stochastic consumption and investment opportunities. Journal of Financial Economics 7, 265-296.

Breeden, D. T., Gibbons, M. R., Litzenberger, R. H., 1989. Empirical tests of the consumptionoriented capm. Journal of Finance 44, 231-262.

Breeden, D. T., Litzenberger, R. H., 1978. Prices of state-contingent claims implicit in option prices. Journal of Business pp. 621-651.

Brennan, M. J., Chordia, T., Subrahmanyam, A., 1998. Alternative factor specifications, security characteristics, and the cross-section of expected stock returns1. Journal of Financial Economics $49,345-373$.

Buss, A., Dumas, B., 2013. The equilibrium dynamics of liquidity and illiquid asset prices. Working Paper.

Campbell, J. Y., 2003. Consumption-based asset pricing. Elsevier, vol. 1, Part B Chapter 13 of Handbook of the Economics of Finance, pp. 803-887.

Chien, Y., Lustig, H., 2010. The market price of aggregate risk and the wealth distribution. Review of Financial Studies 23, 1596-1650.

Chordia, T., Roll, R., Subrahmanyam, A., 2000. Commonality in liquidity. Journal of Financial Economics 56, 3-28.

Cochrane, J. H., 2005. Asset pricing, revised edition. Princeton, NJ: Princeton University Press. 
Constantinides, G. M., 1986. Capital market equilibrium with transaction costs. Journal of Political Economy 94, 842-862.

Corwin, S. A., Schultz, P., 2012. A simple way to estimate bid-ask spreads from daily high and low prices. Journal of Finance 67, 719-760.

Davis, J. L., Fama, E. F., French, K. R., 2000. Characteristics, covariances, and average returns: 1929 to 1997. Journal of Finance 55, 389-406.

Fama, E. F., French, K. R., 1993. Common risk factors in the returns on stocks and bonds. Journal of Financial Economics 33, 3-56.

Fama, E. F., French, K. R., 1997. Industry costs of equity. Journal of Financial Economics 43, 153-193.

Fama, E. F., French, K. R., 2008. Dissecting anomalies. Journal of Finance 63, 1653-1678.

Fama, E. F., MacBeth, J. D., 1973. Risk, return, and equilibrium: Empirical tests. Journal of Political Economy 81, 607-636.

Ferson, W. E., Harvey, C. R., 1991. The variation of economic risk premiums. Journal of Political Economy 99, 385-415.

Ferson, W. E., Harvey, C. R., 1999. Conditioning variables and the cross section of stock returns. Journal of Finance 54, 1325-1360.

Gagliardini, P., Ossola, E., Scaillet, O., 2012. Time-varying risk premium in large cross-sectional equity datasets .

Gârleanu, N., Pedersen, L. H., 2013. Dynamic trading with predictable returns and transaction costs. Journal of Finance 68, 2309-2340.

Hansen, L. P., Heaton, J. C., Li, N., 2008. Consumption strikes back? Measuring long-run risk. Journal of Political Economy 116, 260-302.

Harvey, C. R., 1989. Time-varying conditional covariances in tests of asset pricing models. Journal of Financial Economics 24, 289-317.

Hasbrouck, J., 2004. Liquidity in the futures pits: Inferring market dynamics from incomplete data. Journal of Financial and Quantitative Analysis 39, 305-326.

Hasbrouck, J., 2009. Trading costs and returns for U.S. equities: Estimating effective costs from daily data. Journal of Finance 64, 1445-1477.

Jacoby, G., Fowler, D. J., Gottesman, A. A., 2000. The capital asset pricing model and the liquidity effect: A theoretical approach. Journal of Financial Markets 3, 69-81.

Jagannathan, R., Wang, Y., 2007. Lazy investors, discretionary consumption, and the cross-section of stock returns. Journal of Finance 62, 1623-1661. 
Jang, B. G., Koo, H. K., Liu, H., Loewenstein, M., 2007. Liquidity premia and transaction costs. Journal of Finance 62, 2329-2366.

Kan, R., Robotti, C., Shanken, J., 2013. Pricing model performance and the two-pass cross-sectional regression methodology. Journal of Finance 68, 2617-2649.

Kandel, S., Stambaugh, R. F., 1990. Expectations and volatility of consumption and asset returns. Review of Financial Studies 3, 207-232.

Kandel, S., Stambaugh, R. F., 1995. Portfolio inefficiency and the cross-section of expected returns. Journal of Finance 50, 157-184.

Kang, W., Li, N., 2011. Liquidity premium and consumption. Working Paper.

Lagos, R., 2010. Asset prices and liquidity in an exchange economy. Journal of Monetary Economics 57, 913-930.

Lettau, M., Ludvigson, S., 2001. Resurrecting the (C)CAPM: A cross-sectional test when risk premia are time-varying. Journal of Political Economy 109, 1238-1287.

Lewellen, J., Nagel, S., 2006. The conditional CAPM does not explain asset-pricing anomalies. Journal of Financial Economics 82, 289-314.

Lewellen, J., Nagel, S., Shanken, J., 2010. A skeptical appraisal of asset pricing tests. Journal of Financial Economics 96, 175-194.

Lintner, J., 1965. Security prices, risk, and maximal gains from diversification. Journal of Finance 20, 587-615.

Liu, W., 2006. A liquidity-augmented capital asset pricing model. Journal of Financial Economics $82,631-671$.

Liu, W., 2010. Liquidity risk and asset pricing: Evidence from daily data, 1926-2009. Working Paper, University of Nottingham.

Lo, A. W., Mamaysky, H., Wang, J., 2004. Asset prices and trading volume under fixed transactions costs. Journal of Political Economy 112, 1054-1090.

Lucas, Robert E., J., 1978. Asset prices in an exchange economy. Econometrica 46, 1429-1445.

Lynch, A. W., Tan, S., 2011. Explaining the magnitude of liquidity premia: The roles of return predictability, wealth shocks, and state-dependent transaction costs. Journal of Finance 66, 13291368 .

Márquez, E., Nieto, B., Rubio, G., 2014. Stock returns with consumption and illiquidity risks. International Review of Economics and Finance 29, 57-74.

Merton, R. C., 1969. Lifetime portfolio selection under uncertainty: The continuous-time case. The Review of Economics and Statistics 51, 247-257. 
Næs, R., Skjeltorp, J. A., Ødegaard, B. A., 2011. Stock market liquidity and the business cycle. Journal of Finance 66, 139-176.

Parker, J. A., Julliard, C., 2005. Consumption risk and the cross section of expected returns. Journal of Political Economy 113, 185-222.

Pastor, L., Stambaugh, R. F., 2003. Liquidity risk and expected stock returns. Journal of Political Economy 111, 642-685.

Petkova, R., Zhang, L., 2005. Is value riskier than growth? Journal of Financial Economics 78, $187-202$.

Roll, R., 1984. A simple implicit measure of the effective bid-ask spread in an efficient market. Journal of Finance 39, 1127-1139.

Rubinstein, M., 1976. The valuation of uncertain income streams and the pricing of options. Bell Journal of Economics and Management Science 7, 407-425.

Sadka, R., 2006. Momentum and post-earnings-announcement drift anomalies: The role of liquidity risk. Journal of Financial Economics 80, 309-349.

Samuelson, P. A., 1969. Lifetime portfolio selection by dynamic stochastic programming. Review of Economics and Statistics 51, 239-246.

Savov, A., 2011. Asset pricing with garbage. Journal of Finance 66, 177-201.

Sharpe, W. F., 1964. Capital asset prices: A theory of market equilibrium under conditions of risk. Journal of Finance 19, 425-442.

Vayanos, D., 1998. Transaction costs and asset prices: a dynamic equilibrium model. Review of Financial Studies 11, 1-58.

Watanabe, A., Watanabe, M., 2008. Time-varying liquidity risk and the cross section of stock returns. Review of Financial Studies 21, 2449-2486.

Yogo, M., 2006. A consumption-based explanation of expected stock returns. Journal of Finance $61,539-580$. 


\section{Table 1}

\section{Descriptive statistics}

\begin{tabular}{|c|c|c|c|c|c|c|c|}
\hline \multicolumn{8}{|c|}{ Panel A: market variables } \\
\hline & $\mathrm{MV}(\$ \mathrm{~m})$ & $\mathrm{B} / \mathrm{M}$ & $\mathrm{DV}(\$ 000)$ & $\operatorname{RV}\left(10^{6}\right)$ & $\mathrm{LM}$ & cGibbs $(\%)$ & CSspread(\%) \\
\hline \multicolumn{8}{|c|}{ Descriptive statistics } \\
\hline Mean & 1636.576 & 1.066 & -7389.917 & 4.770 & 10.352 & 0.782 & 1.300 \\
\hline SD & 9540.065 & 5.273 & 45820.669 & 34.176 & 26.028 & 0.999 & 2.291 \\
\hline \multicolumn{8}{|c|}{ Spearman rank correlation } \\
\hline $\mathrm{B} / \mathrm{M}$ & -0.359 & 1 & & & & & \\
\hline DV & -0.899 & 0.343 & 1 & & & & \\
\hline RV & -0.940 & 0.317 & 0.967 & 1 & & & \\
\hline LM & -0.506 & 0.205 & 0.735 & 0.655 & 1 & & \\
\hline cGibbs & -0.680 & 0.207 & 0.611 & 0.691 & 0.252 & 1 & \\
\hline CSspread & -0.627 & 0.244 & 0.529 & 0.605 & 0.188 & 0.705 & 1 \\
\hline \multicolumn{8}{|c|}{ Panel B: consumption growth, consumption beta, and liquidity beta } \\
\hline & $\Delta C(\%)$ & $\Delta C^{S}(\%)$ & $\Delta C^{T}(\%)$ & $\Delta C^{Q 4}(\%)$ & $\beta_{R, c}$ & $\beta_{T C, c}^{c G i b b s}$ & $\beta_{T C, c}^{C S s p r e a d}$ \\
\hline \multicolumn{8}{|c|}{ Descriptive statistics } \\
\hline Mean & 0.511 & 4.138 & 0.545 & 2.065 & 3.908 & 0.107 & 0.396 \\
\hline SD & 0.498 & 3.255 & 0.860 & 1.417 & 23.589 & 0.674 & 2.721 \\
\hline
\end{tabular}

Panel A of this table reports descriptive statistics and correlations for the following variables:

$M V(\$ m)$ : market capitalization measured in millions of dollars;

$B / M$ : book-to-market ratio;

$D V(\$ 000)$ : negative average daily dollar volume over the prior 12 months, where daily dollar volume is the number of shares traded on a day times the closing price on that day;

$R V\left(10^{6}\right)$ : daily ratio of the absolute return on a day to the dollar volume on that day averaged over the prior 12 months;

$L M$ : standardized turnover-adjusted number of zero daily trading volumes over the prior 12 months;

cGibbs(\%): Hasbrouck's (2009) effective transaction costs measure, which is estimated using daily closing prices in the prior 12 months (at least 60 reported trading prices);

CSspread(\%): the bid-ask spread estimates using daily high and low prices by Corwin and Schultz (2012).

The $B / M$-related results are determined based on positive $B / M$ stocks. The calculations of $D V$ and $L M$ require no missing daily trading volumes in the prior 12 months. The calculation of $R V$ requires that there are at least $80 \%$ non-missing daily trading volumes available in the prior 12 months. Note that the calculation of $R V$ excludes zero trading volumes over the prior 12 months. At the end of each month from January 1950 to December 2009, cross-sectional averages for each variable are calculated over NYSE/AMEX stocks. The reported mean and standard deviation are based on these time-series crosssectional averages. Likewise, at the end of each month from January 1950 to December 2009, the cross-sectional Spearman rank correlations are computed, and the time-series average of those correlations are reported. Panel B reports the various consumption growth measures in percentage form and the estimated individual consumption beta and liquidity beta. The symbol $\Delta C$ stands for the consumption growth of nondurable goods and services, $\Delta C^{S}$ for the consumption growth of nondurable goods over 11 quarters $(S=11), \Delta C^{T}$ for the total consumption growth, and $\Delta C^{Q 4}$, the fourth-to-fourth quarter (Q4-Q4) consumption growth based on nondurable goods and services. We use two linear functions of the nondurable goods and services consumption growth to estimate the consumption beta and liquidity beta:

$$
\begin{array}{r}
R_{i, t}-R_{f, t}=\alpha_{i, c}+\beta_{R_{i}, c} \Delta C_{t}+\epsilon_{i, t}, \\
-u_{i, t}=\alpha_{i, t c}+\beta_{T C_{i}, c} \Delta C_{t}+\epsilon_{i, t},
\end{array}
$$

where $R_{i, t}-R_{f, t}$ is the return in quarter $t$ of stock $i$ in excess of the risk-free rate, $\Delta C$ is the consumption growth of nondurable goods and services, and $u_{i, t}$ is the residual of the following regression:

$$
t c_{i, t}=\alpha_{i, 0}+\alpha_{i, 1} t c_{i, t-1}+u_{i, t}
$$

where tc is either cGibbs or CSspread. 


\section{Table 2}

The consumption beta and liquidity beta

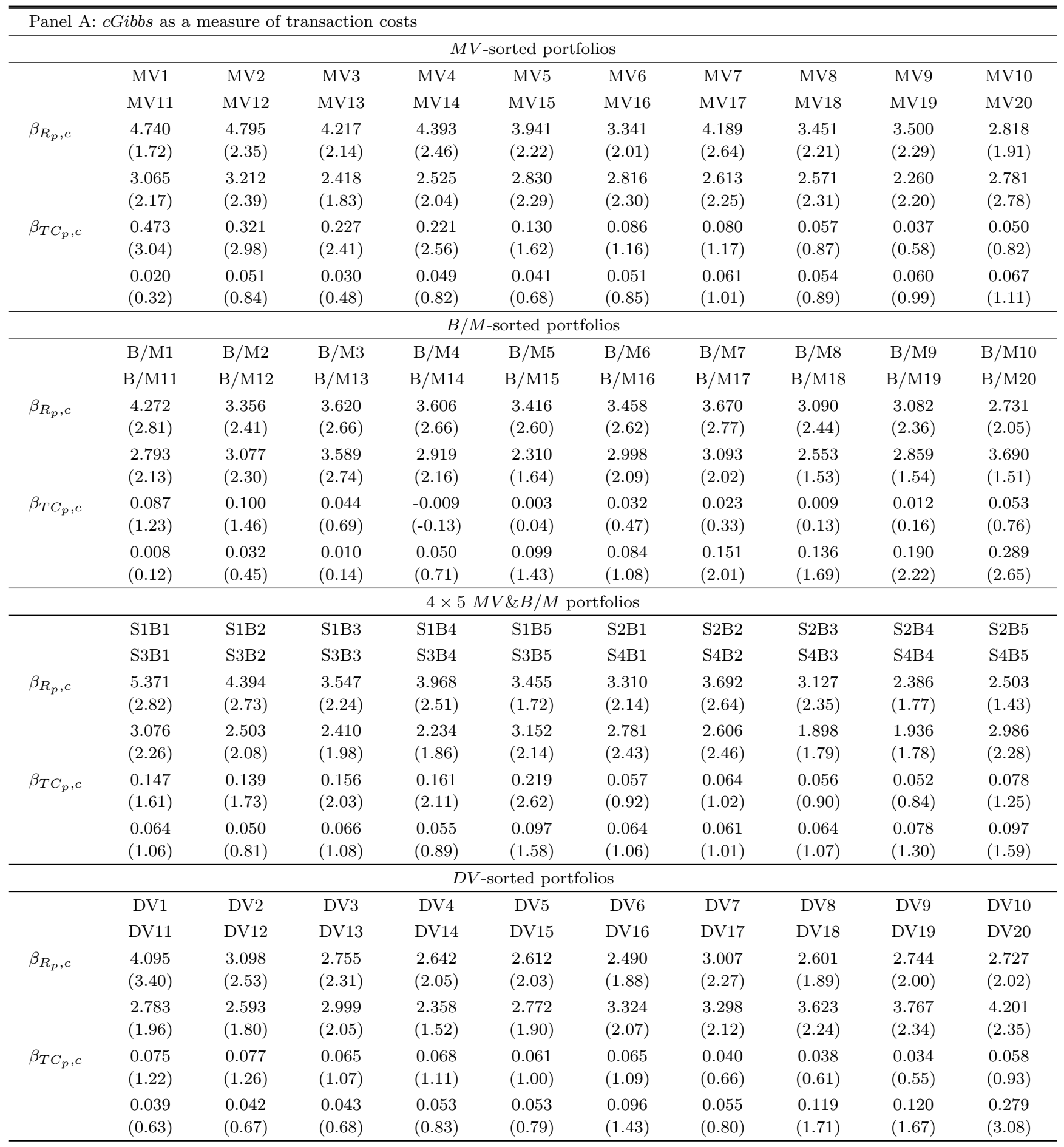


Table 2

\section{Continued}

\begin{tabular}{|c|c|c|c|c|c|c|c|c|c|c|}
\hline \multicolumn{11}{|c|}{$R V$-sorted portfolios } \\
\hline & RV1 & RV2 & RV3 & RV4 & RV5 & RV6 & RV7 & RV8 & RV9 & RV10 \\
\hline & RV11 & RV12 & RV13 & RV14 & RV15 & RV16 & RV17 & RV18 & RV19 & RV20 \\
\hline \multirow[t]{2}{*}{$\beta_{R_{p}, c}$} & $\begin{array}{l}3.247 \\
(3.11)\end{array}$ & $\begin{array}{l}2.864 \\
(2.65)\end{array}$ & $\begin{array}{l}2.432 \\
(2.13)\end{array}$ & $\begin{array}{l}3.038 \\
(2.63)\end{array}$ & $\begin{array}{l}2.610 \\
(2.10)\end{array}$ & $\begin{array}{l}2.339 \\
(1.87)\end{array}$ & $\begin{array}{l}2.988 \\
(2.33)\end{array}$ & $\begin{array}{l}2.496 \\
(1.93)\end{array}$ & $\begin{array}{l}2.205 \\
(1.65)\end{array}$ & $\begin{array}{l}2.909 \\
(2.19)\end{array}$ \\
\hline & $\begin{array}{c}2.676 \\
(1.94)\end{array}$ & $\begin{array}{l}3.086 \\
(2.14)\end{array}$ & $\begin{array}{c}2.730 \\
(1.92)\end{array}$ & $\begin{array}{l}3.226 \\
(2.23)\end{array}$ & $\begin{array}{l}3.151 \\
(2.11)\end{array}$ & $\begin{array}{l}3.336 \\
(2.15)\end{array}$ & $\begin{array}{c}2.559 \\
(1.61)\end{array}$ & $\begin{array}{c}2.898 \\
(1.73)\end{array}$ & $\begin{array}{l}3.656 \\
(2.20)\end{array}$ & $\begin{array}{l}4.398 \\
(2.20)\end{array}$ \\
\hline \multirow[t]{2}{*}{$\beta_{T C_{p}, c}$} & $\begin{array}{c}0.073 \\
(1.20)\end{array}$ & $\begin{array}{c}0.062 \\
(1.02)\end{array}$ & $\begin{array}{c}0.078 \\
(1.29)\end{array}$ & $\begin{array}{l}0.050 \\
(0.83)\end{array}$ & $\begin{array}{l}0.067 \\
(1.09)\end{array}$ & $\begin{array}{l}0.066 \\
(1.10)\end{array}$ & $\begin{array}{l}0.042 \\
(0.70)\end{array}$ & $\begin{array}{l}0.058 \\
(0.94)\end{array}$ & $\begin{array}{l}0.047 \\
(0.77)\end{array}$ & $\begin{array}{l}0.042 \\
(0.70)\end{array}$ \\
\hline & $\begin{array}{c}0.056 \\
(0.92) \\
\end{array}$ & $\begin{array}{r}0.053 \\
(0.89) \\
\end{array}$ & $\begin{array}{c}0.051 \\
(0.81) \\
\end{array}$ & $\begin{array}{l}0.064 \\
(1.03) \\
\end{array}$ & $\begin{array}{c}0.076 \\
(1.21) \\
\end{array}$ & $\begin{array}{c}0.091 \\
(1.44) \\
\end{array}$ & $\begin{array}{c}0.118 \\
(1.83) \\
\end{array}$ & $\begin{array}{l}0.104 \\
(1.52) \\
\end{array}$ & $\begin{array}{l}0.172 \\
(2.55) \\
\end{array}$ & $\begin{array}{l}0.317 \\
(3.31) \\
\end{array}$ \\
\hline \multicolumn{11}{|c|}{$L M$-sorted portfolios } \\
\hline \multirow{4}{*}{$\beta_{R_{p}, c}$} & LM1 & LM2 & LM3 & LM4 & LM5 & LM6 & LM7 & LM8 & LM9 & LM10 \\
\hline & LM11 & LM12 & LM13 & LM14 & LM15 & LM16 & LM17 & LM18 & LM19 & LM20 \\
\hline & $\begin{array}{l}4.244 \\
(2.18)\end{array}$ & $\begin{array}{l}3.992 \\
(2.20)\end{array}$ & $\begin{array}{l}4.037 \\
(2.41)\end{array}$ & $\begin{array}{l}3.222 \\
(1.97)\end{array}$ & $\begin{array}{l}3.291 \\
(2.13)\end{array}$ & $\begin{array}{l}3.186 \\
(2.18)\end{array}$ & $\begin{array}{l}2.505 \\
(1.80)\end{array}$ & $\begin{array}{l}2.569 \\
(1.96)\end{array}$ & $\begin{array}{l}2.311 \\
(1.85)\end{array}$ & $\begin{array}{l}2.515 \\
(2.09)\end{array}$ \\
\hline & $\begin{array}{c}2.311 \\
(1.91)\end{array}$ & $\begin{array}{l}2.207 \\
(1.80)\end{array}$ & $\begin{array}{l}3.077 \\
(2.42)\end{array}$ & $\begin{array}{l}2.362 \\
(1.83)\end{array}$ & $\begin{array}{l}2.676 \\
(2.04)\end{array}$ & $\begin{array}{l}3.047 \\
(2.16)\end{array}$ & $\begin{array}{l}3.759 \\
(2.56)\end{array}$ & $\begin{array}{l}3.098 \\
(2.01)\end{array}$ & $\begin{array}{l}3.812 \\
(2.39)\end{array}$ & $\begin{array}{l}3.999 \\
(2.61)\end{array}$ \\
\hline \multirow[t]{2}{*}{$\beta_{T C_{p}, c}$} & $\begin{array}{l}0.060 \\
(0.95)\end{array}$ & $\begin{array}{l}0.006 \\
(0.09)\end{array}$ & $\begin{array}{l}0.004 \\
(0.06)\end{array}$ & $\begin{array}{l}-0.002 \\
(-0.02)\end{array}$ & $\begin{array}{l}-0.005 \\
(-0.09)\end{array}$ & $\begin{array}{l}0.053 \\
(0.81)\end{array}$ & $\begin{array}{l}0.034 \\
(0.50)\end{array}$ & $\begin{array}{l}0.015 \\
(0.23)\end{array}$ & $\begin{array}{l}0.060 \\
(0.93)\end{array}$ & $\begin{array}{l}0.046 \\
(0.69)\end{array}$ \\
\hline & $\begin{array}{c}0.008 \\
(0.12) \\
\end{array}$ & $\begin{array}{r}0.059 \\
(0.85) \\
\end{array}$ & $\begin{array}{c}0.091 \\
(1.33) \\
\end{array}$ & $\begin{array}{l}0.090 \\
(1.25) \\
\end{array}$ & $\begin{array}{r}0.014 \\
(0.19) \\
\end{array}$ & $\begin{array}{l}0.049 \\
(0.65)\end{array}$ & $\begin{array}{l}0.082 \\
(1.09)\end{array}$ & $\begin{array}{r}0.114 \\
(1.55) \\
\end{array}$ & $\begin{array}{c}0.132 \\
(1.70)\end{array}$ & $\begin{array}{l}0.244 \\
(3.09) \\
\end{array}$ \\
\hline \multicolumn{11}{|c|}{$c G i b b s$-sorted portfolios } \\
\hline \multirow{4}{*}{$\beta_{R_{p}, c}$} & cGibbs1 & cGibbs2 & cGibbs3 & cGibbs4 & cGibbs5 & cGibbs6 & cGibbs7 & cGibbs8 & cGibbs9 & cGibbs10 \\
\hline & cGibbs11 & cGibbs12 & cGibbs13 & cGibbs14 & cGibbs15 & cGibbs16 & cGibbs17 & cGibbs18 & cGibbs19 & cGibbs 20 \\
\hline & $\begin{array}{c}2.626 \\
(2.68)\end{array}$ & $\begin{array}{l}2.983 \\
(2.71)\end{array}$ & $\begin{array}{c}2.890 \\
(2.59)\end{array}$ & $\begin{array}{l}2.796 \\
(2.37)\end{array}$ & $\begin{array}{l}2.597 \\
(2.15)\end{array}$ & $\begin{array}{l}2.993 \\
(2.37)\end{array}$ & $\begin{array}{l}2.873 \\
(2.27)\end{array}$ & $\begin{array}{l}2.943 \\
(2.32)\end{array}$ & $\begin{array}{l}2.938 \\
(2.24)\end{array}$ & $\begin{array}{c}2.782 \\
(2.08)\end{array}$ \\
\hline & $\begin{array}{l}2.694 \\
(2.03)\end{array}$ & $\begin{array}{l}2.881 \\
(2.14)\end{array}$ & $\begin{array}{l}3.100 \\
(2.23)\end{array}$ & $\begin{array}{l}3.427 \\
(2.45)\end{array}$ & $\begin{array}{l}2.544 \\
(1.81)\end{array}$ & $\begin{array}{c}2.811 \\
(1.89)\end{array}$ & $\begin{array}{l}3.207 \\
(2.05)\end{array}$ & $\begin{array}{l}3.394 \\
(2.06)\end{array}$ & $\begin{array}{l}3.762 \\
(2.08)\end{array}$ & $\begin{array}{l}4.534 \\
(1.91)\end{array}$ \\
\hline \multirow[t]{2}{*}{$\beta_{T C_{p}, c}$} & $\begin{array}{l}0.051 \\
(0.83)\end{array}$ & $\begin{array}{l}0.057 \\
(0.93)\end{array}$ & $\begin{array}{l}0.057 \\
(0.94)\end{array}$ & $\begin{array}{l}0.060 \\
(0.98)\end{array}$ & $\begin{array}{c}0.061 \\
(1.00)\end{array}$ & $\begin{array}{l}0.058 \\
(0.96)\end{array}$ & $\begin{array}{l}0.059 \\
(0.96)\end{array}$ & $\begin{array}{l}0.065 \\
(1.05)\end{array}$ & $\begin{array}{l}0.061 \\
(0.99)\end{array}$ & $\begin{array}{l}0.061 \\
(0.99)\end{array}$ \\
\hline & $\begin{array}{c}0.070 \\
(1.15)\end{array}$ & $\begin{array}{l}0.063 \\
(1.03)\end{array}$ & $\begin{array}{c}0.069 \\
(1.13)\end{array}$ & $\begin{array}{c}0.075 \\
(1.22)\end{array}$ & $\begin{array}{c}0.082 \\
(1.32)\end{array}$ & $\begin{array}{c}0.092 \\
(1.47)\end{array}$ & $\begin{array}{c}0.116 \\
(1.80)\end{array}$ & $\begin{array}{l}0.155 \\
(2.29)\end{array}$ & $\begin{array}{l}0.237 \\
(3.18)\end{array}$ & $\begin{array}{c}0.401 \\
(3.38)\end{array}$ \\
\hline \multicolumn{11}{|c|}{ CSspread-sorted portfolios } \\
\hline \multirow{4}{*}{$\beta_{R_{p}, c}$} & CSspread1 & CSspread2 & CSspread3 & CSspread4 & CSspread5 & CSspread6 & CSspread7 & CSspread8 & CSspread9 & CSspread10 \\
\hline & CSspread11 & CSspread12 & CSspread13 & CSspread14 & CSspread15 & CSspread16 & CSspread17 & CSspread18 & CSspread19 & CSspread20 \\
\hline & $\begin{array}{l}2.533 \\
(2.45)\end{array}$ & $\begin{array}{l}2.144 \\
(1.94)\end{array}$ & $\begin{array}{l}2.254 \\
(2.00)\end{array}$ & $\begin{array}{l}2.482 \\
(2.21)\end{array}$ & $\begin{array}{l}2.772 \\
(2.38)\end{array}$ & $\begin{array}{c}3.086 \\
(2.60)\end{array}$ & $\begin{array}{c}2.772 \\
(2.26)\end{array}$ & $\begin{array}{l}3.496 \\
(2.75)\end{array}$ & $\begin{array}{l}3.267 \\
(2.52)\end{array}$ & $\begin{array}{l}3.302 \\
(2.44)\end{array}$ \\
\hline & $\begin{array}{l}3.211 \\
(2.30)\end{array}$ & $\begin{array}{l}3.698 \\
(2.53)\end{array}$ & $\begin{array}{l}3.940 \\
(2.52)\end{array}$ & $\begin{array}{l}3.830 \\
(2.37)\end{array}$ & $\begin{array}{l}3.683 \\
(2.16)\end{array}$ & $\begin{array}{l}3.930 \\
(2.20)\end{array}$ & $\begin{array}{l}4.018 \\
(2.08)\end{array}$ & $\begin{array}{l}3.919 \\
(1.95)\end{array}$ & $\begin{array}{c}3.628 \\
(1.47)\end{array}$ & $\begin{array}{l}5.482 \\
(1.92)\end{array}$ \\
\hline \multirow[t]{2}{*}{$\beta_{T C_{p}, c}$} & $\begin{array}{c}0.071 \\
(1.18)\end{array}$ & $\begin{array}{l}0.059 \\
(0.97)\end{array}$ & $\begin{array}{l}0.045 \\
(0.73)\end{array}$ & $\begin{array}{l}0.043 \\
(0.72)\end{array}$ & $\begin{array}{l}0.055 \\
(0.91)\end{array}$ & $\begin{array}{l}0.027 \\
(0.44)\end{array}$ & $\begin{array}{l}0.049 \\
(0.80)\end{array}$ & $\begin{array}{l}0.048 \\
(0.78)\end{array}$ & $\begin{array}{c}0.051 \\
(0.82)\end{array}$ & $\begin{array}{c}0.054 \\
(0.87)\end{array}$ \\
\hline & $\begin{array}{l}0.042 \\
(0.67)\end{array}$ & $\begin{array}{l}0.050 \\
(0.76)\end{array}$ & $\begin{array}{c}0.075 \\
(1.12)\end{array}$ & $\begin{array}{c}0.079 \\
(1.17)\end{array}$ & $\begin{array}{c}0.105 \\
(1.43)\end{array}$ & $\begin{array}{l}0.165 \\
(2.17)\end{array}$ & $\begin{array}{l}0.246 \\
(2.98)\end{array}$ & $\begin{array}{l}0.292 \\
(3.10)\end{array}$ & $\begin{array}{l}0.304 \\
(2.67)\end{array}$ & $\begin{array}{l}0.500 \\
(2.74)\end{array}$ \\
\hline
\end{tabular}

[Cont.] 


\section{Table 2}

\section{Continued}

\begin{tabular}{|c|c|c|c|c|c|c|c|c|c|c|}
\hline \multicolumn{11}{|c|}{ Panel B: CSspread as a measure of transaction costs } \\
\hline \multicolumn{11}{|c|}{$M V$-sorted portfolios } \\
\hline & MV1 & MV2 & MV3 & MV4 & MV5 & MV6 & MV7 & MV8 & MV9 & MV10 \\
\hline & MV11 & MV12 & MV13 & MV14 & MV15 & MV16 & MV17 & MV18 & MV19 & MV20 \\
\hline \multirow[t]{2}{*}{$\beta_{R_{p}, c}$} & $\begin{array}{l}4.575 \\
(1.66)\end{array}$ & $\begin{array}{l}4.889 \\
(2.41)\end{array}$ & $\begin{array}{l}4.152 \\
(2.10)\end{array}$ & $\begin{array}{l}4.370 \\
(2.44)\end{array}$ & $\begin{array}{l}3.986 \\
(2.25)\end{array}$ & $\begin{array}{l}3.385 \\
(2.03)\end{array}$ & $\begin{array}{l}4.211 \\
(2.64)\end{array}$ & $\begin{array}{l}3.484 \\
(2.22)\end{array}$ & $\begin{array}{l}3.471 \\
(2.26)\end{array}$ & $\begin{array}{l}2.845 \\
(1.93)\end{array}$ \\
\hline & $\begin{array}{l}3.073 \\
(2.18)\end{array}$ & $\begin{array}{l}3.244 \\
(2.39)\end{array}$ & $\begin{array}{l}2.491 \\
(1.88)\end{array}$ & $\begin{array}{l}2.471 \\
(1.98)\end{array}$ & $\begin{array}{l}2.768 \\
(2.23)\end{array}$ & $\begin{array}{l}2.814 \\
(2.30)\end{array}$ & $\begin{array}{l}2.626 \\
(2.26)\end{array}$ & $\begin{array}{l}2.598 \\
(2.33)\end{array}$ & $\begin{array}{l}2.250 \\
(2.19)\end{array}$ & $\begin{array}{l}2.786 \\
(2.79)\end{array}$ \\
\hline \multirow[t]{2}{*}{$\beta_{T C_{p}, c}$} & $\begin{array}{l}1.488 \\
(2.54)\end{array}$ & $\begin{array}{l}0.700 \\
(2.85)\end{array}$ & $\begin{array}{l}0.505 \\
(2.89)\end{array}$ & $\begin{array}{l}0.531 \\
(3.32)\end{array}$ & $\begin{array}{l}0.368 \\
(2.72)\end{array}$ & $\begin{array}{l}0.233 \\
(2.01)\end{array}$ & $\begin{array}{l}0.297 \\
(2.90)\end{array}$ & $\begin{array}{l}0.283 \\
(2.99)\end{array}$ & $\begin{array}{l}0.206 \\
(2.35)\end{array}$ & $\begin{array}{l}0.220 \\
(2.46)\end{array}$ \\
\hline & $\begin{array}{l}0.197 \\
(2.35)\end{array}$ & $\begin{array}{l}0.177 \\
(2.23)\end{array}$ & $\begin{array}{l}0.152 \\
(1.76)\end{array}$ & $\begin{array}{l}0.178 \\
(2.28)\end{array}$ & $\begin{array}{l}0.142 \\
(1.76)\end{array}$ & $\begin{array}{c}0.165 \\
(2.10)\end{array}$ & $\begin{array}{c}0.161 \\
(2.04)\end{array}$ & $\begin{array}{c}0.140 \\
(1.73)\end{array}$ & $\begin{array}{l}0.122 \\
(1.55)\end{array}$ & $\begin{array}{l}0.126 \\
(1.59)\end{array}$ \\
\hline \multicolumn{11}{|c|}{$B / M$-sorted portfolios } \\
\hline \multirow{4}{*}{$\beta_{R_{p}, c}$} & B/M1 & $\mathrm{B} / \mathrm{M} 2$ & B/M3 & B/M4 & B/M5 & $\mathrm{B} / \mathrm{M} 6$ & $\mathrm{~B} / \mathrm{M} 7$ & B/M8 & B/M9 & B/M10 \\
\hline & B/M11 & B/M12 & B/M13 & B/M14 & B/M15 & B/M16 & $\mathrm{B} / \mathrm{M} 17$ & B/M18 & B/M19 & $\mathrm{B} / \mathrm{M} 20$ \\
\hline & $\begin{array}{l}4.276 \\
(2.79)\end{array}$ & $\begin{array}{l}3.397 \\
(2.43)\end{array}$ & $\begin{array}{l}3.659 \\
(2.68)\end{array}$ & $\begin{array}{l}3.609 \\
(2.65)\end{array}$ & $\begin{array}{l}3.448 \\
(2.62)\end{array}$ & $\begin{array}{c}3.431 \\
(2.60)\end{array}$ & $\begin{array}{l}3.698 \\
(2.78)\end{array}$ & $\begin{array}{l}3.060 \\
(2.41)\end{array}$ & $\begin{array}{l}3.075 \\
(2.36)\end{array}$ & $\begin{array}{l}2.744 \\
(2.06)\end{array}$ \\
\hline & $\begin{array}{l}2.795 \\
(2.13)\end{array}$ & $\begin{array}{l}3.079 \\
(2.29)\end{array}$ & $\begin{array}{l}3.597 \\
(2.74)\end{array}$ & $\begin{array}{l}2.957 \\
(2.18)\end{array}$ & $\begin{array}{l}2.334 \\
(1.66)\end{array}$ & $\begin{array}{l}3.018 \\
(2.10)\end{array}$ & $\begin{array}{l}3.094 \\
(2.02)\end{array}$ & $\begin{array}{l}2.571 \\
(1.54)\end{array}$ & $\begin{array}{l}2.958 \\
(1.59)\end{array}$ & $\begin{array}{l}3.478 \\
(1.41)\end{array}$ \\
\hline \multirow[t]{2}{*}{$\beta_{T C_{p}, c}$} & $\begin{array}{l}0.283 \\
(2.52)\end{array}$ & $\begin{array}{l}0.322 \\
(3.19)\end{array}$ & $\begin{array}{l}0.186 \\
(2.01)\end{array}$ & $\begin{array}{l}0.143 \\
(1.46)\end{array}$ & $\begin{array}{l}0.159 \\
(1.40)\end{array}$ & $\begin{array}{l}0.254 \\
(2.61)\end{array}$ & $\begin{array}{l}0.303 \\
(2.81)\end{array}$ & $\begin{array}{l}0.199 \\
(2.02)\end{array}$ & $\begin{array}{l}0.191 \\
(1.86)\end{array}$ & $\begin{array}{l}0.315 \\
(2.89)\end{array}$ \\
\hline & $\begin{array}{l}0.222 \\
(2.20)\end{array}$ & $\begin{array}{l}0.219 \\
(1.85)\end{array}$ & $\begin{array}{l}0.342 \\
(3.13)\end{array}$ & $\begin{array}{l}0.352 \\
(3.04)\end{array}$ & $\begin{array}{l}0.338 \\
(3.03)\end{array}$ & $\begin{array}{l}0.347 \\
(2.53)\end{array}$ & $\begin{array}{c}0.462 \\
(3.32)\end{array}$ & $\begin{array}{l}0.449 \\
(2.66)\end{array}$ & $\begin{array}{l}0.643 \\
(3.22)\end{array}$ & $\begin{array}{l}0.847 \\
(3.11)\end{array}$ \\
\hline \multicolumn{11}{|c|}{$4 \times 5 M V \& B / M$ portfolios } \\
\hline \multirow{4}{*}{$\beta_{R_{p}, c}$} & S1B1 & S1B2 & S1B3 & S1B4 & S1B5 & S2B1 & $\mathrm{S} 2 \mathrm{~B} 2$ & S2B3 & S2B4 & S2B5 \\
\hline & S3B1 & S3B2 & S3B3 & S3B4 & S3B5 & S4B1 & $\mathrm{S} 4 \mathrm{~B} 2$ & S4B3 & $\mathrm{S} 4 \mathrm{~B} 4$ & S4B5 \\
\hline & $\begin{array}{l}5.317 \\
(2.78)\end{array}$ & $\begin{array}{l}4.314 \\
(2.68)\end{array}$ & $\begin{array}{l}3.556 \\
(2.25)\end{array}$ & $\begin{array}{l}3.998 \\
(2.53)\end{array}$ & $\begin{array}{l}3.433 \\
(1.70)\end{array}$ & $\begin{array}{l}3.342 \\
(2.15)\end{array}$ & $\begin{array}{l}3.750 \\
(2.68)\end{array}$ & $\begin{array}{l}3.134 \\
(2.35)\end{array}$ & $\begin{array}{l}2.410 \\
(1.79)\end{array}$ & $\begin{array}{l}2.511 \\
(1.43)\end{array}$ \\
\hline & $\begin{array}{l}3.079 \\
(2.25)\end{array}$ & $\begin{array}{l}2.513 \\
(2.09)\end{array}$ & $\begin{array}{l}2.392 \\
(1.96)\end{array}$ & $\begin{array}{l}2.237 \\
(1.87)\end{array}$ & $\begin{array}{l}3.154 \\
(2.14)\end{array}$ & $\begin{array}{l}2.790 \\
(2.43)\end{array}$ & $\begin{array}{l}2.604 \\
(2.45)\end{array}$ & $\begin{array}{l}1.907 \\
(1.80)\end{array}$ & $\begin{array}{l}1.934 \\
(1.78)\end{array}$ & $\begin{array}{l}2.992 \\
(2.29)\end{array}$ \\
\hline \multirow[t]{2}{*}{$\beta_{T C_{p}, c}$} & $\begin{array}{l}0.555 \\
(3.24)\end{array}$ & $\begin{array}{l}0.406 \\
(2.56)\end{array}$ & $\begin{array}{l}0.361 \\
(2.46)\end{array}$ & $\begin{array}{l}0.512 \\
(3.64)\end{array}$ & $\begin{array}{l}0.676 \\
(3.50)\end{array}$ & $\begin{array}{l}0.220 \\
(2.49)\end{array}$ & $\begin{array}{l}0.240 \\
(2.88)\end{array}$ & $\begin{array}{l}0.220 \\
(2.79)\end{array}$ & $\begin{array}{l}0.241 \\
(2.90)\end{array}$ & $\begin{array}{l}0.317 \\
(3.19)\end{array}$ \\
\hline & $\begin{array}{l}0.157 \\
(1.97) \\
\end{array}$ & $\begin{array}{l}0.157 \\
(2.01) \\
\end{array}$ & $\begin{array}{l}0.161 \\
(2.02) \\
\end{array}$ & $\begin{array}{l}0.154 \\
(1.88) \\
\end{array}$ & $\begin{array}{l}0.295 \\
(3.24) \\
\end{array}$ & $\begin{array}{l}0.118 \\
(1.52) \\
\end{array}$ & $\begin{array}{l}0.136 \\
(1.71) \\
\end{array}$ & $\begin{array}{l}0.129 \\
(1.58) \\
\end{array}$ & $\begin{array}{l}0.179 \\
(2.27) \\
\end{array}$ & $\begin{array}{l}0.231 \\
(2.58) \\
\end{array}$ \\
\hline \multicolumn{11}{|c|}{$D V$-sorted portfolios } \\
\hline \multirow{4}{*}{$\beta_{R_{p}, c}$} & DV1 & DV2 & DV3 & DV4 & DV5 & DV6 & DV7 & DV8 & DV9 & DV10 \\
\hline & DV11 & DV12 & DV13 & DV14 & DV15 & DV16 & DV17 & DV18 & DV19 & DV20 \\
\hline & $\begin{array}{l}4.093 \\
(3.39)\end{array}$ & $\begin{array}{l}3.102 \\
(2.53)\end{array}$ & $\begin{array}{l}2.762 \\
(2.32)\end{array}$ & $\begin{array}{l}2.647 \\
(2.05)\end{array}$ & $\begin{array}{l}2.618 \\
(2.03)\end{array}$ & $\begin{array}{l}2.500 \\
(1.89)\end{array}$ & $\begin{array}{l}2.996 \\
(2.26)\end{array}$ & $\begin{array}{c}2.588 \\
(1.88)\end{array}$ & $\begin{array}{c}2.738 \\
(1.99)\end{array}$ & $\begin{array}{l}2.727 \\
(2.01)\end{array}$ \\
\hline & $\begin{array}{l}2.775 \\
(1.95)\end{array}$ & $\begin{array}{l}2.580 \\
(1.79)\end{array}$ & $\begin{array}{l}3.002 \\
(2.05)\end{array}$ & $\begin{array}{l}2.353 \\
(1.52)\end{array}$ & $\begin{array}{l}2.773 \\
(1.90)\end{array}$ & $\begin{array}{l}3.284 \\
(2.03)\end{array}$ & $\begin{array}{l}3.311 \\
(2.12)\end{array}$ & $\begin{array}{l}3.624 \\
(2.24)\end{array}$ & $\begin{array}{l}3.731 \\
(2.31)\end{array}$ & $\begin{array}{l}4.176 \\
(2.35)\end{array}$ \\
\hline \multirow[t]{2}{*}{$\beta_{T C_{p}, c}$} & $\begin{array}{l}0.146 \\
(1.74)\end{array}$ & $\begin{array}{l}0.155 \\
(1.80)\end{array}$ & $\begin{array}{l}0.137 \\
(1.61)\end{array}$ & $\begin{array}{l}0.181 \\
(2.25)\end{array}$ & $\begin{array}{l}0.150 \\
(1.84)\end{array}$ & $\begin{array}{l}0.188 \\
(2.34)\end{array}$ & $\begin{array}{l}0.155 \\
(1.91)\end{array}$ & $\begin{array}{c}0.159 \\
(1.90)\end{array}$ & $\begin{array}{c}0.136 \\
(1.62)\end{array}$ & $\begin{array}{l}0.223 \\
(2.65)\end{array}$ \\
\hline & $\begin{array}{l}0.222 \\
(2.45)\end{array}$ & $\begin{array}{l}0.270 \\
(3.11)\end{array}$ & $\begin{array}{l}0.248 \\
(2.69)\end{array}$ & $\begin{array}{l}0.225 \\
(2.51)\end{array}$ & $\begin{array}{l}0.313 \\
(3.28)\end{array}$ & $\begin{array}{l}0.385 \\
(3.80)\end{array}$ & $\begin{array}{l}0.355 \\
(3.39)\end{array}$ & $\begin{array}{l}0.400 \\
(3.51)\end{array}$ & $\begin{array}{l}0.434 \\
(3.45)\end{array}$ & $\begin{array}{l}0.828 \\
(3.37)\end{array}$ \\
\hline
\end{tabular}




\section{Table 2}

\section{Continued}

\begin{tabular}{|c|c|c|c|c|c|c|c|c|c|c|}
\hline \multicolumn{11}{|c|}{$R V$-sorted portfolios } \\
\hline & RV1 & RV2 & RV3 & RV4 & RV5 & RV6 & RV7 & RV8 & RV9 & RV10 \\
\hline \multirow{3}{*}{$\beta_{R_{p}, c}$} & RV11 & RV12 & RV13 & RV14 & RV15 & RV16 & RV17 & RV18 & RV19 & RV20 \\
\hline & $\begin{array}{l}3.248 \\
(3.11)\end{array}$ & $\begin{array}{l}2.865 \\
(2.64)\end{array}$ & $\begin{array}{l}2.446 \\
(2.14)\end{array}$ & $\begin{array}{l}3.036 \\
(2.62)\end{array}$ & $\begin{array}{c}2.616 \\
(2.11)\end{array}$ & $\begin{array}{c}2.332 \\
(1.87)\end{array}$ & $\begin{array}{l}2.995 \\
(2.33)\end{array}$ & $\begin{array}{c}2.489 \\
(1.92)\end{array}$ & $\begin{array}{l}2.204 \\
(1.65)\end{array}$ & $\begin{array}{l}2.885 \\
(2.17)\end{array}$ \\
\hline & $\begin{array}{l}2.670 \\
(1.93)\end{array}$ & $\begin{array}{l}3.089 \\
(2.14)\end{array}$ & $\begin{array}{c}2.729 \\
(1.91)\end{array}$ & $\begin{array}{l}3.237 \\
(2.23)\end{array}$ & $\begin{array}{l}3.149 \\
(2.11)\end{array}$ & $\begin{array}{l}3.340 \\
(2.15)\end{array}$ & $\begin{array}{l}2.555 \\
(1.60)\end{array}$ & $\begin{array}{c}2.891 \\
(1.73)\end{array}$ & $\begin{array}{c}3.611 \\
(2.17)\end{array}$ & $\begin{array}{l}4.362 \\
(2.19)\end{array}$ \\
\hline \multirow[t]{2}{*}{$\beta_{T C_{p}, c}$} & $\begin{array}{c}0.098 \\
(1.14)\end{array}$ & $\begin{array}{c}0.129 \\
(1.61)\end{array}$ & $\begin{array}{c}0.148 \\
(1.86)\end{array}$ & $\begin{array}{c}0.131 \\
(1.59)\end{array}$ & $\begin{array}{c}0.156 \\
(1.89)\end{array}$ & $\begin{array}{c}0.178 \\
(2.22)\end{array}$ & $\begin{array}{l}0.149 \\
(1.88)\end{array}$ & $\begin{array}{c}0.171 \\
(2.09)\end{array}$ & $\begin{array}{c}0.168 \\
(2.15)\end{array}$ & $\begin{array}{c}0.182 \\
(2.29)\end{array}$ \\
\hline & $\begin{array}{l}0.227 \\
(2.54)\end{array}$ & $\begin{array}{l}0.219 \\
(2.61)\end{array}$ & $\begin{array}{l}0.265 \\
(3.10)\end{array}$ & $\begin{array}{l}0.272 \\
(3.09)\end{array}$ & $\begin{array}{l}0.314 \\
(3.40)\end{array}$ & $\begin{array}{c}0.279 \\
(3.07)\end{array}$ & $\begin{array}{c}0.360 \\
(3.66)\end{array}$ & $\begin{array}{c}0.346 \\
(3.20)\end{array}$ & $\begin{array}{c}0.476 \\
(3.84)\end{array}$ & $\begin{array}{l}1.034 \\
(3.65)\end{array}$ \\
\hline \multicolumn{11}{|c|}{$L M$-sorted portfolios } \\
\hline \multirow{4}{*}{$\beta_{R_{p}, c}$} & LM1 & LM2 & LM3 & LM4 & LM5 & LM6 & LM7 & LM8 & LM9 & LM10 \\
\hline & LM11 & LM12 & LM13 & LM14 & LM15 & LM16 & LM17 & LM18 & LM19 & LM20 \\
\hline & $\begin{array}{l}4.169 \\
(2.12)\end{array}$ & $\begin{array}{l}4.002 \\
(2.19)\end{array}$ & $\begin{array}{l}4.036 \\
(2.41)\end{array}$ & $\begin{array}{l}3.231 \\
(1.97)\end{array}$ & $\begin{array}{c}3.260 \\
(2.11)\end{array}$ & $\begin{array}{l}3.175 \\
(2.17)\end{array}$ & $\begin{array}{l}2.506 \\
(1.80)\end{array}$ & $\begin{array}{l}2.553 \\
(1.95)\end{array}$ & $\begin{array}{l}2.313 \\
(1.85)\end{array}$ & $\begin{array}{l}2.507 \\
(2.08)\end{array}$ \\
\hline & $\begin{array}{l}2.321 \\
(1.91)\end{array}$ & $\begin{array}{l}2.210 \\
(1.80)\end{array}$ & $\begin{array}{c}3.066 \\
(2.41)\end{array}$ & $\begin{array}{l}2.370 \\
(1.84)\end{array}$ & $\begin{array}{l}2.682 \\
(2.05)\end{array}$ & $\begin{array}{l}3.063 \\
(2.17)\end{array}$ & $\begin{array}{l}3.764 \\
(2.57)\end{array}$ & $\begin{array}{l}3.141 \\
(2.04)\end{array}$ & $\begin{array}{l}3.796 \\
(2.38)\end{array}$ & $\begin{array}{l}3.961 \\
(2.59)\end{array}$ \\
\hline \multirow[t]{2}{*}{$\beta_{T C_{p}, c}$} & $\begin{array}{l}0.221 \\
(2.01)\end{array}$ & $\begin{array}{c}0.260 \\
(2.41)\end{array}$ & $\begin{array}{l}0.224 \\
(2.05)\end{array}$ & $\begin{array}{l}0.222 \\
(2.31)\end{array}$ & $\begin{array}{l}0.187 \\
(1.98)\end{array}$ & $\begin{array}{c}0.170 \\
(1.60)\end{array}$ & $\begin{array}{l}0.221 \\
(2.24)\end{array}$ & $\begin{array}{c}0.180 \\
(1.97)\end{array}$ & $\begin{array}{l}0.243 \\
(2.56)\end{array}$ & $\begin{array}{l}0.227 \\
(2.39)\end{array}$ \\
\hline & $\begin{array}{l}0.136 \\
(1.35)\end{array}$ & $\begin{array}{l}0.262 \\
(2.62)\end{array}$ & $\begin{array}{l}0.228 \\
(2.30)\end{array}$ & $\begin{array}{l}0.247 \\
(2.38)\end{array}$ & $\begin{array}{l}0.118 \\
(1.12)\end{array}$ & $\begin{array}{l}0.299 \\
(2.50)\end{array}$ & $\begin{array}{l}0.321 \\
(2.71)\end{array}$ & $\begin{array}{c}0.448 \\
(3.60)\end{array}$ & $\begin{array}{l}0.353 \\
(2.35)\end{array}$ & $\begin{array}{l}0.720 \\
(3.19)\end{array}$ \\
\hline \multicolumn{11}{|c|}{$c G i b b s$-sorted portfolios } \\
\hline \multirow{4}{*}{$\beta_{R_{p}, c}$} & cGibbs1 & cGibbs2 & cGibbs3 & cGibbs4 & cGibbs5 & cGibbs6 & cGibbs7 & cGibbs8 & cGibbs9 & cGibbs10 \\
\hline & cGibbs11 & cGibbs12 & cGibbs13 & cGibbs14 & cGibbs15 & cGibbs16 & cGibbs17 & cGibbs18 & cGibbs19 & cGibbs20 \\
\hline & $\begin{array}{l}2.619 \\
(2.66)\end{array}$ & $\begin{array}{l}2.987 \\
(2.71)\end{array}$ & $\begin{array}{c}2.902 \\
(2.59)\end{array}$ & $\begin{array}{l}2.803 \\
(2.38)\end{array}$ & $\begin{array}{c}2.576 \\
(2.13)\end{array}$ & $\begin{array}{l}2.989 \\
(2.36)\end{array}$ & $\begin{array}{c}2.889 \\
(2.28)\end{array}$ & $\begin{array}{l}2.950 \\
(2.32)\end{array}$ & $\begin{array}{l}2.924 \\
(2.23)\end{array}$ & $\begin{array}{l}2.790 \\
(2.08)\end{array}$ \\
\hline & $\begin{array}{l}2.702 \\
(2.03)\end{array}$ & $\begin{array}{l}2.875 \\
(2.13)\end{array}$ & $\begin{array}{l}3.100 \\
(2.23)\end{array}$ & $\begin{array}{l}3.421 \\
(2.45)\end{array}$ & $\begin{array}{l}2.535 \\
(1.80)\end{array}$ & $\begin{array}{c}2.812 \\
(1.89)\end{array}$ & $\begin{array}{l}3.209 \\
(2.05)\end{array}$ & $\begin{array}{c}3.379 \\
(2.05)\end{array}$ & $\begin{array}{c}3.703 \\
(2.04)\end{array}$ & $\begin{array}{l}4.547 \\
(1.90)\end{array}$ \\
\hline \multirow[t]{2}{*}{$\beta_{T C_{p}, c}$} & $\begin{array}{c}0.114 \\
(1.53)\end{array}$ & $\begin{array}{c}0.142 \\
(1.83)\end{array}$ & $\begin{array}{c}0.143 \\
(1.80)\end{array}$ & $\begin{array}{c}0.173 \\
(2.08)\end{array}$ & $\begin{array}{c}0.141 \\
(1.83)\end{array}$ & $\begin{array}{c}0.166 \\
(1.92)\end{array}$ & $\begin{array}{c}0.169 \\
(1.98)\end{array}$ & $\begin{array}{c}0.212 \\
(2.53)\end{array}$ & $\begin{array}{c}0.234 \\
(2.79)\end{array}$ & $\begin{array}{l}0.207 \\
(2.44)\end{array}$ \\
\hline & $\begin{array}{c}0.230 \\
(2.69)\end{array}$ & $\begin{array}{c}0.236 \\
(2.80)\end{array}$ & $\begin{array}{c}0.233 \\
(2.58)\end{array}$ & $\begin{array}{c}0.262 \\
(2.91)\end{array}$ & $\begin{array}{l}0.315 \\
(3.53)\end{array}$ & $\begin{array}{l}0.276 \\
(3.00)\end{array}$ & $\begin{array}{c}0.339 \\
(3.52)\end{array}$ & $\begin{array}{l}0.438 \\
(4.17)\end{array}$ & $\begin{array}{c}0.636 \\
(4.69)\end{array}$ & $\begin{array}{l}1.194 \\
(3.77)\end{array}$ \\
\hline \multicolumn{11}{|c|}{ CSspread-sorted portfolios } \\
\hline \multirow{4}{*}{$\beta_{R_{p}, c}$} & CSspread1 & CSspread2 & CSspread3 & CSspread4 & CSspread5 & CSspread6 & CSspread7 & CSspread8 & CSspread9 & CSspread10 \\
\hline & CSspread11 & CSspread12 & CSspread13 & CSspread14 & CSspread15 & CSspread16 & CSspread17 & CSspread18 & CSspread19 & CSspread20 \\
\hline & $\begin{array}{l}2.550 \\
(2.45)\end{array}$ & $\begin{array}{c}2.115 \\
(1.90)\end{array}$ & $\begin{array}{c}2.332 \\
(2.06)\end{array}$ & $\begin{array}{c}2.444 \\
(2.16)\end{array}$ & $\begin{array}{c}2.802 \\
(2.40)\end{array}$ & $\begin{array}{l}3.045 \\
(2.55)\end{array}$ & $\begin{array}{c}2.801 \\
(2.26)\end{array}$ & $\begin{array}{l}3.495 \\
(2.73)\end{array}$ & $\begin{array}{l}3.309 \\
(2.54)\end{array}$ & $\begin{array}{l}3.259 \\
(2.41)\end{array}$ \\
\hline & $\begin{array}{l}3.192 \\
(2.28)\end{array}$ & $\begin{array}{l}3.788 \\
(2.59)\end{array}$ & $\begin{array}{l}3.960 \\
(2.52)\end{array}$ & $\begin{array}{c}3.833 \\
(2.36)\end{array}$ & $\begin{array}{c}3.765 \\
(2.21)\end{array}$ & $\begin{array}{c}3.913 \\
(2.19)\end{array}$ & $\begin{array}{l}4.018 \\
(2.08)\end{array}$ & $\begin{array}{c}3.934 \\
(1.96)\end{array}$ & $\begin{array}{c}3.600 \\
(1.46)\end{array}$ & $\begin{array}{l}5.219 \\
(1.82)\end{array}$ \\
\hline \multirow[t]{2}{*}{$\beta_{T C_{p}, c}$} & $\begin{array}{c}0.082 \\
(1.30)\end{array}$ & $\begin{array}{c}0.118 \\
(1.68)\end{array}$ & $\begin{array}{c}0.118 \\
(1.57)\end{array}$ & $\begin{array}{c}0.148 \\
(1.96)\end{array}$ & $\begin{array}{l}0.160 \\
(2.13)\end{array}$ & $\begin{array}{c}0.145 \\
(1.86)\end{array}$ & $\begin{array}{c}0.174 \\
(2.19)\end{array}$ & $\begin{array}{l}0.188 \\
(2.30)\end{array}$ & $\begin{array}{l}0.187 \\
(2.31)\end{array}$ & $\begin{array}{c}0.201 \\
(2.43)\end{array}$ \\
\hline & $\begin{array}{c}0.232 \\
(2.76)\end{array}$ & $\begin{array}{l}0.236 \\
(2.60)\end{array}$ & $\begin{array}{l}0.313 \\
(3.47)\end{array}$ & $\begin{array}{l}0.303 \\
(3.32)\end{array}$ & $\begin{array}{l}0.344 \\
(3.37)\end{array}$ & $\begin{array}{c}0.368 \\
(3.04)\end{array}$ & $\begin{array}{l}0.569 \\
(4.02)\end{array}$ & $\begin{array}{c}0.708 \\
(3.72)\end{array}$ & $\begin{array}{c}0.851 \\
(3.33)\end{array}$ & $\begin{array}{l}1.606 \\
(2.51)\end{array}$ \\
\hline
\end{tabular}

This table reports the consumption beta and liquidity beta estimates. Consumption beta is estimated through a time-series regression of returns in excess of the risk-free rate on consumption growth for each portfolio. Liquidity beta is estimated through a time-series regression of liquidity innovations on consumption growth for each portfolio. Test assets are: the 20 $M V$-sorted portfolios, $20 \mathrm{~B} / M$-sorted portfolios, $4 \times 5 M V \& B / M$-sorted portfolios, $20 D V$-sorted portfolios, $20 R V$-sorted

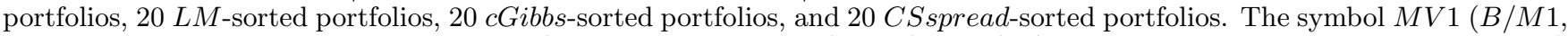
$D V 1, R V 1, L M 1, c G i b b s 1$, and $C S$ spread1) denotes the smallest (lowest) $M V(B / M, D V, R V, L M, c G i b b s$, and $C S s p r e a d)$ vigintiles portfolio and $M V 20$ (B/M20, DV20, RV20, LM20, cGibbs20, and CSspread20) denotes the biggest (highest) $M V$ $(B / M, D V, R V, L M, c G i b b s$, and $C S$ spread) portfolio. For the $4 \times 5 M V \& B / M$-sorted portfolios, the digit after $S$ denotes the size quintile ( 1 representing the smallest and 4 the largest), and the digit after $B$ denotes the book-to-market quartile (1 representing the lowest and 5 the highest). Transaction costs are proxied by the effective costs estimates (cGibbs) of Hasbrouck (2009) in Panel A and the bid-ask spread estimate (CSspread) of Corwin and Schultz (2012) in Panel B. 


\section{Table 3}

Regressions on the transaction costs, consumption beta, and liquidity beta

Panel A: cGibbs as a measure of transaction costs

\begin{tabular}{cccc}
\hline $20 M V$-sorted portfolios & $\hat{\gamma}_{1}=0.546(2.15) \quad \hat{\gamma}_{2}=-0.030 \%(-0.17)$, & $\hat{\gamma}_{3}=3.837 \%(1.72)$ \\
\hline $20 B M$-sorted portfolios & $\hat{\gamma}_{1}=0.244(0.86) \quad \hat{\gamma}_{2}=-0.529 \%(-2.99)$, & $\hat{\gamma}_{3}=5.221 \%(2.07)$ \\
\hline $4 \times 5 M V \& B / M$-sorted portfolios $\quad \hat{\gamma}_{1}=0.116(0.43) \quad \hat{\gamma}_{2}=-0.383 \%(-2.37), \quad \hat{\gamma}_{3}=8.763 \%(2.09)$ \\
\hline $20 D V$-sorted portfolios $\quad \hat{\gamma}_{1}=0.587(1.90) \quad \hat{\gamma}_{2}=-0.234 \%(-2.12), \quad \hat{\gamma}_{3}=6.746 \%(3.18)$ \\
\hline $20 R V$-sorted portfolios $\quad \hat{\gamma}_{1}=0.695(1.93) \quad \hat{\gamma}_{2}=-0.193 \%(-2.01), \quad \hat{\gamma}_{3}=5.405 \%(2.12)$ \\
\hline $20 L M$-sorted portfolios $\quad \hat{\gamma}_{1}=0.400(1.55) \quad \hat{\gamma}_{2}=-0.437 \%(-2.90), \quad \hat{\gamma}_{3}=6.089 \%(3.81)$ \\
\hline $20 c G$ ibbs-sorted portfolios $\quad \hat{\gamma}_{1}=0.181(0.79) \quad \hat{\gamma}_{2}=-0.159 \%(-1.03), \quad \hat{\gamma}_{3}=4.992 \%(2.11)$ \\
\hline $20 C S$ spread-sorted portfolios $\quad \hat{\gamma}_{1}=-0.110(-0.50) \quad \hat{\gamma}_{2}=0.121 \%(0.69), \quad \hat{\gamma}_{3}=0.085 \%(0.04)$ \\
\hline
\end{tabular}

Panel B: CSspread as a measure of transaction costs

\begin{tabular}{cccc}
\hline $20 M V$-sorted portfolios & $\hat{\gamma}_{1}=0.054(0.33) \quad \hat{\gamma}_{2}=-0.022 \%(-0.12), \quad \hat{\gamma}_{3}=1.787 \%(2.49)$ \\
\hline $20 B M$-sorted portfolios & $\hat{\gamma}_{1}=-0.038(-0.23) \quad \hat{\gamma}_{2}=-0.512 \%(-1.99)$, & $\hat{\gamma}_{3}=2.706 \%(2.30)$ \\
\hline $4 \times 5 M V \& B / M$-sorted portfolios $\quad \hat{\gamma}_{1}=-0.306(-1.24) \quad \hat{\gamma}_{2}=-0.373 \%(-1.88), \quad \hat{\gamma}_{3}=2.969 \%(2.09)$ \\
\hline $20 D V$-sorted portfolios $\quad \hat{\gamma}_{1}=-0.002(-0.01) \quad \hat{\gamma}_{2}=-0.356 \%(-2.42), \quad \hat{\gamma}_{3}=3.077 \%(2.84)$ \\
\hline $20 R V$-sorted portfolios $\quad \hat{\gamma}_{1}=-0.519(-2.18) \quad \hat{\gamma}_{2}=-0.201 \%(-1.87), \quad \hat{\gamma}_{3}=2.016 \%(2.30)$ \\
\hline $20 L M$-sorted portfolios $\quad \hat{\gamma}_{1}=0.053(0.34) \quad \hat{\gamma}_{2}=-0.283 \%(-1.73), \quad \hat{\gamma}_{3}=2.771 \%(3.85)$ \\
\hline $20 c G$ ibbs-sorted portfolios $\quad \hat{\gamma}_{1}=-0.039(-0.22) \quad \hat{\gamma}_{2}=-0.172 \%(-1.20), \quad \hat{\gamma}_{3}=1.851 \%(2.16)$ \\
\hline $20 C S$ spread-sorted portfolios $\quad \hat{\gamma}_{1}=-0.036(-0.21) \quad \hat{\gamma}_{2}=0.193 \%(1.27), \quad \hat{\gamma}_{3}=0.018 \%(0.02)$ \\
\hline
\end{tabular}

This table reports the coefficients from regressing the portfolio returns on the transaction costs, consumption beta, and liquidity beta. Test portfolios are the $20 M V$-sorted, $20 \mathrm{~B} / \mathrm{M}$-sorted, $4 \times 5 \mathrm{MV} \& \mathrm{~B} / \mathrm{M}$-sorted, $20 \mathrm{DV}$-sorted, 20

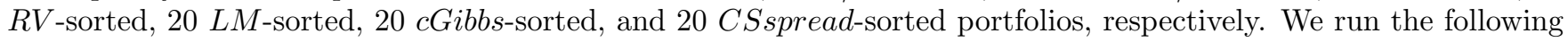
Fama-MacBeth (1973) cross-sectional regression:

$$
R_{p, t}-R_{f, t}=\gamma_{0}+\gamma_{1} t c_{p, t}^{\star}+\gamma_{2} \beta_{R_{p}, c}+\gamma_{3} \beta_{T C_{p}, c}+\epsilon_{p, t}
$$

where $R_{p, t}-R_{f, t}$ is the quarterly return of portfolio $p$ in excess of the risk-free rate, $t c_{p, t}^{\star}$ is the transaction costs of portfolio $p$ orthogonalized to liquidity beta (i.e., $t c_{p, t}^{\star}$ is the residual from regressing transaction costs against liquidity betas), $\beta_{R_{p}, c}$ is the consumption beta, and $\beta_{T C_{p}, c}$ is the liquidity beta. Transaction costs are proxied by the effective costs estimates (cGibbs) of Hasbrouck (2009) in Panel A and the bid-ask spread estimate (CSspread) of Corwin and Schultz (2012) in Panel B. Numbers in parentheses are $t$ statistics. 


\section{Table 4}

Robustness tests on adjusted $R^{2}$

\begin{tabular}{|c|c|c|c|c|c|}
\hline \multicolumn{2}{|c|}{$c G i b b s$ as a measure of transaction costs } & \multicolumn{2}{|c|}{ CSspread as a measure of transaction costs } & \multicolumn{2}{|c|}{$c R V$ as a measure of transaction costs } \\
\hline Tra & Liquid & & Liqui & $\operatorname{Tra}$ & ed \\
\hline CCAPM & CCAPM & CCAPM & CCAPM & CCAPM & CCAPM \\
\hline
\end{tabular}

Panel A: Plus 10 industry portfolios

\begin{tabular}{|c|c|c|c|c|c|c|}
\hline $20 M V$-sorted portfolios & $R^{2}=30.19 \%$ & $R^{2}=55.69 \%$ & $R^{2}=25.89 \%$ & $R^{2}=61.73 \%$ & $R^{2}=25.02 \%$ & $R^{2}=43.64 \%$ \\
\hline $20 B / M$-sorted portfolios & $R^{2}=-3.57 \%$ & $R^{2}=54.54 \%$ & $R^{2}=-3.55 \%$ & $R^{2}=51.35 \%$ & $R^{2}=-3.57 \%$ & $R^{2}=16.39 \%$ \\
\hline $4 \times 5 M V \& B / M$ portfolios & $R^{2}=-0.25 \%$ & $R^{2}=31.75 \%$ & $R^{2}=-0.45 \%$ & $R^{2}=10.89 \%$ & $R^{2}=0.58 \%$ & $R^{2}=5.98 \%$ \\
\hline $20 D V$-sorted portfolios & $R^{2}=13.05 \%$ & $R^{2}=58.75 \%$ & $R^{2}=12.06 \%$ & $R^{2}=47.35 \%$ & $R^{2}=13.18 \%$ & $R^{2}=31.88 \%$ \\
\hline $20 R V$-sorted portfolios & $R^{2}=21.72 \%$ & $R^{2}=52.76 \%$ & $R^{2}=20.09 \%$ & $R^{2}=44.19 \%$ & $R^{2}=22.11 \%$ & $R^{2}=35.66 \%$ \\
\hline $20 L M$-sorted portfolios & $R^{2}=0.14 \%$ & $R^{2}=40.92 \%$ & $R^{2}=0.53 \%$ & $R^{2}=22.27 \%$ & $R^{2}=1.13 \%$ & $R^{2}=18.87 \%$ \\
\hline $20 c G i b b s$-sorted portfolios & $R^{2}=35.00 \%$ & $R^{2}=77.38 \%$ & $R^{2}=33.78 \%$ & $R^{2}=66.33 \%$ & $R^{2}=32.48 \%$ & $R^{2}=50.59 \%$ \\
\hline 20 CSspread-sorted portfolios & $R^{2}=32.28 \%$ & $R^{2}=40.14 \%$ & $R^{2}=31.15 \%$ & $R^{2}=38.43 \%$ & $R^{2}=33.74 \%$ & $R^{2}=36.32 \%$ \\
\hline
\end{tabular}

Panel B: Long-run consumption growth

\begin{tabular}{|c|c|c|c|c|c|c|}
\hline $20 M V$-sorted portfolios & $R^{2}=31.91 \%$ & $R^{2}=85.67 \%$ & $R^{2}=26.60 \%$ & $R^{2}=72.26 \%$ & $R^{2}=35.20 \%$ & $R^{2}=90.31 \%$ \\
\hline $20 B / M$-sorted portfolios & $R^{2}=46.88 \%$ & $R^{2}=71.89 \%$ & $R^{2}=54.43 \%$ & $R^{2}=66.49 \%$ & $R^{2}=55.58 \%$ & $R^{2}=75.93 \%$ \\
\hline $4 \times 5 M V \& B / M$ portfolios & $R^{2}=16.95 \%$ & $R^{2}=12.13 \%$ & $R^{2}=17.98 \%$ & $R^{2}=12.83 \%$ & $R^{2}=17.85 \%$ & $R^{2}=27.00 \%$ \\
\hline $20 D V$-sorted portfolios & $R^{2}=33.90 \%$ & $R^{2}=76.08 \%$ & $R^{2}=33.83 \%$ & $R^{2}=70.36 \%$ & $R^{2}=35.19 \%$ & $R^{2}=53.26 \%$ \\
\hline $20 R V$-sorted portfolios & $R^{2}=31.28 \%$ & $R^{2}=76.98 \%$ & $R^{2}=32.29 \%$ & $R^{2}=79.32 \%$ & $R^{2}=33.73 \%$ & $R^{2}=40.01 \%$ \\
\hline $20 L M$-sorted portfolios & $R^{2}=5.92 \%$ & $R^{2}=41.00 \%$ & $R^{2}=7.36 \%$ & $R^{2}=37.30 \%$ & $R^{2}=7.92 \%$ & $R^{2}=53.67 \%$ \\
\hline $20 c G i b b s$-sorted portfolios & $R^{2}=33.85 \%$ & $R^{2}=91.08 \%$ & $R^{2}=33.72 \%$ & $R^{2}=92.40 \%$ & $R^{2}=34.87 \%$ & $R^{2}=94.43 \%$ \\
\hline 20 CSspread-sorted portfolios & $R^{2}=37.77 \%$ & $R^{2}=41.72 \%$ & $R^{2}=44.92 \%$ & $R^{2}=40.16 \%$ & $R^{2}=53.10 \%$ & $R^{2}=58.30 \%$ \\
\hline
\end{tabular}




\section{Table 4}

Continued

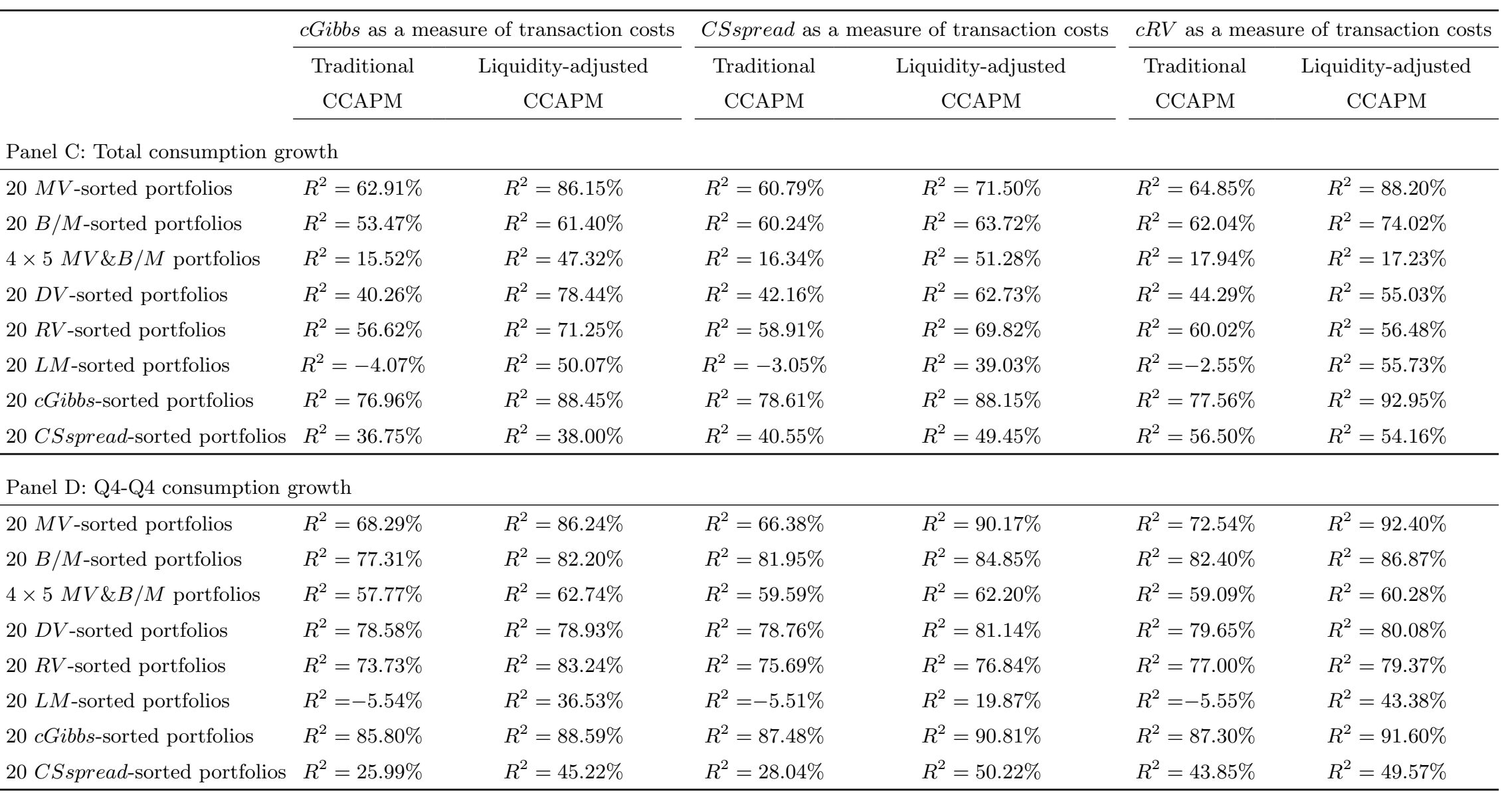




\section{Table 4}

Continued

\begin{tabular}{|c|c|c|c|c|c|}
\hline \multicolumn{2}{|c|}{$c G i b b s$ as a measure of transaction costs } & \multicolumn{2}{|c|}{ CSspread as a measure of transaction costs } & \multicolumn{2}{|c|}{$c R V$ as a measure of transaction costs } \\
\hline Traditional & Liquidity-adjusted & Traditional & Liquidity-adjusted & Traditional & Liquidity-adjusted \\
\hline CCAPM & CCAPM & CCAPM & CCAPM & CCAPM & CCAPM \\
\hline
\end{tabular}

Panel E: Net betas

\begin{tabular}{|c|c|c|c|c|c|c|}
\hline $20 M V$-sorted portfolios & $R^{2}=40.60 \%$ & $R^{2}=67.57 \%$ & $R^{2}=34.66 \%$ & $R^{2}=72.61 \%$ & $R^{2}=35.13 \%$ & $R^{2}=58.33 \%$ \\
\hline $20 B / M$-sorted portfolios & $R^{2}=28.19 \%$ & $R^{2}=88.23 \%$ & $R^{2}=30.09 \%$ & $R^{2}=82.33 \%$ & $R^{2}=28.64 \%$ & $R^{2}=91.04 \%$ \\
\hline $4 \times 5 M V \& B / M$ portfolios & $R^{2}=-5.53 \%$ & $R^{2}=2.81 \%$ & $R^{2}=-5.47 \%$ & $R^{2}=7.13 \%$ & $R^{2}=-5.24 \%$ & $R^{2}=20.82 \%$ \\
\hline $20 D V$-sorted portfolios & $R^{2}=1.98 \%$ & $R^{2}=81.11 \%$ & $R^{2}=1.76 \%$ & $R^{2}=63.27 \%$ & $R^{2}=2.90 \%$ & $R^{2}=54.68 \%$ \\
\hline $20 R V$-sorted portfolios & $R^{2}=15.34 \%$ & $R^{2}=67.29 \%$ & $R^{2}=16.77 \%$ & $R^{2}=51.36 \%$ & $R^{2}=18.27 \%$ & $R^{2}=41.91 \%$ \\
\hline $20 L M$-sorted portfolios & $R^{2}=-3.81 \%$ & $R^{2}=58.07 \%$ & $R^{2}=-4.55 \%$ & $R^{2}=37.73 \%$ & $R^{2}=-4.83 \%$ & $R^{2}=52.12 \%$ \\
\hline $20 c G i b b s$-sorted portfolios & $R^{2}=66.08 \%$ & $R^{2}=87.96 \%$ & $R^{2}=67.57 \%$ & $R^{2}=86.69 \%$ & $R^{2}=65.11 \%$ & $R^{2}=90.49 \%$ \\
\hline 20 CSspread-sorted portfolios & $R^{2}=36.43 \%$ & $R^{2}=31.44 \%$ & $R^{2}=36.08 \%$ & $R^{2}=35.22 \%$ & $R^{2}=40.26 \%$ & $R^{2}=52.38 \%$ \\
\hline \multicolumn{7}{|c|}{ Panel F: Net betas and capped transaction costs } \\
\hline $20 M V$-sorted portfolios & $R^{2}=40.60 \%$ & $R^{2}=68.64 \%$ & $R^{2}=34.66 \%$ & $R^{2}=67.22 \%$ & $R^{2}=35.13 \%$ & $R^{2}=58.33 \%$ \\
\hline $20 B / M$-sorted portfolios & $R^{2}=28.19 \%$ & $R^{2}=88.27 \%$ & $R^{2}=30.09 \%$ & $R^{2}=84.04 \%$ & $R^{2}=28.64 \%$ & $R^{2}=91.04 \%$ \\
\hline $4 \times 5 M V \& B / M$ portfolios & $R^{2}=-5.53 \%$ & $R^{2}=21.94 \%$ & $R^{2}=-5.47 \%$ & $R^{2}=23.61 \%$ & $R^{2}=-5.24 \%$ & $R^{2}=20.82 \%$ \\
\hline $20 D V$-sorted portfolios & $R^{2}=1.98 \%$ & $R^{2}=80.13 \%$ & $R^{2}=1.76 \%$ & $R^{2}=67.72 \%$ & $R^{2}=2.90 \%$ & $R^{2}=54.68 \%$ \\
\hline $20 R V$-sorted portfolios & $R^{2}=15.34 \%$ & $R^{2}=67.66 \%$ & $R^{2}=16.77 \%$ & $R^{2}=55.42 \%$ & $R^{2}=18.27 \%$ & $R^{2}=41.91 \%$ \\
\hline $20 L M$-sorted portfolios & $R^{2}=-3.81 \%$ & $R^{2}=58.30 \%$ & $R^{2}=-4.55 \%$ & $R^{2}=40.70 \%$ & $R^{2}=-4.83 \%$ & $R^{2}=52.12 \%$ \\
\hline $20 c G i b b s$-sorted portfolios & $R^{2}=66.08 \%$ & $R^{2}=88.12 \%$ & $R^{2}=67.57 \%$ & $R^{2}=89.23 \%$ & $R^{2}=65.11 \%$ & $R^{2}=90.49 \%$ \\
\hline 20 CSspread-sorted portfolios & $R^{2}=36.43 \%$ & $R^{2}=31.34 \%$ & $R^{2}=36.08 \%$ & $R^{2}=33.66 \%$ & $R^{2}=40.26 \%$ & $R^{2}=52.38 \%$ \\
\hline
\end{tabular}

This table reports the adjusted R-squares obtained from several robustness tests. We use three transaction costs measures: the first is the effective trading costs measure (cGibbs) of Hasbrouck (2009), the second is the bid-ask spread estimate (CSspread) of Corwin and Schultz (2012), and the third is the adjusted price impact measure $(c R V)$ in the spirit of Acharya and Pedersen (2005). Test assets are the $20 M V$-sorted, $20 B / M$-sorted, $4 \times 5 M V \& B / M$-sorted, $20 D V$-sorted,

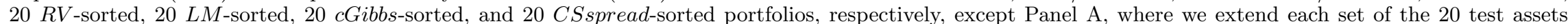
with 10 industry portfolios. The classification of the 10 industries is based on Fama and French (1997). In Panels B, C and D, we take into account the long run consumption growth (Parker and Julliard (2005)), the total consumption growth (Yogo (2006)) and the fourth quarter consumption growth (Jagannathan and Wang (2007)), respectively. Specifically, in Panel B, we measure consumption risk using the 11-quarter consumption growth of nondurable goods and services. In Panel C, we use the total consumption growth. Following Breeden et al. (1989) and Jagannathan and Wang (2007), in Panel D, we construct a mimicking consumption growth factor using the maximum-correlation portfolio (MCP) approach. We run regression of the demeaned fourth-to-fourth quarter consumption growth on annual excess returns of the $2 \times 3$ equally-weighted $M V \& B / M$-sorted portfolios to obtain the MCP weights. We then replace the consumption growth of nondurable goods and services with the MCP estimate. Similar to Acharya and Pedersen (2005), we, in Panel E, calculate the net beta (the combined effect of consumption and liquidity risk) and then regress returns on the net beta. In Panel F, we further cap the transaction costs at a maximum value of $30 \%$ in addition to using the net beta. 


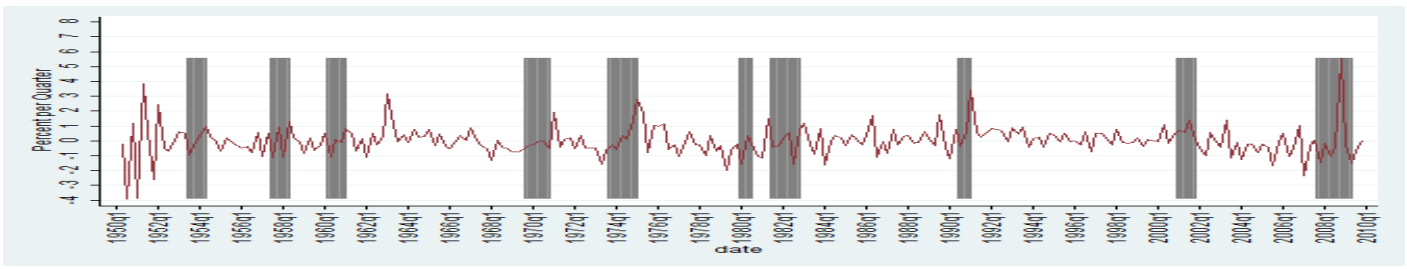

Full sample

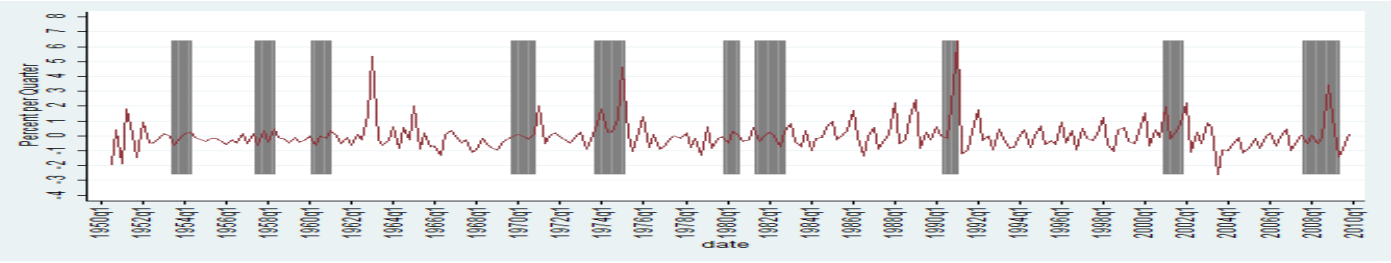

Small stocks

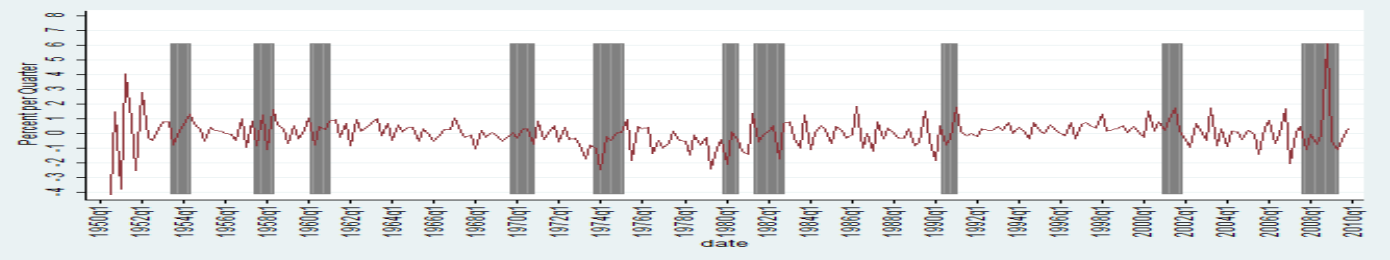

Large stocks

Panel A: cGibbs as a measure of transaction costs

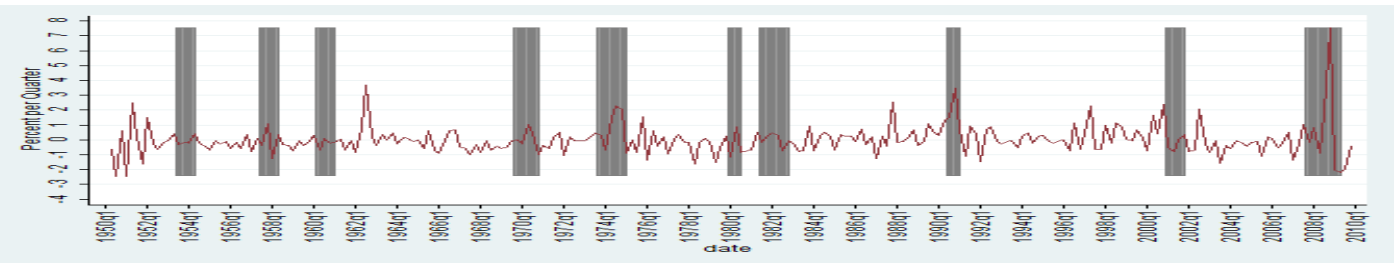

Full sample

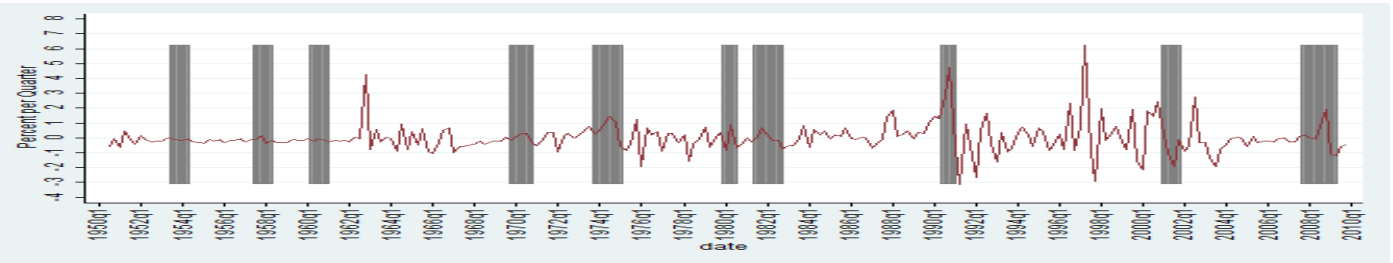

Small stocks

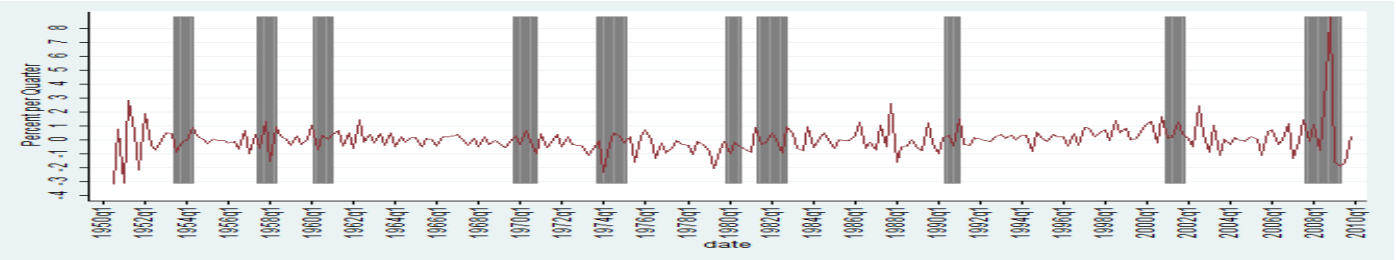

Large stocks

Panel B: CSspread as a measure of transaction costs

Fig. 1. This figure plots the standardized liquidity innovations. The shaded regions are recession periods defined by the National Bureau of Economic Research (NBER). The innovation in market liquidity $\left(u_{m, t}\right)$ is the residual of the following regression:

$$
t c_{m, t}=\alpha_{0}+\alpha_{1} t c_{m, t-1}+u_{m, t}
$$

where $t c_{m, t}$ denotes the average of the transaction costs measures over the sample stocks in quarter $t$. The time series of liquidity innovation are scaled to have zero mean and unit standard deviation. We also plot the standardized liquidity innovations for subsamples classified by market values. Small stocks are those in the smallest of the $20 M V$-sorted portfolios. Big stocks are those in the biggest of the $20 M V$-sorted portfolios. Transaction costs are proxied by the effective trading costs estimate (cGibbs) of Hasbrouck (2009) in Panel A and the bid-ask spread estimate (CSspread) of Corwin and Schultz (2012) in Panel B. 


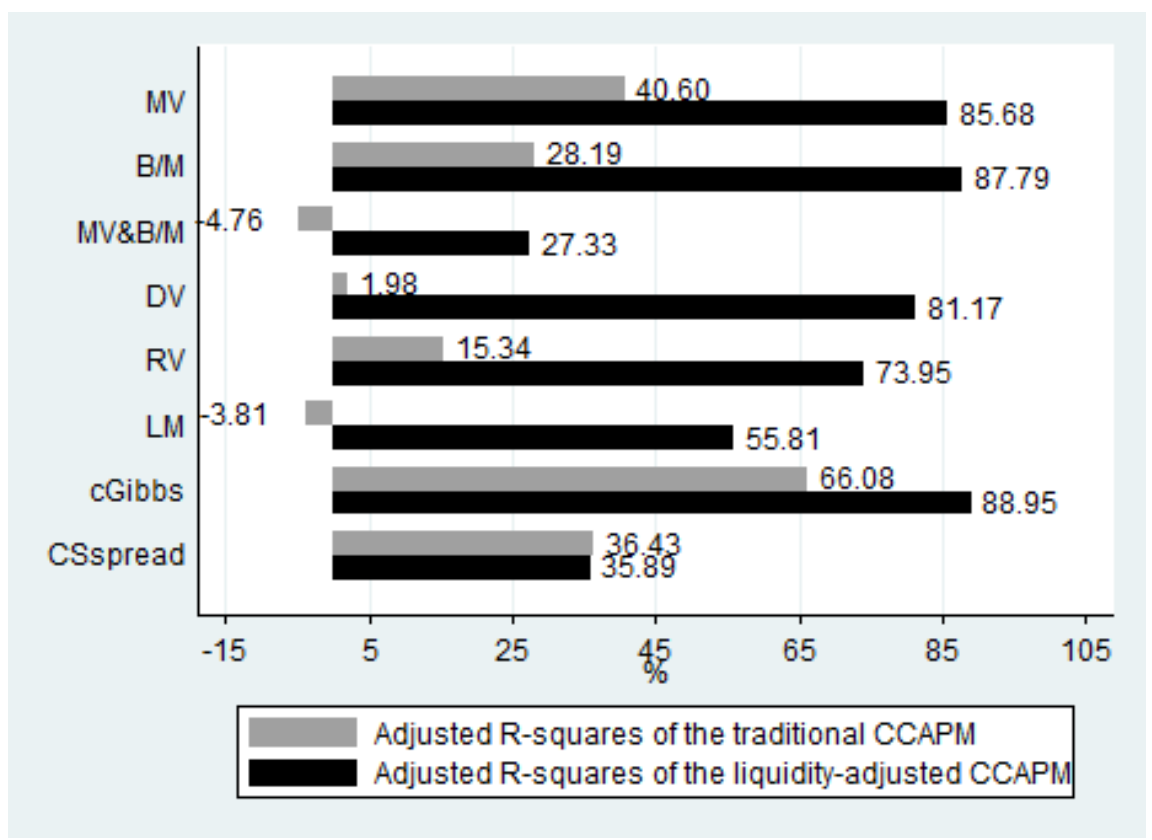

Panel A: cGibbs as a measure of transaction costs

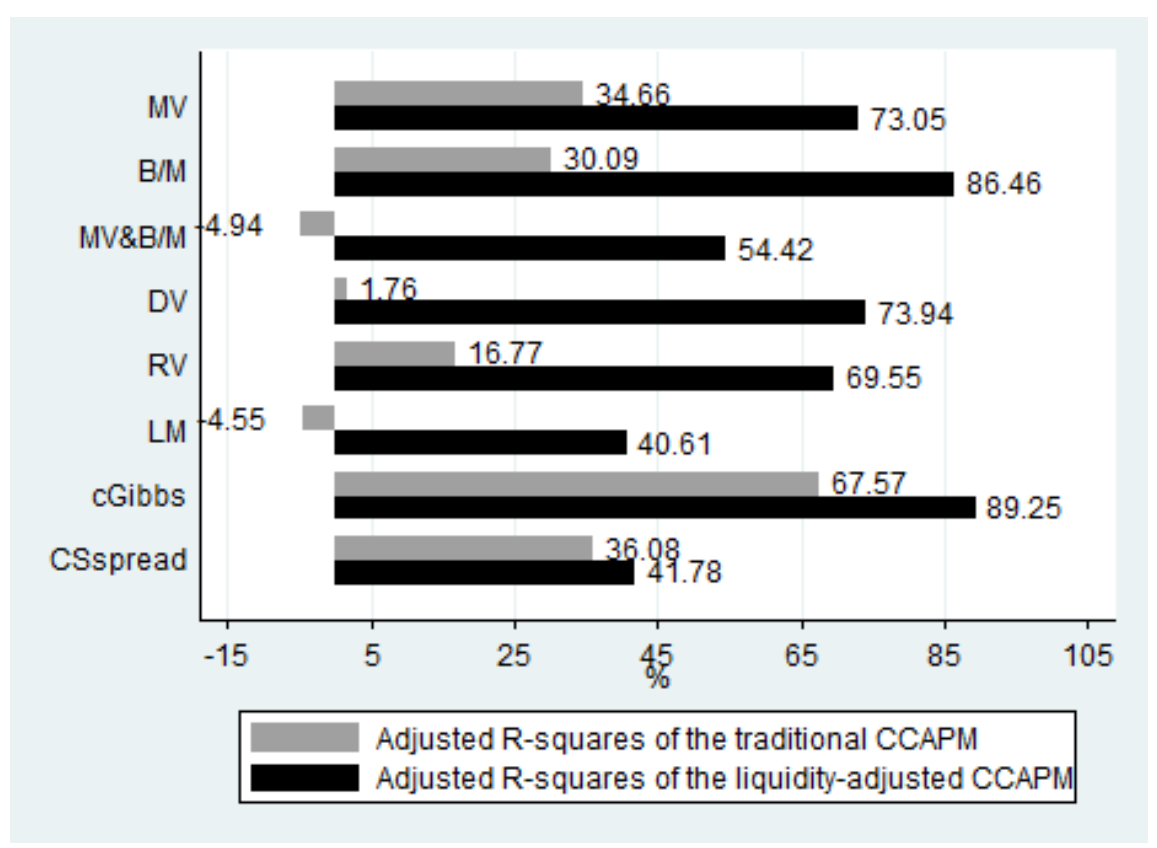

Panel B: CSspread as a measure of transaction costs

Fig. 2. This figure plots the adjusted R-squares for the traditional CCAPM and the liquidity-adjusted model. Test assets are the $20 M V$-sorted, $20 \mathrm{~B} / \mathrm{M}$-sorted, $4 \times 5 \mathrm{MV} \& \mathrm{~B} / \mathrm{M}$-sorted, $20 \mathrm{DV}$-sorted, $20 \mathrm{RV}$-sorted, $20 \mathrm{LM}$-sorted, 20 cGibbs-sorted, and 20 CSspread-sorted portfolios, respectively. Transaction costs are proxied by the effective trading costs estimate (cGibbs) of Hasbrouck (2009) in Panel A and the bid-ask spread estimate (CSspread) of Corwin and Schultz (2012) in Panel B. 

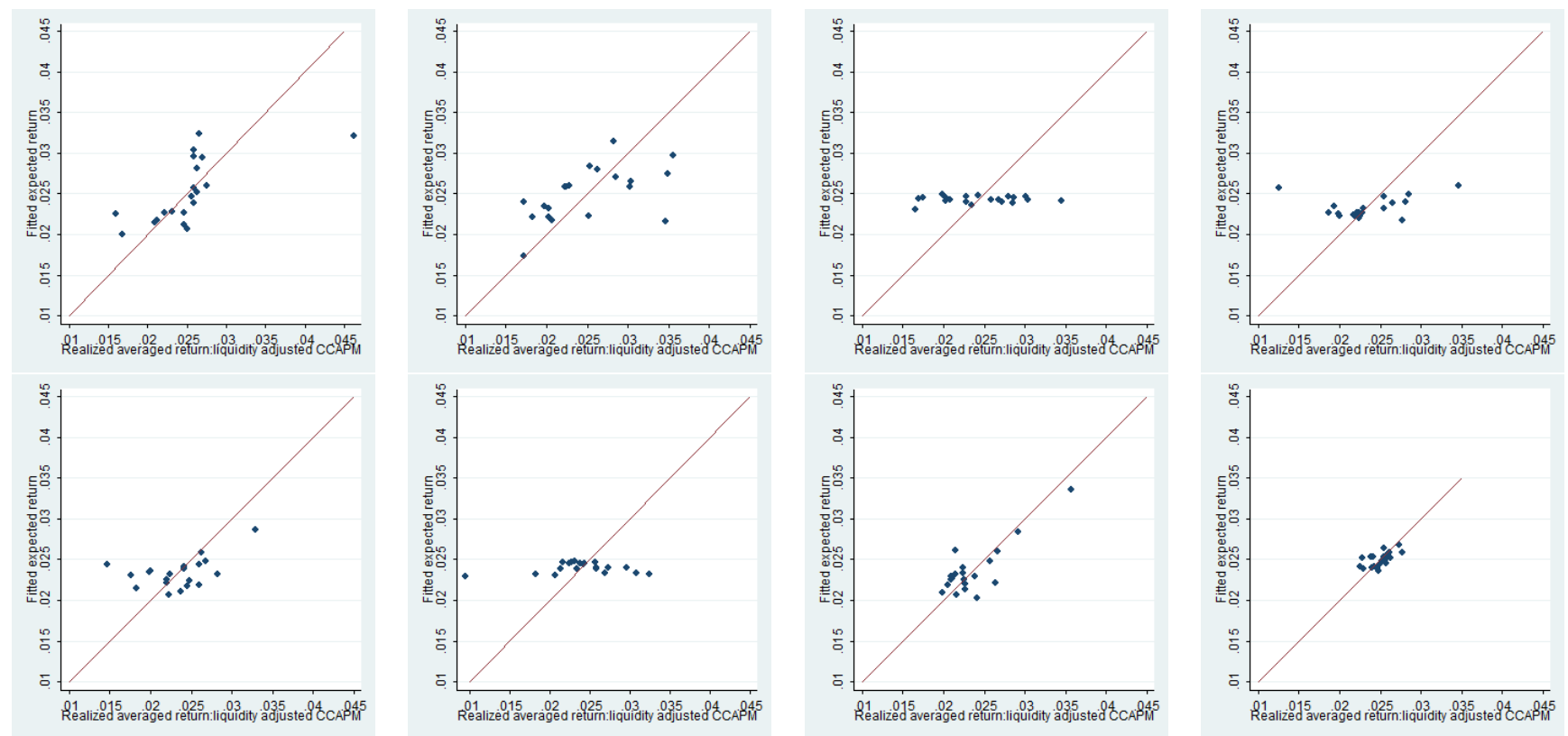

The traditional CCAPM 

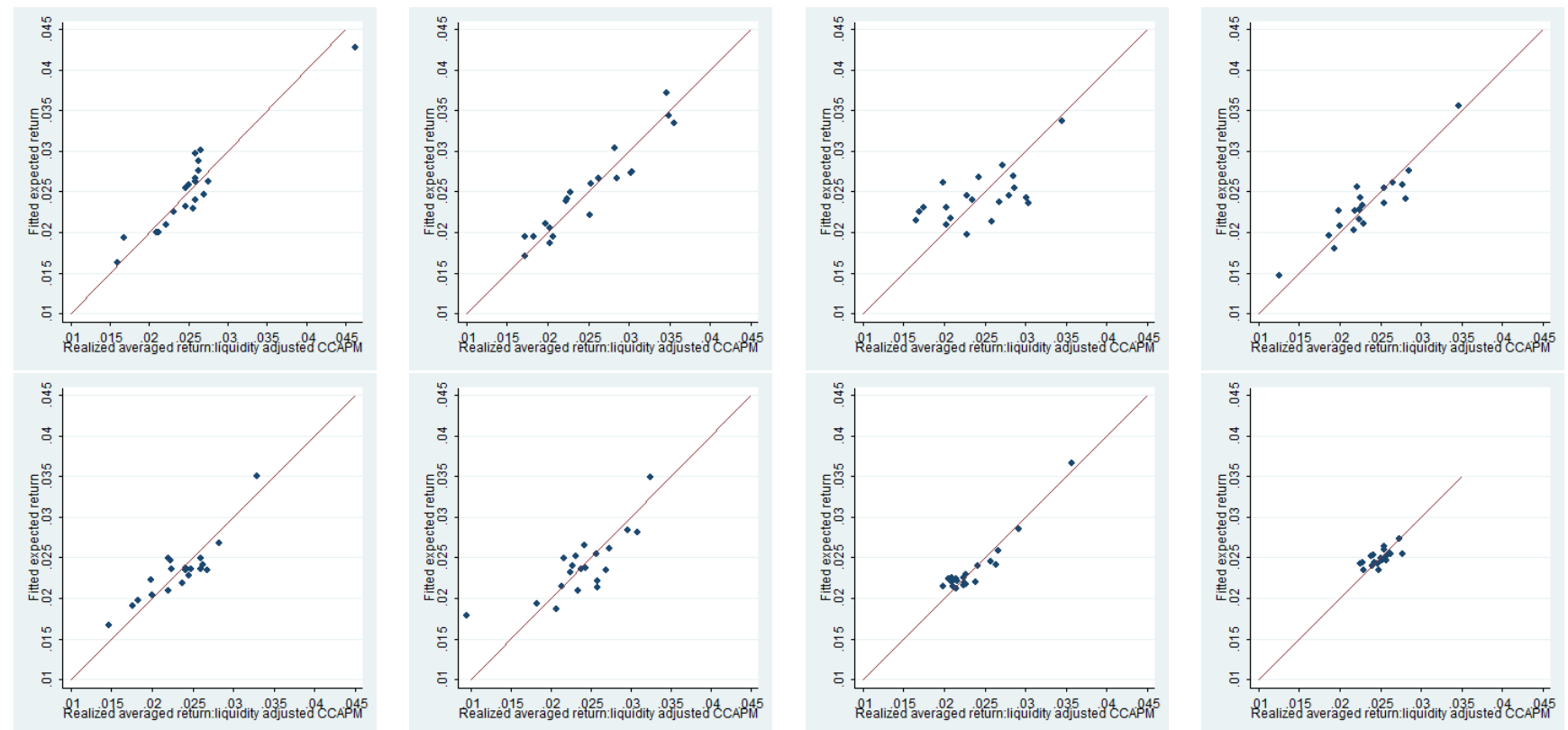

The liquidity-adjusted CCAPM 
Panel B: CSspread as a measure of transaction costs
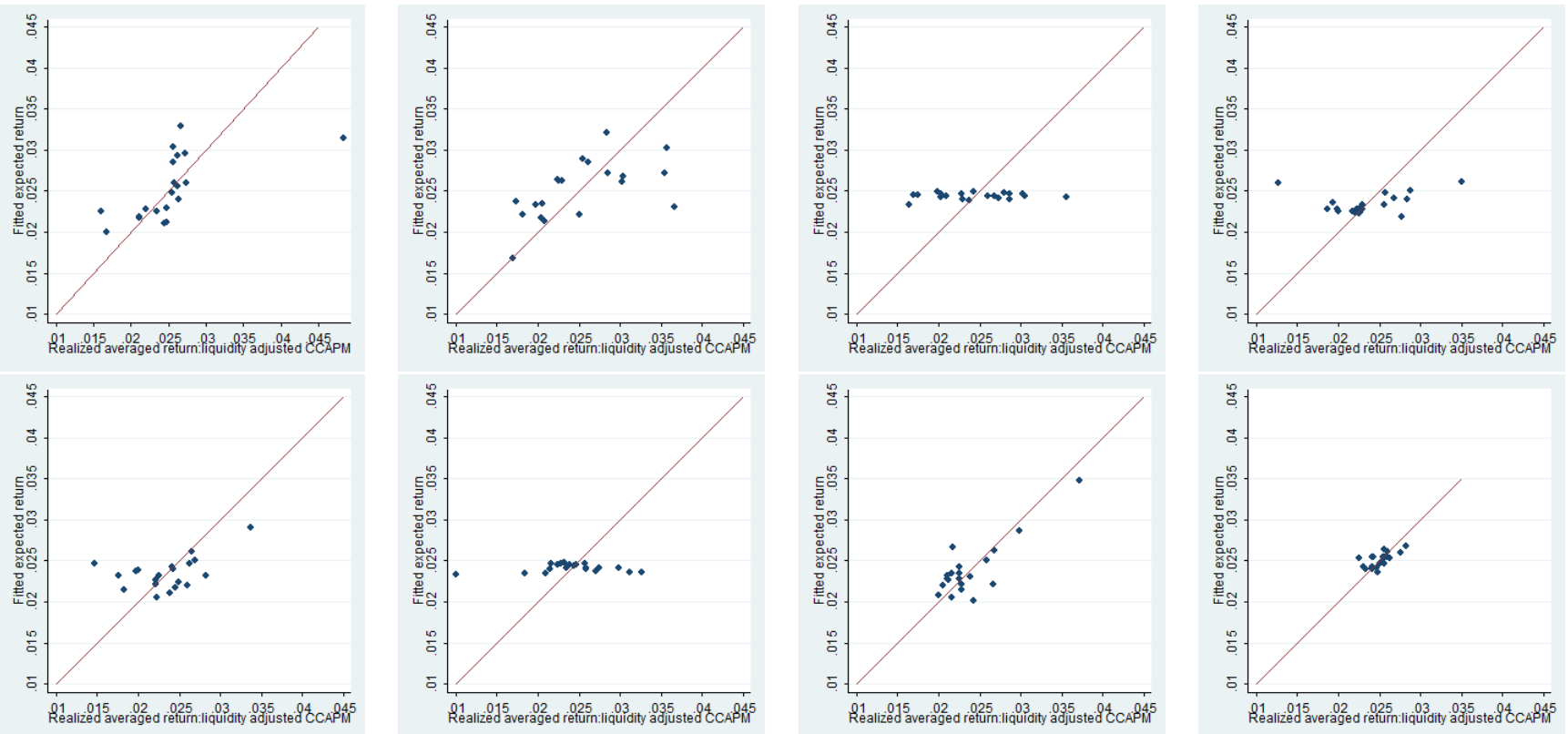

The traditional CCAPM 

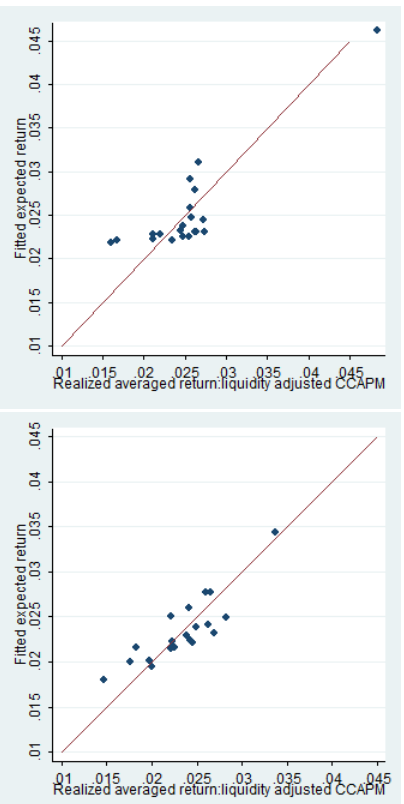
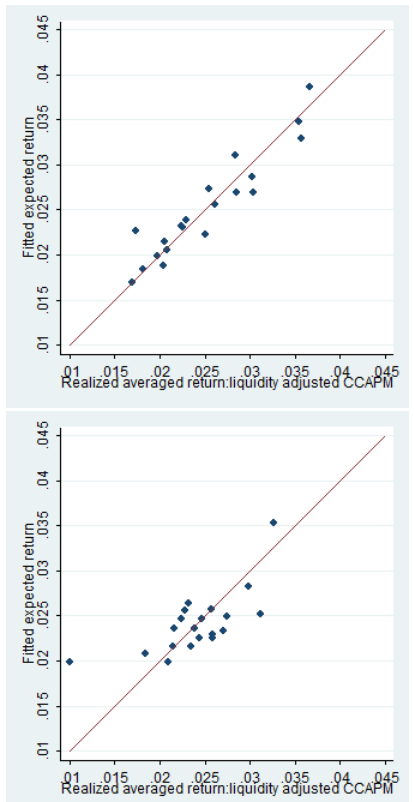
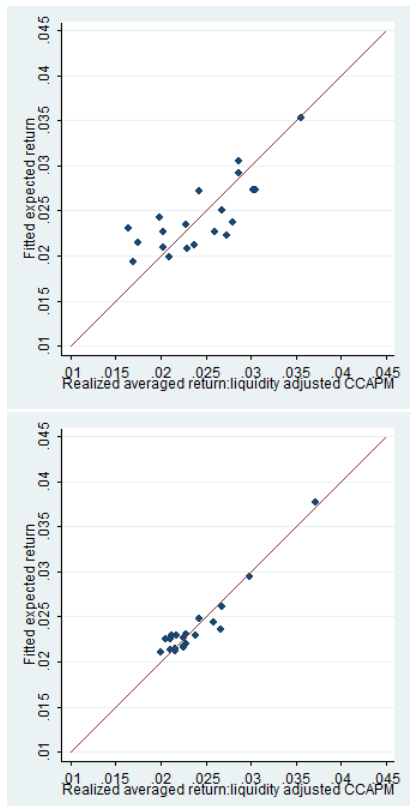
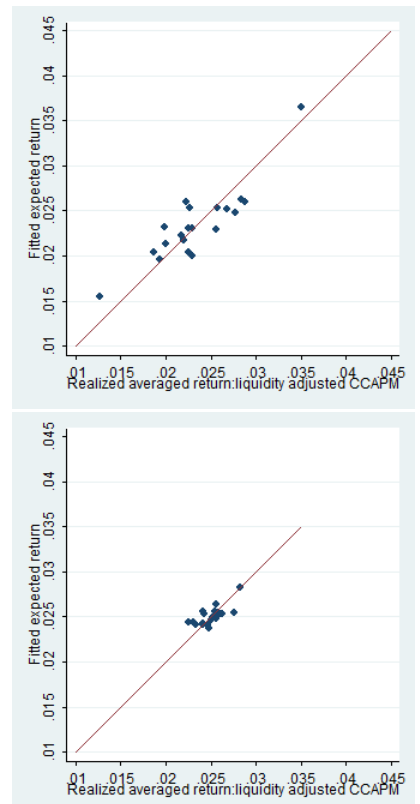

The liquidity-adjusted CCAPM

Fig. 3. This figure plots the fitted returns versus realized returns. The horizonal axis shows the realized average excess return and the vertical axis shows the model fitted excess return. Test assets from left to right are the $20 M V$-sorted, $20 B / M$-sorted, $4 \times 5 M V \& B / M$-sorted, $20 D V$-sorted, $20 R V$-sorted, $20 \mathrm{LM}$-sorted, $20 \mathrm{cGibbs}$-sorted, and $20 \mathrm{CS}$ spread-sorted portfolios, respectively. The realized average returns are the time-series average returns in excess of the risk-free rate. The fitted excess expected returns for the CCAPM are calculated as the fitted value from $R_{p, t}-R_{f, t}=\gamma_{0}+\gamma_{1} \beta_{R_{p}, c}+\epsilon_{p, t}$. The fitted excess expected returns for the liquidity-adjusted CCAPM are calculated as the fitted value from $R_{p, t}-R_{f, t}=\gamma_{0}+\gamma_{1} t c_{i, t}+\gamma_{2} \beta_{R_{p}, c}+\gamma_{3} \beta_{T C_{p}, c}+\epsilon_{p, t}$. Transaction costs are proxied by the effective trading costs (cGibbs) of Hasbrouck (2009) in Panel A and by the bid-ask spread estimate (CSspread) of Corwin and Schultz (2012) in Panel B. 


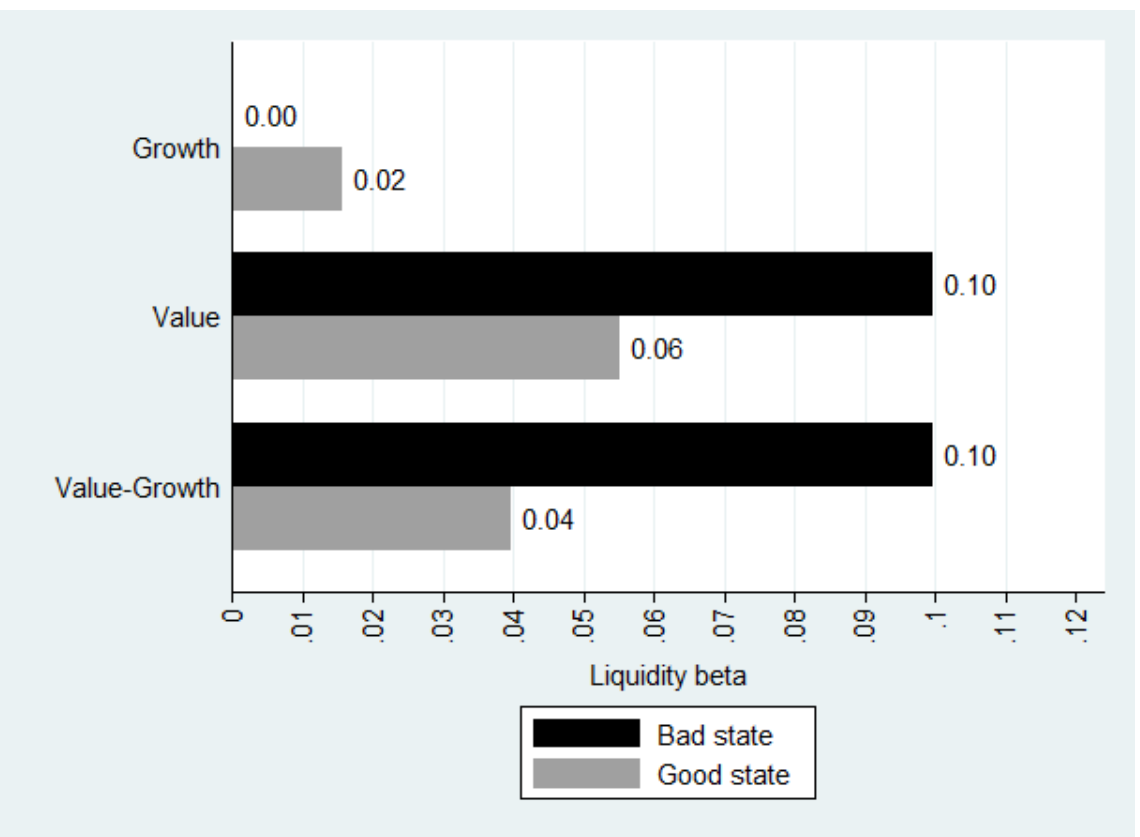

Panel A: cGibbs as a measure of transaction costs

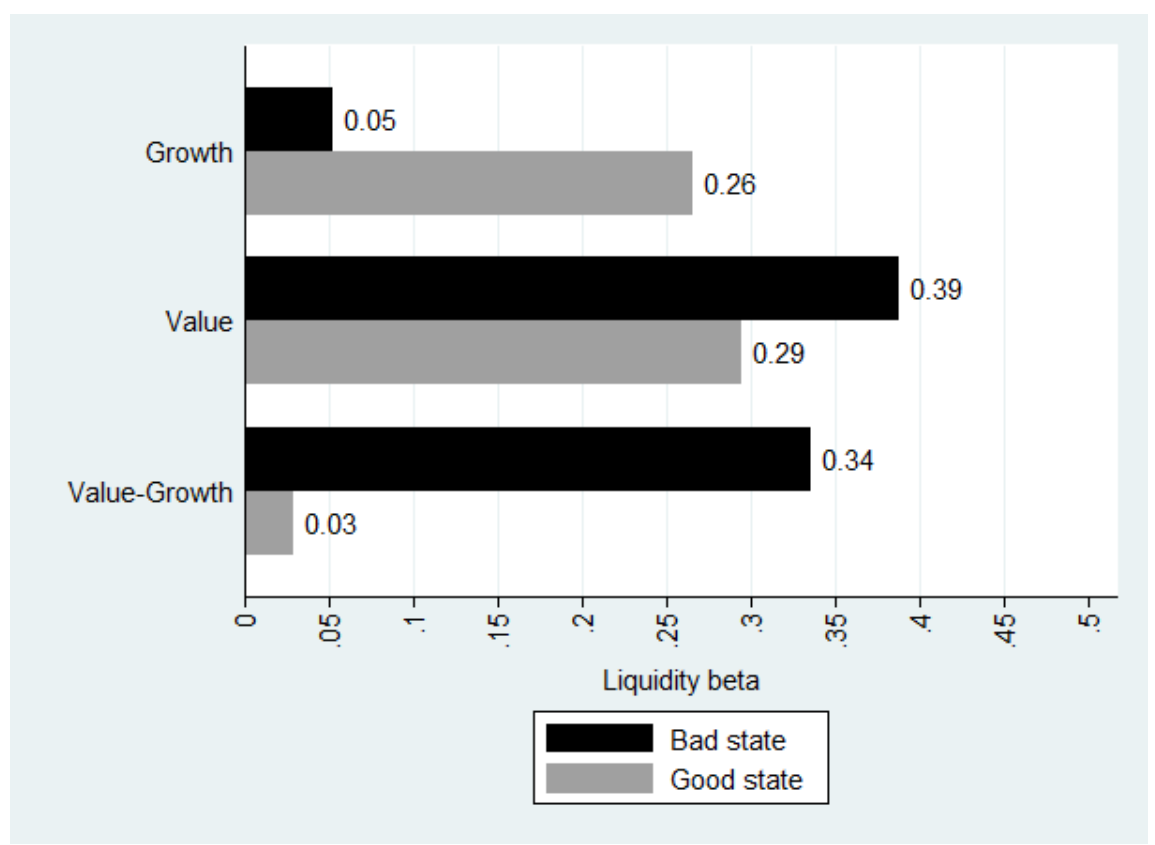

Panel B: CSspread as a measure of transaction costs

Fig. 4. This figure plots the average rolling liquidity betas for growth and value stocks in bad and good states. The rolling liquidity betas for each stock are estimated from the 10-year rolling regressions based on Eqs. (14) and (15). The estimated liquidity betas are then allocated into the $20 \mathrm{~B} / \mathrm{M}$ portfolios. The plotted rolling liquidity betas are the cross-sectional time-series averages for the lowest and highest $B / M$ portfolios. We use NBER recession periods to identify bad states and other periods as good states. Transaction costs are proxied by the effective trading costs estimate (cGibbs) of Hasbrouck (2009) in Panel A and the bid-ask spread estimate (CSspread) of Corwin and Schultz (2012) in Panel B. 

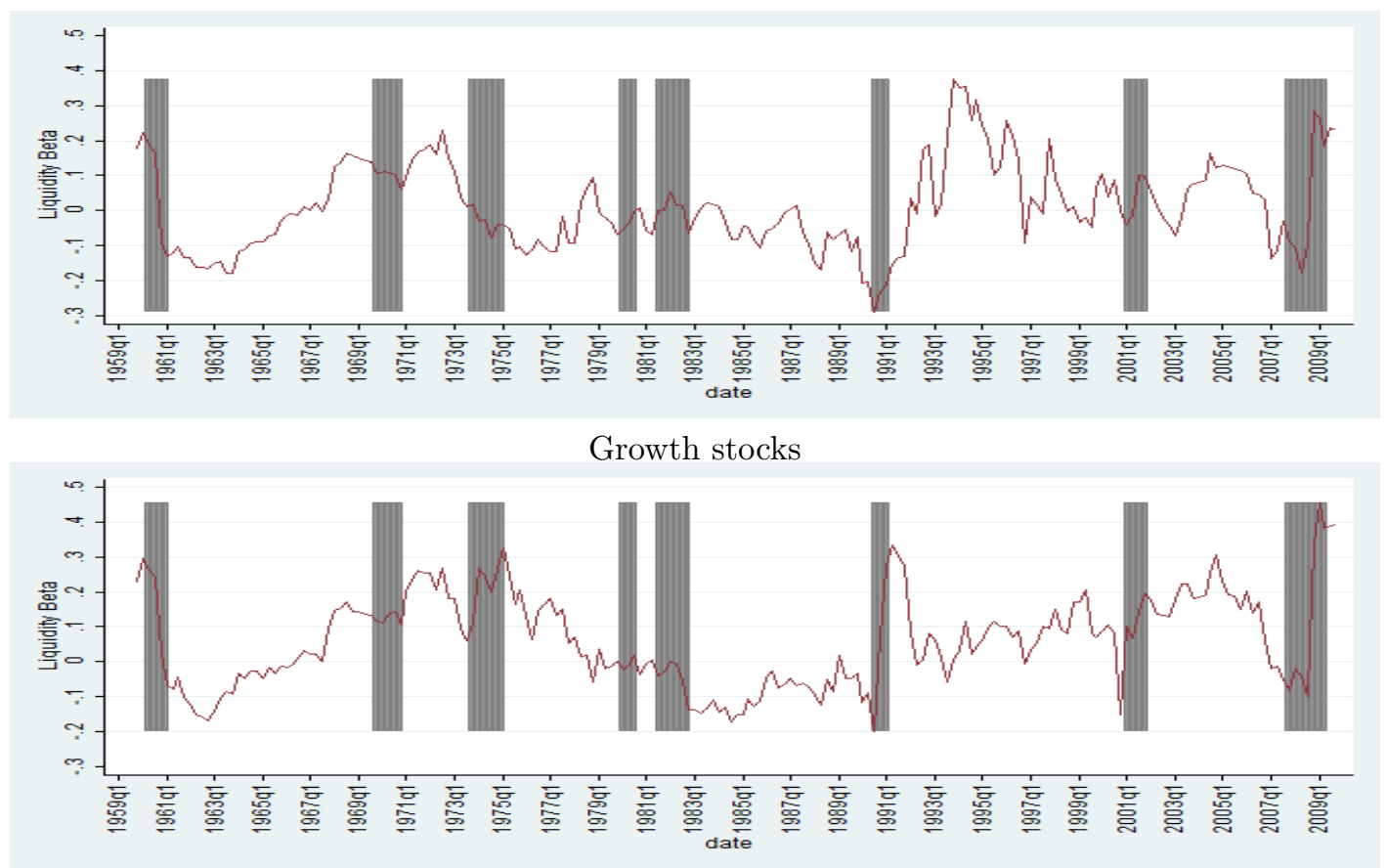

Value stocks

Panel A: cGibbs as a measure of transaction costs

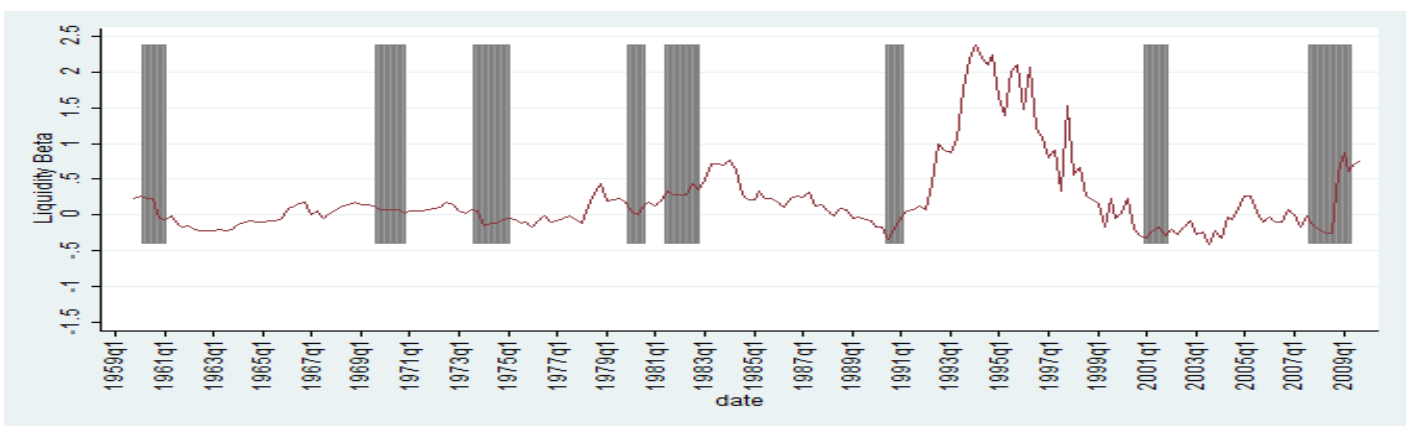

Growth stocks

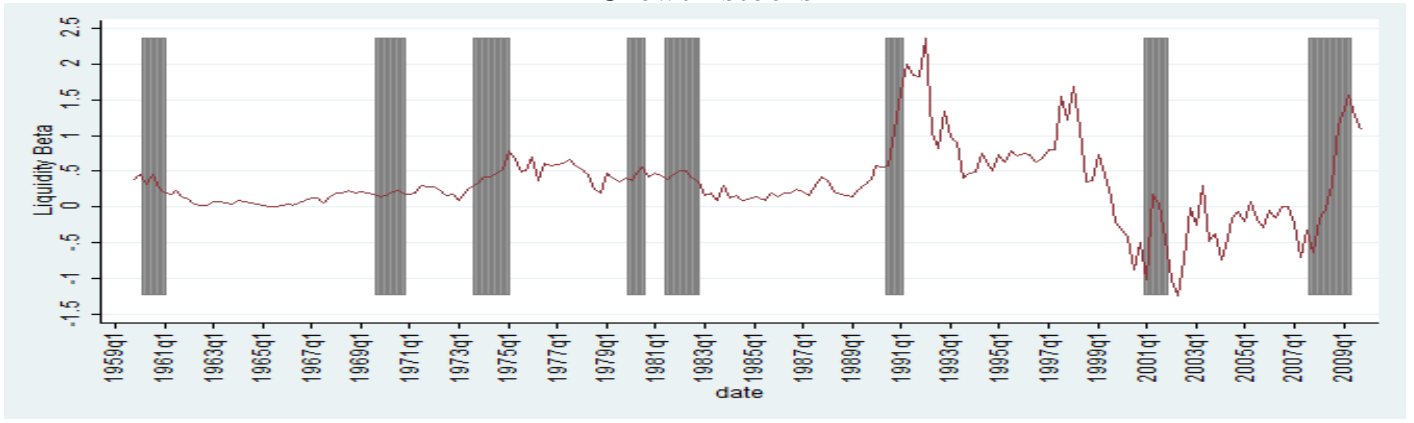

Value stocks

Panel B: CSspread as a measure of transaction costs

Fig. 5. This figure plots the average rolling liquidity betas for growth and value stocks. The shaded regions are recession periods defined by the National Bureau of Economic Research (NBER). The rolling liquidity betas for each stock are estimated from the 10-year rolling regressions based on Eqs. (14) and (15). The estimated liquidity betas are then allocated into the $20 \mathrm{~B} / \mathrm{M}$ portfolios. The plotted rolling liquidity betas are the cross-sectional time-series averages for the lowest and highest $B / M$ portfolios. Transaction costs are are proxied by the effective trading costs estimate (cGibbs) of Hasbrouck (2009) in Panel A and the bid-ask spread estimate (CSspread) of Corwin and Schultz (2012) in Panel B. 


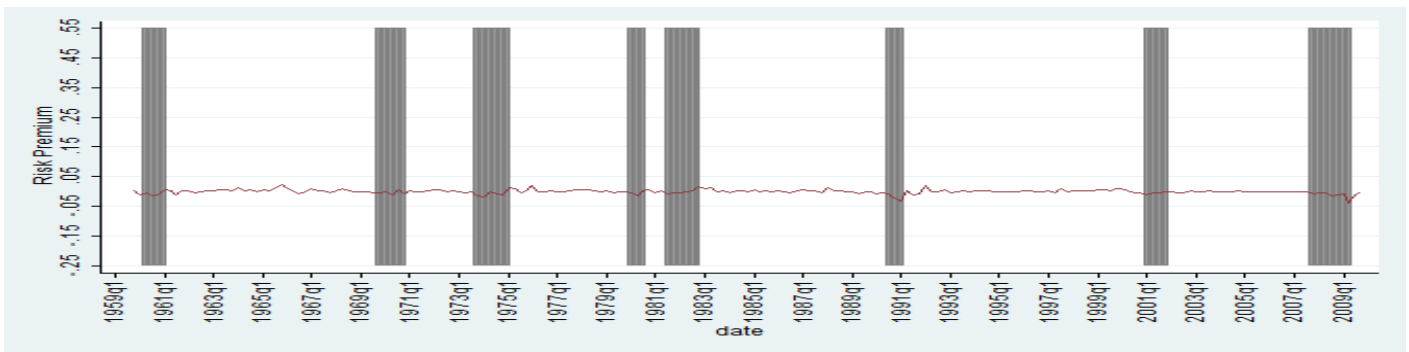

Consumption risk premium

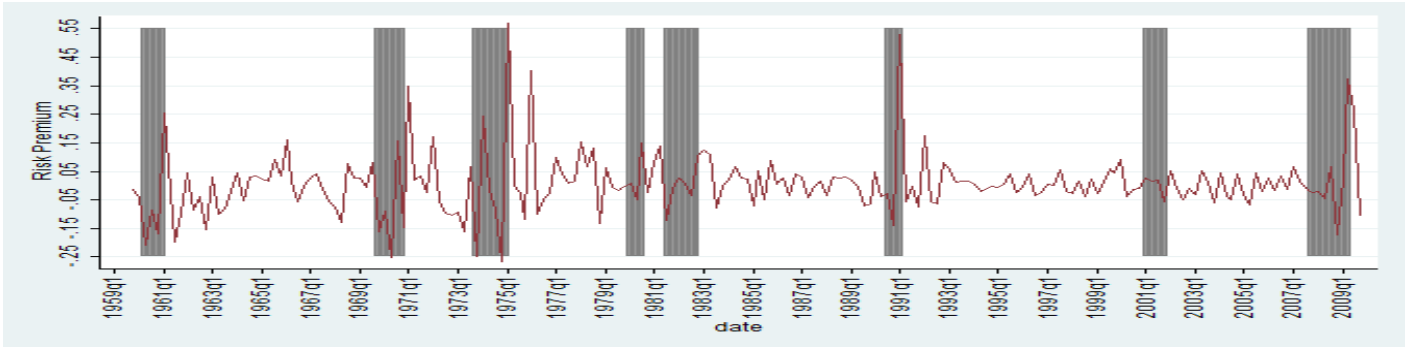

Liquidity risk premium

Panel A: cGibbs as a measure of transaction costs

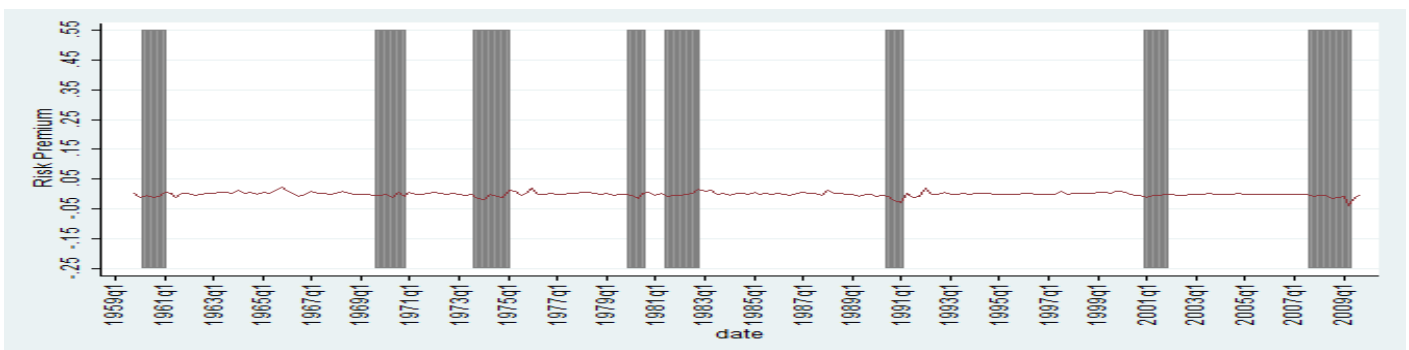

Consumption risk premium

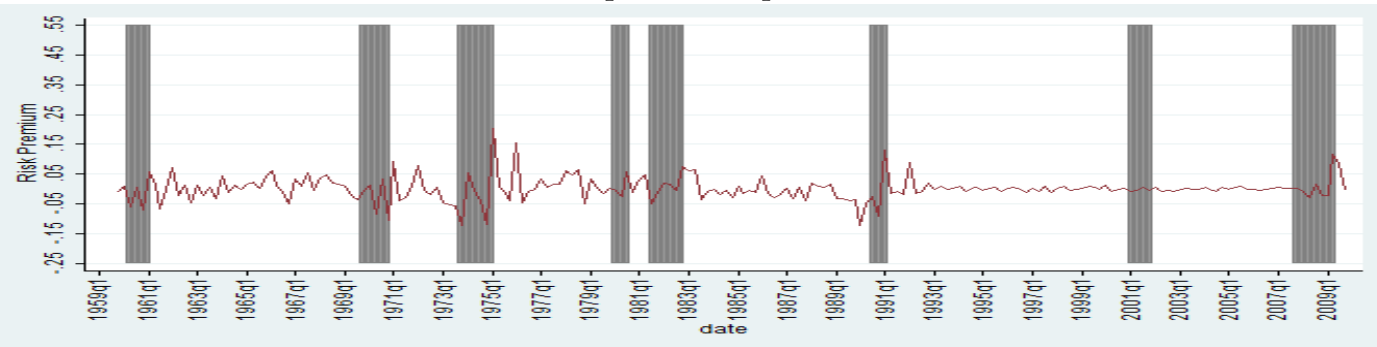

Liquidity risk premium

Panel B: CSspread as a measure of transaction costs

Fig. 6. This figure plots the risk premium. The shaded regions are recession periods defined by the National Bureau of Economic Research (NBER). The risk premium is estimated according to the following two equations:

$$
\begin{aligned}
& R_{i, t}-R_{f, t}=\gamma_{0}+\gamma_{1, t} \beta_{R_{i}, c, t}+\epsilon_{i, t}, \\
& R_{i, t}-R_{f, t}=\gamma_{0}+\gamma_{1, t} \beta_{T C_{i}, c, t}+\epsilon_{i, t},
\end{aligned}
$$

where $R_{i, t}-R_{f, t}$ is the return of portfolio $i$ in excess of the risk-free rate, $\beta_{R_{i}, c, t}$ is the rolling consumption beta, and $\beta_{T C_{i}, c, t}$ is the rolling liquidity beta. We estimate the rolling consumption beta and liquidity beta for each stock using prior 10-year observations. Transaction costs are proxied by the effective costs estimate (cGibbs) of Hasbrouck (2009) in Panel A and the bid-ask spread estimate (CSspread) of Corwin and Schultz (2012) in Panel B. 


\section{APPENDIX A}

In this appendix, we derive the first-order conditions of Eq. (4) using stochastic dynamic

programming. Specifically, we solve Eq. (4) backwards and explore the last two-period function first. The last two-period function of Eq. (4) is:

$$
\begin{aligned}
I\left(W_{T-1}\right) & =\max _{C_{T-1}, \omega_{i, T-1}} E_{T-1}\left[\delta^{T-1} U\left(C_{T-1}\right)+\delta^{T} B\left(W_{T}\right)\right] \\
& =\max _{C_{T-1}, \omega_{i, T-1}} \delta^{T-1} U\left(C_{T-1}\right)+E_{T-1}\left[\delta^{T} B\left(W_{T}\right)\right],
\end{aligned}
$$

where $W_{T}=\left(W_{T-1}-C_{T-1}\right)\left[R_{f, T}+\sum_{i=1}^{n} \omega_{i, T}\left(R_{i, T}-t c_{i, T}-R_{f, T}\right)\right]$.

Differentiating Eq. (A-1) with respect to $C_{T-1}$ and $\omega_{i, T}$, we can obtain the following two firstorder conditions:

$$
U_{C}\left(C_{T-1}\right)=E_{T-1}\left[\delta B_{W}\left(W_{T}\right)\left[R_{f, T}+\sum_{i=1}^{n} \omega_{i, T}\left(R_{i, T}-t c_{i, T}-R_{f, T}\right)\right]\right]
$$

and

$$
E_{T-1}\left[B_{W}\left(W_{T}\right)\left(R_{i, T}-t c_{i, T}-R_{f, T}\right)\right]=0
$$

where $U_{C}$ and $B_{W}$ are partial differentiations with respect to consumption and wealth, respectively. Using the results of Eq. (A-3), we can rewritten Eq. (A-2) as:

$$
U_{C}\left(C_{T-1}\right)=R_{f, T} E_{T-1}\left[\delta B_{W}\left(W_{T}\right)\right]
$$

Substituting the first-order conditions of Eqs. (A-2) and (A-3) into Eq. (A-1) and differentiating it with respect to $W_{T-1}$, we have 


$$
\begin{aligned}
I_{W} & =\delta^{T-1} U_{C} \frac{\partial C_{T-1}^{*}}{\partial W_{T-1}}+E_{T-1}\left[\delta^{T} B_{W_{T}}\left(\frac{\partial W_{T}}{\partial W_{T-1}}+\sum_{i=1}^{n} \frac{\partial W_{T}}{\partial \omega_{i, T-1}^{*}} \frac{\partial \omega_{i, T-1}^{*}}{\partial W_{T-1}}+\frac{\partial W_{T}}{\partial C_{T-1}^{*}} \frac{\partial C_{T-1}^{*}}{\partial W_{T-1}}\right)\right] \\
& =\delta^{T-1} U_{C} \frac{\partial C_{T-1}^{*}}{\partial W_{T-1}}+E_{T-1}\left[\delta ^ { T } B _ { W _ { T } } \left\{\sum_{i=1}^{n}\left(R_{i, T}-t c_{i, T}-R_{f, T}\right)\left(W_{T-1}-C_{T-1}\right) \frac{\partial \omega_{i, T-1}^{*}}{\partial W_{T-1}}\right.\right. \\
& \left.\left.+\left[R_{f, T}+\sum_{i=1}^{n} \omega_{i, T}\left(R_{i, T}-t c_{i, T}-R_{f, T}\right)\right]\left(1-\frac{\partial C_{T-1}^{*}}{\partial W_{T-1}}\right)\right\}\right],
\end{aligned}
$$

where $C_{T-1}^{*}$ and $\omega_{i, T-1}^{*}$ are the representative consumer's optimal decisions of consumption and investment, respectively.

Using Eqs. (A-2), (A-3), and (A-4), we can simplify Eq. (A-5) as:

$$
I_{W}\left(W_{T-1}\right)=\delta^{T-1} U_{C}\left(C_{T-1}^{*}\right)
$$

Eq. (A-6) indicates that when the representative consumer optimizes her consumption and investment decisions, the marginal utility of wealth is equal to the marginal utility of current consumption.

Following the principle of optimality (Bellman (1957)), we can write the optimal decisions of time $T-2$ as:

$$
\begin{aligned}
I\left(W_{T-2}\right) & =\max _{C_{T-2}, \omega_{i, T-2}}\left\{\delta^{T-2} U\left(C_{T-2}\right)+E_{T-2}\left[\max _{C_{T-1}, \omega_{i, T-1}} E_{T-1}\left[\delta^{T-1} U\left(C_{T-1}\right)+\delta^{T} B\left(W_{T}\right)\right]\right]\right\} \\
& =\max _{C_{T-2}, \omega_{i, T-2}} \delta^{T-2} U\left(C_{T-2}\right)+E_{T-2}\left[I\left(W_{T-1}\right)\right] .
\end{aligned}
$$


Note that Eq. (A-7) is similar to Eq. (A-1). Thus, by differentiating Eq. (A-7), we can have the following first-order conditions:

$$
I_{W}\left(W_{T-2}\right)=\delta^{T-2} U_{C}\left(C_{T-2}^{*}\right)
$$

and

$$
R_{f, T-1} E_{T-2}\left[I_{W}\left(W_{T-1}\right)\right]=E_{T-2}\left[\left(R_{i, T-1}-t c_{i, T-1}\right) I_{W}\left(W_{T-1}\right)\right]
$$

If we apply the principle of optimality to other time periods, for any $t=0,1, \ldots, T-1$, we can generalize the representative consumer's optimal objective function as:

$$
I\left(W_{t}\right)=\max _{C_{t}, \omega_{i, t}} U\left(C_{t}\right)+E_{t}\left[\delta I\left(W_{t+1}\right)\right]
$$

Similarly, the first-order conditions are

$$
I_{W}\left(W_{t}\right)=\delta^{t} U_{C}\left(C_{t}^{*}\right)
$$

and

$$
R_{f, t+1} E_{t}\left[I_{W}\left(W_{t+1}\right)\right]=E_{t}\left[\left(R_{i, t+1}-t c_{i, t+1}\right) I_{W}\left(W_{t+1}\right)\right]
$$

Substituting $I_{W}\left(W_{t+1}\right)=\delta^{t+1} U_{C}\left(C_{t+1}^{*}\right)$ into Eq. (A-12) and using Eq. (A-11), we have

$$
E_{t}\left[\delta \frac{U_{C}\left(C_{t+1}^{*}\right)}{U_{C}\left(C_{t}^{*}\right)} R_{f, t+1}\right]=1
$$

and

$$
E_{t}\left[\delta \frac{U_{C}\left(C_{t+1}^{*}\right)}{U_{C}\left(C_{t}^{*}\right)}\left(R_{i, t+1}-t c_{i, t+1}\right)\right]=1
$$




\section{APPENDIX B}

In this appendix, we derive the model of Acharya and Pedersen (2005) based on the liquidityadjusted model (11). Following Breeden (1979) and Cochrane (2005), we assume that the return of a market portfolio after netting out aggregate transaction costs is perfectly negatively correlated with the marginal utility of time $t+1$ consumption, i.e., $R_{m, t+1}-t c_{m, t+1}=-\frac{1}{\kappa} U_{C}\left(C_{t+1}^{*}\right) . R_{m, t+1}$ is the returns of market portfolio, $t c_{m, t+1}$ is the aggregate transaction costs, $C_{t+1}^{*}$ is the optimal consumption, and $\kappa>0$. Hence, we can have

$$
\operatorname{Cov}\left[U_{C}\left(C_{t+1}^{*}\right), R_{m, t+1}-t c_{m, t+1}\right]=-\kappa \operatorname{Var}\left(R_{m, t+1}-t c_{m, t+1}\right)
$$

and

$$
\operatorname{Cov}\left[U_{C}\left(C_{t+1}^{*}\right), R_{i, t+1}-t c_{i, t+1}\right]=-\kappa \operatorname{Cov}\left(R_{m, t+1}-t c_{m, t+1}, R_{i, t+1}-t c_{i, t+1}\right) .
$$

We can rewrite Eq. (7) as:

$$
E\left[R_{i, t+1}-t c_{i, t+1}-R_{f, t+1}\right]=\frac{\operatorname{Cov}\left[U_{C}\left(C_{t+1}^{*}\right), R_{i, t+1}-t c_{i, t+1}\right]}{E\left[U_{C}\left(C_{t+1}^{*}\right]\right.}
$$

Replacing $R_{i, t+1}-t c_{i, t+1}$ with $R_{m, t+1}-t c_{m, t+1}$ in Eq. (B-3) and using Eq. (B-1), we have

$$
E\left[R_{m, t+1}-t c_{m, t+1}-R_{f, t+1}\right]=-\frac{\kappa \operatorname{Var}\left(R_{m, t+1}-t c_{m, t+1}\right)}{E\left[U_{C}\left(C_{t+1}^{*}\right)\right]}
$$

Using Eqs. (B-2), (B-3), and (B-4), we have

$$
\frac{E\left[R_{m, t+1}-t c_{m, t+1}-R_{f, t+1}\right]}{E\left[R_{i, t+1}-t c_{i, t+1}-R_{f, t+1}\right]}=\frac{\kappa \operatorname{Var}\left(R_{m, t+1}-t c_{m, t+1}\right)}{\kappa \operatorname{Cov}\left(R_{m, t+1}-t c_{m, t+1}, R_{i, t+1}-t c_{i, t+1}\right)} .
$$

The beta representation of Eq. (B-5) has the form: 


$$
E\left[R_{i, t+1}-R_{f, t+1}\right]=E\left[t c_{i, t+1}\right]+E\left[R_{m, t+1}-t c_{m, t+1}-R_{f, t+1}\right]\left(\beta_{i, 1}+\beta_{i, 2}+\beta_{i, 3}+\beta_{i, 4}\right),
$$

where $\beta_{i, 1}=\operatorname{Cov}\left(R_{i, t+1}, R_{m, t+1}\right) / \operatorname{Var}\left(R_{m, t+1}-t c_{m, t+1}\right), \beta_{i, 2}=\operatorname{Cov}\left(t c_{i, t+1}, t c_{m, t+1}\right) / \operatorname{Var}\left(R_{m, t+1}-t c_{m, t+1}\right)$, $\beta_{i, 3}=\operatorname{Cov}\left(-R_{i, t+1}, t c_{m, t+1}\right) / \operatorname{Var}\left(R_{m, t+1}-t c_{m, t+1}\right)$, and $\beta_{i, 4}=\operatorname{Cov}\left(-t c_{i, t+1}, t c_{m, t+1}\right) / \operatorname{Var}\left(R_{m, t+1}-t c_{m, t+1}\right)$. Eq. (B-6) is the liquidity-adjusted CAPM in Acharya and Pedersen (2005). 


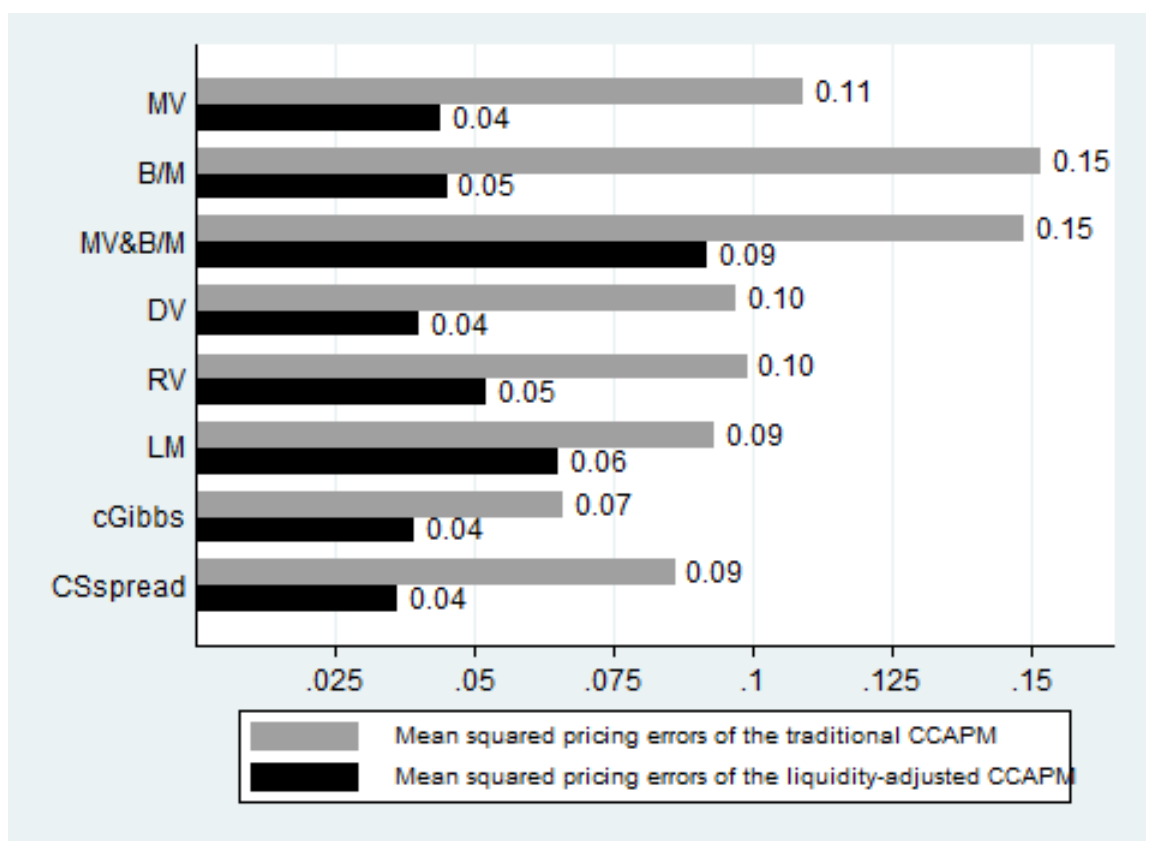

Panel A: cGibbs as a measure of transaction costs

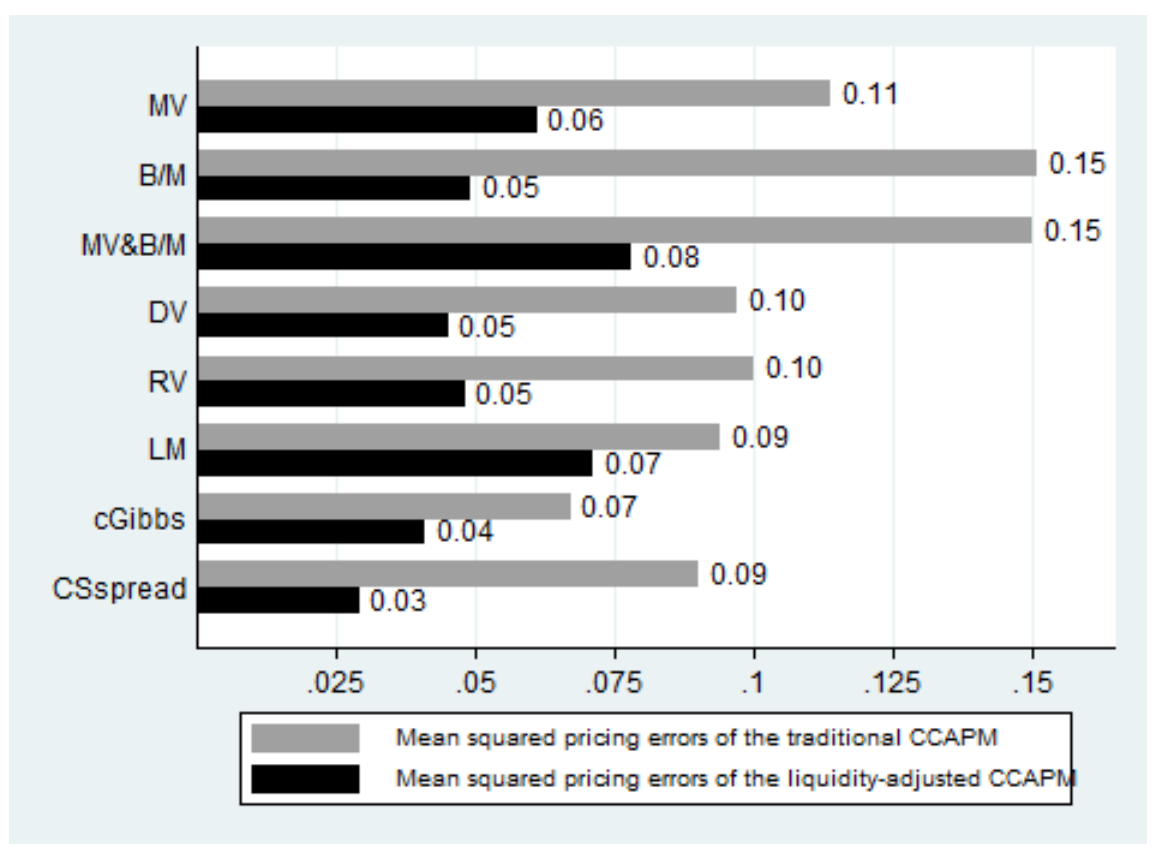

Panel B: CSspread as a measure of transaction costs

Fig. A.1. This figure plots the magnitudes of mean squared pricing errors for each set of the test portfolios for the traditional CCAPM and the liquidity-adjusted model. Test portfolios are the $20 M V$-sorted, $20 B / M$-sorted,

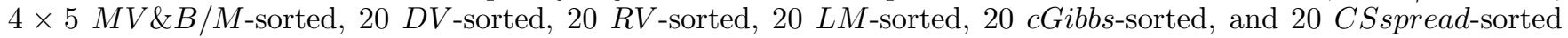
portfolios, respectively. Transaction costs are proxied by the effective costs estimate (cGibbs) of Hasbrouck (2009) in Panel A and the bid-ask spread estimate (CSspread) of Corwin and Schultz (2012) in Panel B. 